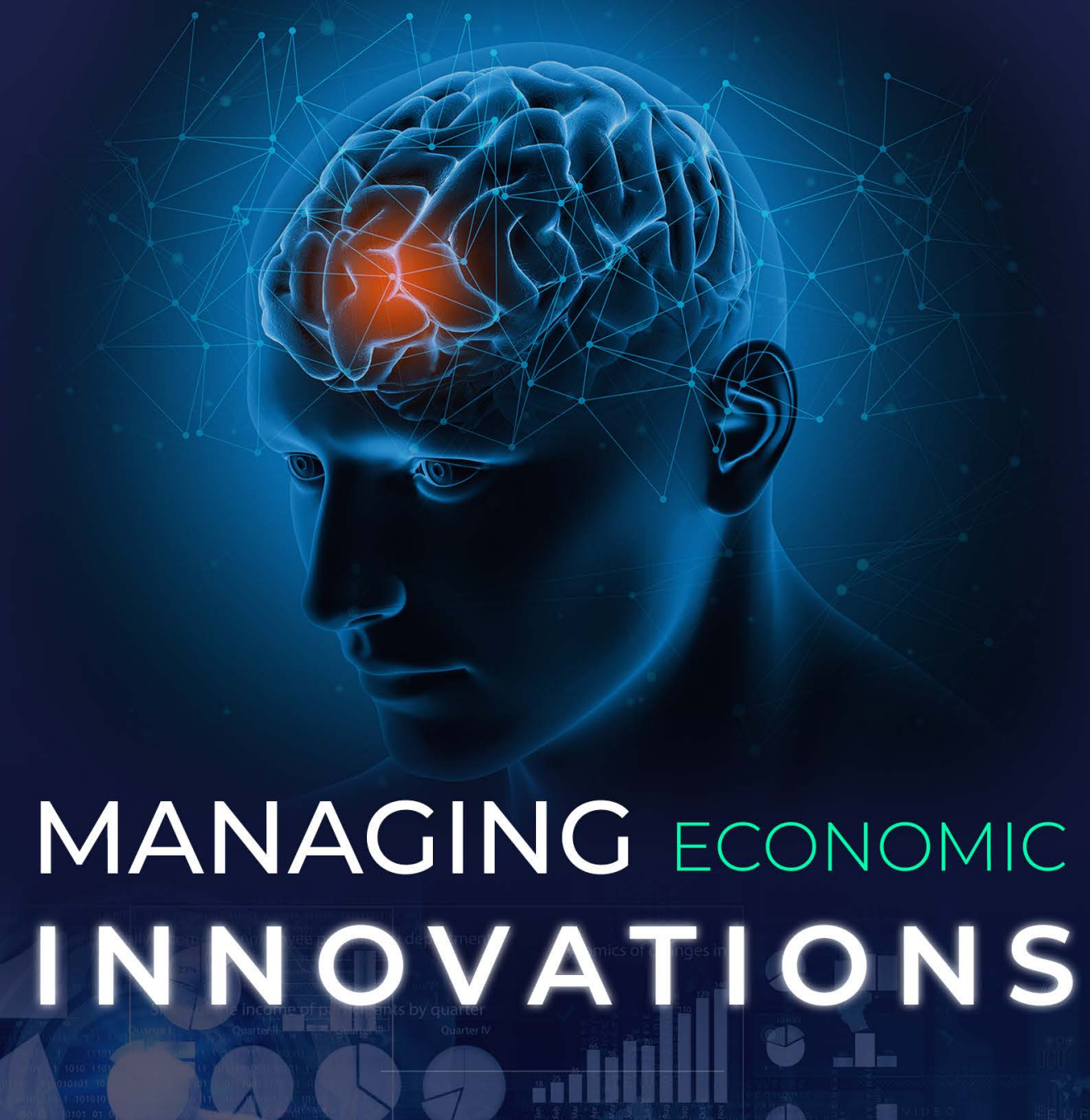

METHODS AND INSTRUMENTS

\author{
edited by \\ Robert Romanowski
}

Bogucki WYYDAWINICTWO NAUKOWE

European

Funds

Knowledge Education Development
European Union European Social Fund 


\title{
Managing Economic Innovations - Methods and Instruments
}

\author{
Edited by: \\ Robert Romanowski
}


Reviewers:

Barbara Borusiak

Barbara Kucharska

Cover design:

Julia Bogucka

Publication co-financed by the European Union from the European Social Fund under the Operational Programme Knowledge Education Development 2014-2020.

\section{European} Funds

Knowledge Education Development

\section{European Union}

European Social Fund

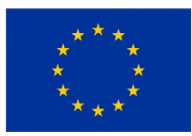

Copyright @ Authors, 2019

ISBN 978-83-7986-277-1

DOI: $10.12657 / 9788379862771$

Bogucki Wydawnictwo Naukowe

Górna Wilda 90

61-576 Poznań

Poland

biuro@bogucki.com.pl

www.bogucki.com.pl 


\section{Contents}

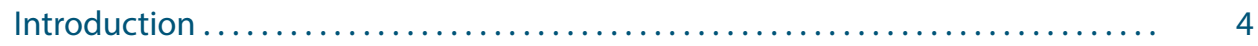

Robert Romanowski

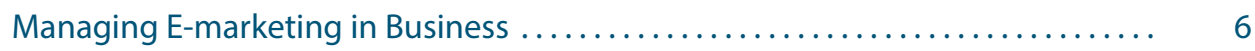

Marcin Lewicki

Instagram as a New Promotion and Sales Channel .................... 24

Elżbieta Baron, Wiesław Ciechomski

Physiological Measurement as a (Controversial) Research Method .......... 38

Bartłomiej Pierański

An Overview to Neuromarketing Research Methods ................ 54

Urszula Garczarek-Bąk

Measurement of Electrodermal Activity in Marketing Research ............ 73

Sylwester Białowąs, Adrianna Szyszka

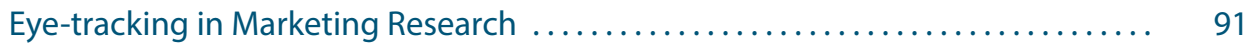

Sylwester Białowąs, Adrianna Szyszka 
Romanowski R. (Ed.): Managing Economic Innovations - Methods and Instruments

Bogucki Wyd. Nauk., Poznań 2019. ISBN 978-83-7986-277-1

DOI: $10.12657 / 9788379862771-0$

\section{Introduction}

Keywords: innovation management, economic innovations, physiological measurement, neuromarketing, eye-tracking

The nature of innovation management is based on understanding the innovation process, which implicates necessary resources, the structure of an organization and expected outcomes. This process of innovation management is grounded on the assumption of a gradual opening up towards external sources of information that is necessary for the effective implementation of an invention on the market. One must also remember that the idea of innovation management is centred around shortening the process of invention with cost reductions and making the outcome of innovation successful by market acceptation (Romanowski, 2019). This search for assumptions concerning the introduction of a new product should be guided by market logic over those that are technical in order to reduce the risk.

Due to rapid advent of the Internet, it is necessary to use e-marketing tools to diagnose consumer behaviour in their interactions with the digital environment. This is all the more important in today's academic sphere where more focus is given to the holistic steps involved in innovation and not towards the diagnosing of physiological reactions and preferences in the purchasing process. This book, therefore, is devoted to selected methods used within the research and development stage of the innovation process.

All described methods and instruments are part of the Innovation Management Master Study Programme, provided by Poznań University of Economics and Business through two laboratories dedicated to testing consumer behaviour in marketing innovations: ConsumerLab and ShopLab. The described methods include measuring consumer behaviour on the Internet, physiological, electrodermal activity measurements and neuroscience research methods to test reactions on innovation.

The first chapter will see a review of tools related to Search Engine Marketing (SEM), Content Marketing, E-mail Marketing, Marketing automation, Social Media Marketing, data collection and research. The data presented in this chapter clearly indicates the

Robert Romanowski: Associate Professor at Department of Commerce and Marketing, Institut of Marketing, Poznań University of Economics and Business, ORCID: https://orcid.org/0000-0002-8585-6806, e-mail: robert.romanowski@ue.poznan.pl 
importance of understanding the behaviour of modern consumers on the internet and undertaking e-marketing to match it. It also highlights the importance of staying updated on the latest trends and technologies on the internet if one is to continue being successful (Keeley, Pikkel, Quinn, Walters, 2013).

The second chapter is devoted to content marketing and the significance of social media, with a particular emphasis on Instagram as a promotional tool and a channel for selling goods and services. Such a review, in our opinion is vital as social networks are becoming the leading instrument for promotion and image creation, with companies using it for creating an optimal self-image whilst consumers use it for posting original illustrations, photos and videos.

The third chapter presents the essence and specificity of physiological measurements that can only be performed using appropriate apparatuses. It also reviews how physiological data that cannot be directly observed by humans (e.g. brainwaves, eye fixations) are advantageous due to its objectivity, continuity and non-invasiveness of measurement. The chapter then classifies the methods of physiological measurements, taking the human nervous system structure as a point of reference.

The fourth chapter is dedicated to neuroscience research methods that help understand cognitive processes and underlying mechanisms of consumer behaviour. The aim of this systematic review is to summarize the techniques, contributions and limitations of several key neuromarketing methods.

The fifth chapter takes a closer look at the measuring of electrodermal activity (EDA), its essential elements, assumptions related to the concept and possibilities in marketing research. The chapter also discusses examples EDA use, together with other measurement methods.

The final chapter is dedicated to reviewing eye-tracking as a neuromarketing tool, enabling scientists to measure subconscious reactions in response to stimuli, thereby giving insight into decision-making processes, consumer preferences or motivations. It also presents the main research areas and possibilities of using eye-tracking in marketing research as per previous research.

We hope this publication will be useful for students studying Innovation Management, its enthusiasts as well as for those working in R\&D.

Robert Romanowski

1. Keeley L., Walters H., Pikkel R., Quinn B. (2013). Ten Types of Innovation: The Discipline of Building Breakthroughs. John Wiley \& Sons, Hoboken, NJ.

2. Romanowski, R. (2019). The Nature of Innovation Management. [In:] Romanowski R. (Ed.) Managing Economic Innovations - Ideas and Institutions. Bogucki Wydawnictwo Naukowe, Poznań, pp. 6-21, DOI: 10.12657/9788379862764-1. 
Romanowski R. (Ed.): Managing Economic Innovations - Methods and Instruments

Bogucki Wyd. Nauk., Poznań 2019. ISBN 978-83-7986-277-1

DOI: $10.12657 / 9788379862771-1$

\title{
Chapter 1
}

\section{Managing E-marketing in Business}

\author{
Marcin Lewicki
}

\begin{abstract}
The main purpose of this chapter is to present basic principles of managing e-marketing in business. The first subchapter focuses on presenting the issue of classification of e-marketing tools. This is then followed up with a data backed review on consumer behaviour on the Internet, the importance of understanding it and the increasing need for e-marketing. In the third subchapter The RACE Digital Marketing Planning Framework is presented and reviewed as one of the most common approaches to manage e-marketing. The final part of the article saw the presentation of a case study on Frisco.pl, a successful Polish e-marketing campaign.
\end{abstract}

Keywords: consumer behaviour, digital marketing, Internet, e-commerce

\section{Introduction}

The proliferation of the internet which gave rise to the beginning of e-commerce in 1995 (Tian, Stewart, 2006) shows no signs of slowing down, making e-marketing an integral strategy of any modern organisation. So much so that the use of digital media, data and technology to support marketing activities (Chaffey, Ellis-Chadwick, 2016) have become a key link in staying competitive on the market. Such use of e-marketing is paramount as customers are now more digital savvy and seek value in their transactions (Stephen, 2016), requiring organisations to be knowledgeable about online consumer behaviour and their interactions with it (Chaffey, Ellis-Chadwick, 2016). The main purpose of the chapter is to present the basic principles of managing e-marketing in

Marcin Lewicki: PhD, Assistant Professor at Department of Commerce and Marketing, Institute of Marketing, Poznań University of Economics and Business, ORCID: https://orcid.org/0000-0002-3526-487X, e-mail: marcin.lewicki@ue.poznan.pl 
business and will see the classification of e-marketing tools (Subchapter 1), a review of the most recent data concerning consumer behaviour on the Internet (Subchapter 2), a framework for e-marketing management (Subchapter 3) and an example of an e-marketing campaign (Subchapter 4).

\section{E-marketing tools}

With no universal means of classifying e-marketing tools, many different approaches to doing so have sprung up. It was in this context that Kierzkowski, McQuade, Waitman and Zeisser (1996) introduced the Digital Marketing Framework in which they indicated five essential elements for success in digital marketing,

1. attracting users,

2. engaging users' interest and participation,

3. retaining users,

4. learning about users preferences,

5. relating back to users to provide customised interactions.

This framework then allowed Teo (2005) in distinguishing specific e-marketing tools (Table 1) which then were subject of his research.

Table 1. E-marketing tools and their purpose based on the Digital Marketing Framework

\begin{tabular}{ll}
\hline \multicolumn{1}{c}{ Tool } & \multicolumn{1}{c}{ Purpose } \\
\hline $\begin{array}{ll}\text { mnemonic branding, listing in search engine, adequate bandwidth, promo- } \\
\text { tions, piggyback advertising, affiliate program, banner ads }\end{array}$ & attracting users \\
\hline $\begin{array}{l}\text { informative and useful content, transaction capabilities, unique content, } \\
\text { creative programming, lucky draws/contests, create virtual communities, } \\
\text { multilingual website, forums/discussion groups }\end{array}$ & $\begin{array}{l}\text { engaging users' interest } \\
\text { and participation }\end{array}$ \\
\hline $\begin{array}{l}\text { dynamic content, security features, rapid information loading time, privacy } \\
\text { statements, hyperlinks to related sites, loyalty programs, provide online order }\end{array}$ & retaining users \\
tracking, create switching costs via communities, interactive functions & \\
\hline $\begin{array}{l}\text { information capture, feedback via online surveys, webpage tracking devices, } \\
\text { feedback via open-ended survey forms, gather information about new }\end{array}$ & learning about users \\
potential customeren, cookies, holding virtual focus groups, supporting chat \\
groups
\end{tabular}

Note. Reprinted [adapted] from Usage and effectiveness of online marketing tools among Business-to-Consumer (B2C) firms in Singapore. Teo, T.S. (2005), International journal of information management, 25(3), 203-213.

For comparison, according to Maciorowski (2013, p. 26), it is possible to distinguish 7 groups of e-marketing tools based on the purpose for which they are used (Table 2).

As useful as the above classification are, it should also be noted that both classifications seem imprecise (Maciorowski's to a greater extent), the effectiveness of some 
tools does not depend solely on the company which use them e.g "rapid information loading time" (Table 1), moreover some of them do not actually deserve this term, for example "indication of the unique values of the product" is nothing else but the direction of activities (Table 2).

Table 2. Types of e-marketing tools by Maciorowski

\begin{tabular}{|c|c|c|}
\hline Tool & Essence & Purpose \\
\hline $\begin{array}{l}\text { word of mouth marketing, viral } \\
\text { marketing }\end{array}$ & $\begin{array}{l}\text { using a network of friends, experts, trendsetters } \\
\text { and brand ambassadors in order to increase an } \\
\text { awareness of a service, brand, company and } \\
\text { product }\end{array}$ & $\begin{array}{l}\text { recommenda- } \\
\text { tion }\end{array}$ \\
\hline $\begin{array}{l}\text { affiliate marketing, performance } \\
\text { marketing }\end{array}$ & $\begin{array}{l}\text { running a partnership program created inde- } \\
\text { pendently or in cooperation with the agency }\end{array}$ & purchase \\
\hline $\begin{array}{l}\text { promotional codes, rebates, dis- } \\
\text { count coupons }\end{array}$ & $\begin{array}{l}\text { stimulating sales by means of attractive shop- } \\
\text { ping incentives }\end{array}$ & privileges \\
\hline $\begin{array}{l}\text { purchase statistics, highlighting } \\
\text { USP (unique selling proposal) of the } \\
\text { offer, customer reviews, segmenting } \\
\text { content }\end{array}$ & $\begin{array}{l}\text { providing reliable arguments in order to prove } \\
\text { the attractiveness of the offer, which will elimi- } \\
\text { nate any dissonance before and after purchase }\end{array}$ & convincing \\
\hline $\begin{array}{l}\text { indication of the unique values of } \\
\text { the product }\end{array}$ & $\begin{array}{l}\text { arousing the desire to have a product by empha- } \\
\text { sizing its qualities }\end{array}$ & encouraging \\
\hline $\begin{array}{l}\text { target pages, microservices focused } \\
\text { around the product }\end{array}$ & $\begin{array}{l}\text { providing comprehensive information about the } \\
\text { offer, building the image of a reliable seller }\end{array}$ & knowledge \\
\hline $\begin{array}{l}\text { SEO, SEM, PPC advertisement, pres- } \\
\text { ence on partner websites }\end{array}$ & $\begin{array}{l}\text { building awareness of the website and its } \\
\text { attractive offer }\end{array}$ & awareness \\
\hline
\end{tabular}

Note. Reprinted [adapted] from UE-marketing w praktyce. Strategie skutecznej promocji online. by Maciorowski A., (2013), Samo Sedno Edgard, Warszawa.

Nevertheless, recalling the definition of e-marketing proposed by Armstrong and Kotler (2012) "business conducted through the Internet, which is designed to: the promotion of goods and services, the sale of goods and services and building relations with customers" and assuming that most of e-marketing tools often fulfil more than one of the purposes mentioned in the definition, e-marketing tools could be grouped as shown in Table 3.

Table 3. Groups of e-marketing tools

\begin{tabular}{|c|c|c|c|}
\hline Tool group & Superior purpose & Description & $\begin{array}{l}\text { Examples of tech- } \\
\text { nical solution }\end{array}$ \\
\hline $\begin{array}{l}\text { Search Engine } \\
\text { Marketing (SEM) }\end{array}$ & $\begin{array}{l}\text { the promotion of } \\
\text { good and services }\end{array}$ & $\begin{array}{l}\text { SEO (Search Engine Optimization) + } \\
\text { PPC (Pay Per Click) tools, mostly used to } \\
\text { increase traffic to a given website and } \\
\text { website visibility for consumers }\end{array}$ & SEMrush, Unamo \\
\hline $\begin{array}{l}\text { Content Market- } \\
\text { ing }\end{array}$ & $\begin{array}{l}\text { the sale of goods and } \\
\text { services }\end{array}$ & $\begin{array}{l}\text { Tools used to create and manage content } \\
\text { of a given website }\end{array}$ & $\begin{array}{l}\text { Percolate, News- } \\
\text { Cred }\end{array}$ \\
\hline E-mail Marketing & $\begin{array}{l}\text { building relations } \\
\text { with consumers }\end{array}$ & $\begin{array}{l}\text { Tools to manage all types of e-mail com- } \\
\text { munication with consumers }\end{array}$ & $\begin{array}{l}\text { MailChimp, } \\
\text { FreshMail }\end{array}$ \\
\hline $\begin{array}{l}\text { Marketing auto- } \\
\text { mation }\end{array}$ & $\begin{array}{l}\text { the sale of goods and } \\
\text { services }\end{array}$ & $\begin{array}{l}\text { Tools used to manage all e-marketing } \\
\text { activities in one place }\end{array}$ & $\begin{array}{l}\text { HubSpot, Sales- } \\
\text { Manago }\end{array}$ \\
\hline $\begin{array}{l}\text { Social Media } \\
\text { Marketing }\end{array}$ & $\begin{array}{l}\text { building relations } \\
\text { with consumers }\end{array}$ & $\begin{array}{l}\text { Tools designed to manage all social media } \\
\text { activities }\end{array}$ & Socedo, Brand24 \\
\hline $\begin{array}{l}\text { Data collection } \\
\text { and research }\end{array}$ & $\begin{array}{l}\text { the sale of goods and } \\
\text { services }\end{array}$ & $\begin{array}{l}\text { Tools used to collect and analyse data } \\
\text { from different Internet activities and } \\
\text { sources }\end{array}$ & $\begin{array}{l}\text { Google Analytics, } \\
\text { WebTrends }\end{array}$ \\
\hline
\end{tabular}

Note. Author developed (2019). 


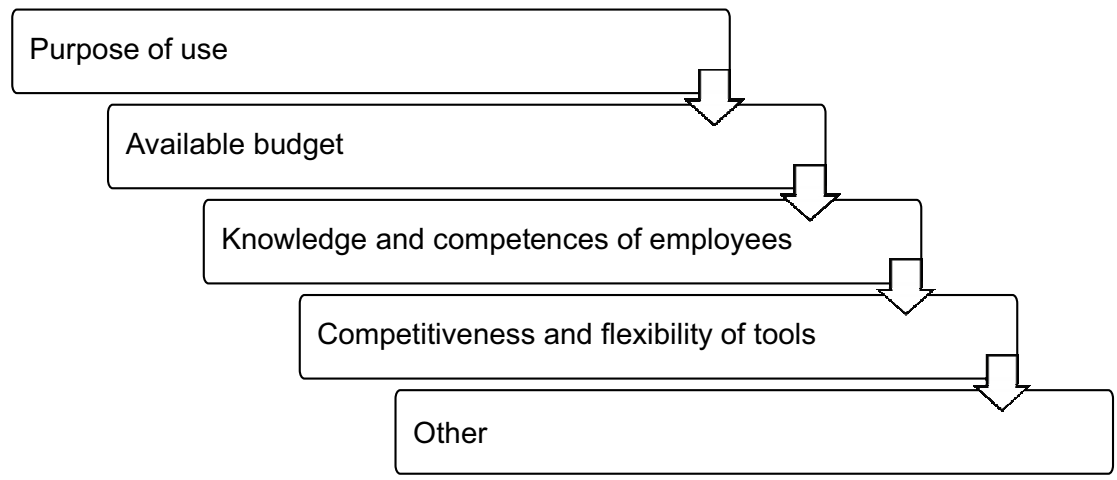

Figure 1. Criteria for selecting e-marketing tools

Author developed (2019).

It should be added that the groups of tools highlighted are very capacious, which is why all three purposes mentioned by Armstrong and Kotler (2012) can be achieved through their use. Naturally, some of them could be of higher priority within a given group in what has been marked in "Superior purpose" column. Furthermore, the groups are not completely disjunctive, as those such as "Marketing automation" is actually a combination of solutions that can be found in other groups, while "Social Media Marketing" is one of the biggest and often includes content creation tools. Finally, it is not possible to indicate all of the technical solutions that can be assigned to a group due to their very large number (See as an example TechWyse Internet Marketing Tools 2017 (TechWyse)). Having reviewed the above information, it is clear that picking the right e-marketing tool is based on many factors.

The first criterion is the selection of a tool that matches e-marketing activities that are being undertaken. If the primary purpose is the building of communities and customer advocacy, social media marketing is an ideal tool, whereas Search Engine Marketing is optimum if the primary purpose is building awareness and brand visibility. The next criterion is the determining of a budget which can be used to implement the tool that was selected. Doing so is important as tools are of varying prices and an organisation serious about their e-marketing will need to use a dedicated solution and not one of the free solutions on the market. The factor that must be taken into account after this is the knowledge and competences of the company's employees as they should be able to use the available tools. The final criterion one should keep in mind when picking a tool is the competitiveness and flexibility of individual tools to keep up with the dynamic nature of the internet landscape. Undoubtedly, the above-mentioned criteria for e-marketing tools selection do not exhaust all possible determinants of the choice and can be extended depending on the company nature and extended needs. 


\section{Consumer behaviour on the Internet - the case study of Poland}

With over $57 \%$ of the world's population connected to the Internet, spending more than $61 / 2$ hours online each day, more and more customers are now searching for information, building relationships and shopping (Digital in 2019). There are over 5.1 billion unique mobile users ( $67 \%$ of the world's population) and over 3,5 billion active social media users ( $45 \%$ of the world's population). This growth rate in the case of the Internet and social media users which was over $9 \%$ (Digital in 2019) is impressive and is the reason why social media is considered the heart of all digital customer touchpoints. It is able to help

1. Rebuild trust with consumers - There is no doubt that the case of Cambridge Analytica and fake news eroded consumer confidence in search engines, businesses, and social channels in 2018. Therefore, in order to rebuild trust, companies must be clear on why data collection is important for creating personalized, one-to-one experiences that offer new value to customers.

2. Breaking down marketing silos $-54 \%$ of organizations report that marketing teams can increase their influence by guiding other departments, stimulating digital transformation wherever possible. Establishing common KPIs with other departments, using social media to achieve broad business objectives like brand health, revenue and consumer retention, could serve as an appropriate starting point.

3. Making a unified view of consumers - Nowadays, the average Internet user has accounts on 8 different social and messaging services, creating a need to build a unified view of their consumers across every touchpoint. Doing so is very important as such unification of data helps work more fluidly and provides a competitive edge on the market.

Social media and their indisputable role in online communication are conducive to directing marketing activities to this area, strengthening the importance of social media marketing among other groups of tools. In connection with the above, it is justified to pay a bit more attention to consumer behaviour within social media (Digital in 2019). Based on active user accounts (Fig. 2), the five biggest social platforms are Facebook over 2.2 billion users, YouTube - over 1.9 billion users, WhatsApp - over 1.5 billion users, FB Messenger - over 1.3 billion users and WbXin/WeChat - over 1 billion users. While Facebook remains a leader among social media platforms, WhatsApp is a leader among instant messengers.

Social media is definitely the domain of young people. Based on the combined advertising audiences of Facebook, Instagram and Facebook Messenger majority of users are between 18 and 44 years old. Users 65+ years old constitute only $4 \%$ of the population (Fig. 3). Additionally, based on the survey conducted in USA (Chaffey, 2019), YouTube Instagram and Snapchat are the most popular online platforms among teens. 


Facebook
YouTube
WhatsApp
FB Messenger
WBXIN/WeChat
Instagram
QQ
QZone
Douyin/TikTok
Sina Weibo
Reddit
Twitter
Douban
Linkedln
Skype
BaiduTieba
Snapchat
Viber
Pinterest
Line

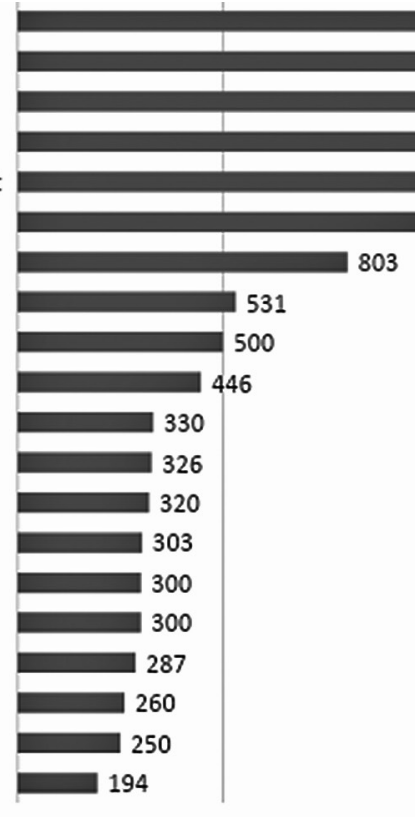

0

500

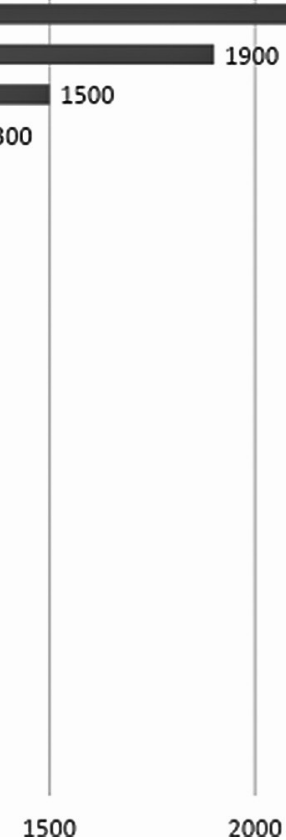

Figure 2. Social platforms by active user accounts worldwide in 2019 (in millions)

Global Digital Report 2019: Free Download: We Are Social UK. (2019). Retrieved from https://wearesocial. com/uk/digital-2019.

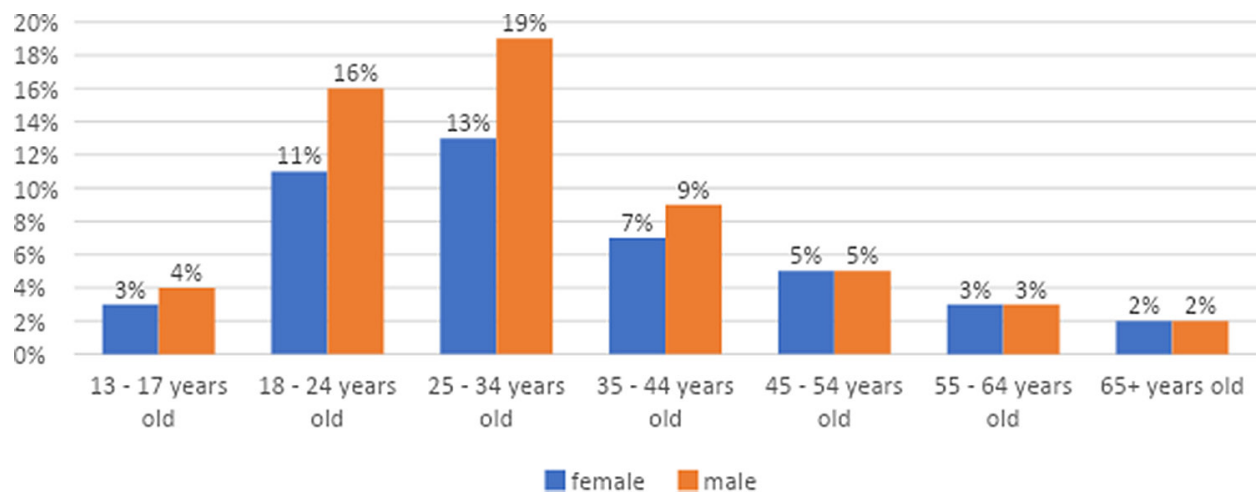

Figure 3. Social media audience profile in USA

Global Digital Report 2019: Free Download: We Are Social UK. (2019). Retrieved from https://wearesocial. com/uk/digital-2019.

Determining the reasons for using social media is one of the most important issues in the context of consumer behaviour on the Internet. The top three reasons for using social media as per the research from GlobalWeblndex is staying in touch with their friends $-42 \%$, staying up-to-date with news and current events $-41 \%$ and filling up 
spare time - 39\% (Chart 3). From the perspective of e-marketing, it is worth paying particular attention to the percentage of users who:

- are staying up-to-date with news and current events $-41 \%$,

- are looking for funny or entertaining content $-37 \%$,

- network with other people - 34\%,

- share their opinion - 30\%,

- conduct research prior to purchasing products - $29 \%$.

All of the abovementioned reasons are important when analysing data collected via social marketing tools.

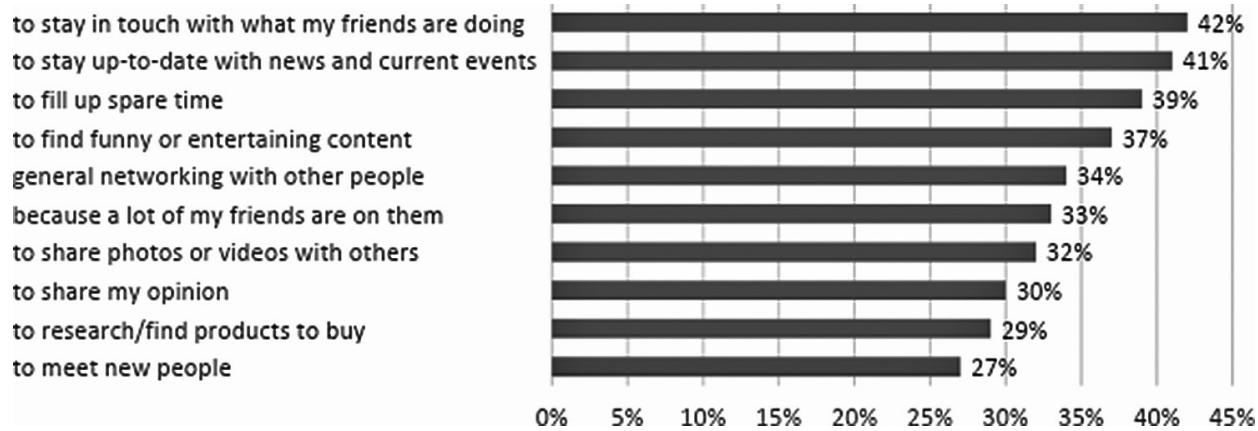

Figure 4. Top 10 reasons for social media usage worldwide

Top 10 Reasons for Using Social Media - GlobalWeblndex. (2018, March 1). Retrieved from https://blog. globalwebindex.com/chart-of-the-day/social-media/.

Poland is relatively one of the fastest-growing countries in terms of the use of digital technologies by consumers. According to the report (Digital in 2019 B), there are over 30 million Internet users in Poland (79\% of the population), 26 million of which are mobile Internet users (69\% of the population) and 18 million of which are active social media users (47\% of population). While the number of Internet users increased only by $1.1 \%$ compared to the previous year, the growth rate of active social media users amounted to almost $6 \%$ which resulted in the emergence of one million new users. Over $82 \%$ of Poles use the Internet on a daily basis with Google.pl, Google.com, Facebook.com and Allegro.pl taking most of the traffic (Table 4).

$45 \%$ of Poles declared using ad-blocking tools when surfing through the Internet which can be seen as a difficulty in conducting e-marketing activities in Poland. In the case of social media usage, the average number of social media accounts per Internet user was 7,3, while the top five most active social platforms (based on the percentage of Internet users who reported using them) were YouTube, Facebook, FB Messenger, Instagram and Skype. Taking into account advertising audiences Facebook seems to have the most potential from the perspective of e-marketing, followed by Instagram and Snapchat (Table 5). 
Table 4. Ranking of websites in Poland based on the average monthly traffic in 2019

\begin{tabular}{rllccc}
\hline $\begin{array}{c}\text { Posi- } \\
\text { tion }\end{array}$ & \multicolumn{1}{c}{ Website } & \multicolumn{1}{c}{ Category } & Monthly Traffic & Time per visit & $\begin{array}{c}\text { Pages per } \\
\text { visit }\end{array}$ \\
\hline 1 & Google.pl & Search & 861,4 million & $10 \mathrm{M} 37 \mathrm{~S}$ & 7,9 \\
\hline 2 & Google.com & Search & 714,6 million & $09 \mathrm{M} 54 \mathrm{~S}$ & 8,6 \\
\hline 3 & Facebook.com & Social & 540,1 million & $13 \mathrm{M} 22 \mathrm{~S}$ & 11,1 \\
\hline 4 & YouTube.com & TV\&Video & 503,3 million & $24 \mathrm{M} 34 \mathrm{~S}$ & 10,2 \\
\hline 5 & WP.pl & News & 245,2 million & $07 \mathrm{M} 24 \mathrm{~S}$ & 6,6 \\
\hline 6 & Onet.pl & News & 229,9 million & $06 \mathrm{M} \mathrm{55S}$ & 6,8 \\
\hline 7 & Allegro.pl & Shopping & 199,7 million & $10 \mathrm{M} 27 \mathrm{~S}$ & 13,8 \\
\hline 8 & Interia.pl & News & 136,3 million & $06 \mathrm{M} \mathrm{35S}$ & 6 \\
\hline 9 & OLX.pl & Shopping & 122,8 million & $09 \mathrm{M} 46 \mathrm{~S}$ & 12,5 \\
\hline 10 & Wikipedia.org & Reference & 119,2 million & $04 \mathrm{M} 07 \mathrm{~S}$ & 3,1 \\
\hline
\end{tabular}

Note. Reprinted [adapted] from Kemp, S. (2019, January 31). Digital 2019: Poland - DataReportal - Global Digital Insights. Retrieved from https://datareportal.com/reports/digital-2019-poland.

Table 5. Social media advertising audiences in Poland in 2019 (in million)

\begin{tabular}{lccccr}
\hline \multicolumn{1}{c}{ Platform } & Facebook & Instagram & Twitter & Snapchat & \multicolumn{2}{c}{ Linkedln } \\
\hline Audience & 17 & 6,8 & 0,934 & 3,8 & 3,3 \\
\hline Female & $52 \%$ & $58 \%$ & $32 \%$ & $58 \%$ & $48 \%$ \\
\hline Male & $48 \%$ & $42 \%$ & $68 \%$ & $42 \%$ & $52 \%$ \\
\hline Quarterly growth & $0 \%$ & $6 \%$ & $5 \%$ & $-15 \%$ & $3 \%$ \\
\hline
\end{tabular}

Note. Reprinted [adapted] from Kemp, S. (2019, January 31). Digital 2019: Poland - DataReportal - Global Digital Insights. Retrieved from https://datareportal.com/reports/digital-2019-poland.

Similarly to the global social media audience profile, a majority of users in Poland are between 18 and 44 years old where users $65+$ years old constitute only $4 \%$ of the population (Fig. 5).

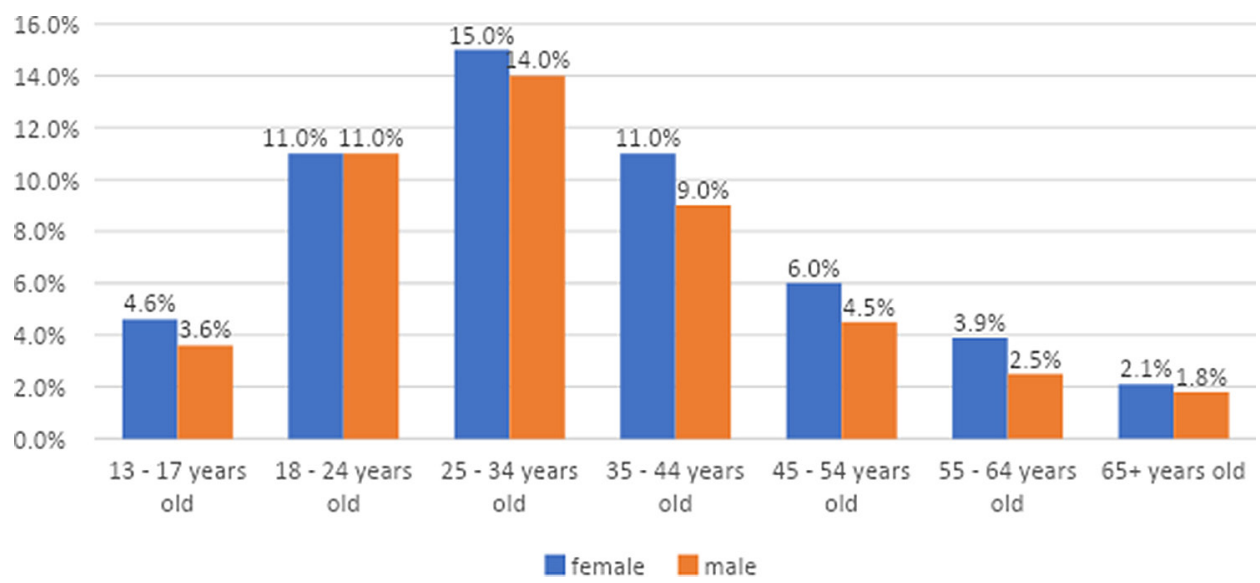

Figure 5. Social media audience profile in Poland in 2019

Kemp, S. (2019, January 31). Digital 2019: Poland - DataReportal - Global Digital Insights. Retrieved from https://datareportal.com/reports/digital-2019-poland. 
Facebook remains the main social media platform in Poland and can serve as a valuable platform for e-marketing activities (Table 6). As shown in the table, females on Facebook were more active than males in every type of activity except for sharing posts. It should also be noted, that the most common type of activity was liking posts and clicking advertisements.

Table 6. Facebook activity frequency in Poland in 2019

\begin{tabular}{lccccc}
\hline $\begin{array}{c}\text { Activity } \\
\text { type }\end{array}$ & $\begin{array}{c}\text { Number of Face- } \\
\text { book pages liked } \\
\text { (lifetime) }\end{array}$ & $\begin{array}{c}\text { Posts Liked in the } \\
\text { past 30 days (all } \\
\text { post types) }\end{array}$ & $\begin{array}{c}\text { Comments made } \\
\text { in the past 30 } \\
\text { days (all post } \\
\text { types) }\end{array}$ & $\begin{array}{c}\text { Facebook posts } \\
\text { shared in the } \\
\text { past 30 days (all } \\
\text { post types) }\end{array}$ & $\begin{array}{c}\text { Facebook adverts } \\
\text { clicked in the } \\
\text { past 30 days (any } \\
\text { click type) }\end{array}$ \\
\hline Overall & $1^{*}$ & 10 & 3 & 1 & 11 \\
\hline Female & 2 & 15 & 5 & 1 & 15 \\
\hline Male & 1 & 7 & 2 & 1 & 8 \\
\hline
\end{tabular}

*Figures represent median values for active Facebook users aged 18 and above.

Note. Reprinted [adapted] from Kemp, S. (2019, January 31). Digital 2019: Poland - DataReportal - Global Digital Insights. Retrieved from https://datareportal.com/reports/digital-2019-poland.

In the context of e-marketing and consumer behaviour on the Internet, the subject of e-commerce cannot be omitted. According to the latest report (Digital in 2019) 65\% of Poles (24,2 million people) make online purchases and/or pay bills online. Among e-commerce activities, it should be noted that:

- $86 \%$ searched online for a product or service to buy,

- $92 \%$ visited an online store on the web (with the use of any device),

- $76 \%$ purchased a product or service online (any device),

- $65 \%$ made an online purchase via a laptop or desktop computer,

- $36 \%$ made an online purchase via a mobile device.

The most popular category of products purchased online was Travel (including accommodation) in which over 4,5 billion dollars have been spent (Table 7), while the total annual sales revenue from selling consumer goods in e-commerce amounted to 8,194 billion dollars (average annual revenue per user - 339 dollars) with a significant annual growth rate of $11 \%$.

When searching for products online, Polish consumers most often used phrases like: Allegro, Buty, Nike, Adidas and Samsung (Table 8).

Undoubtedly, collecting data about consumer behaviour on the Internet is a top priority in e-marketing and should be conducted with the use of dedicated tools and data that is freely availble. Analysis of such data allows for the creation of a more general picture of consumer behaviour and helps to determine current market trends. 6 such trends that will be important for e-marketing as per Euromonitor International are

- Everyone's an Expert - refers to the almost compulsive need for digital consumers to absorb and share information. As Internet retailing continues to increase globally, all industries will have to adapt to consumers' new demands to stay relevant. 
Table 7. E-commerce spend and annual growth by product category in Poland in 2019

\begin{tabular}{lcc}
\hline \multicolumn{1}{c}{ Category } & $\begin{array}{c}\text { Total amount spent } \\
\text { in billion US dollars }\end{array}$ & Annual growth \\
\hline Travel (including accomodation) & 4,511 & $13 \%$ \\
\hline Fashion \& Beauty & 2,801 & $12 \%$ \\
\hline Electronics \& Physical Media & 2,013 & $8,5 \%$ \\
\hline Toys, DIY \& Hobbies & 1,703 & $8,6 \%$ \\
\hline Furniture \& Appliances & 0,961 & $16 \%$ \\
\hline Food \& Personal Care & 0,715 & $12 \%$ \\
\hline Video games & 0,300 & $9,4 \%$ \\
\hline Digital music & 0,060 & $10 \%$ \\
\hline
\end{tabular}

Note. Reprinted [adapted] from Kemp, S. (2019, January 31). Digital 2019: Poland - DataReportal - Global Digital Insights. Retrieved from https://datareportal.com/reports/digital-2019-poland.

Table 8. Top Google shopping queries based on searches in Poland throughout 2018

\begin{tabular}{clll}
\hline Position & \multicolumn{1}{c}{ Search query } & Position & \multicolumn{1}{c}{ Search query } \\
\hline 1 & Allegro & 11 & Castorama \\
\hline 2 & Buty & 12 & PS4 \\
\hline 3 & Nike & 13 & Calvin Klein \\
\hline 4 & Adidas & 14 & Xiaomi \\
\hline 5 & Samsung & 15 & Ceneo \\
\hline 6 & iPhone & 16 & Buty Nike \\
\hline 7 & Sukienki & 17 & Nike Air \\
\hline 8 & Huawei & 18 & Media Expert \\
\hline 9 & OLX & 19 & Tommy Hilfiger \\
\hline 10 & Ikea & 20 & Vans
\end{tabular}

Note. Reprinted [adapted] from Kemp, S. (2019, January 31). Digital 2019: Poland - DataReportal - Global Digital Insights. Retrieved from https://datareportal.com/reports/digital-2019-poland.

- I Can Look After Myself - is the preventative, consumable measures against illness, unhappiness and discomfort that people can take without having to consult a professional. Consumers make use of apps and personalisation services to create a product uniquely for them without the need to constantly engage with social media and brand marketing.

- I Want it Now! - efficiency-driven lifestyles transcend instant gratification. Consumers seek frictionless experiences that mesh with their lifestyles, allowing them to dedicate more time to their professional or social lives. Central to this concern is the management of user data and a company's access to this data.

- Finding My JOMO - the fear of missing out has now given place to the re-appropriation of self-time as people find joy in missing out. To protect their mental wellbeing, consumers want to be more intentional with their time, to set their own boundaries and be more selective in their activities (especially millennials). Planned disconnection provides them with time to reflect and to act freely, fo- 
cusing on what they really want and enjoy doing. And in developing markets, reliance on the Internet may be the origin of higher stress levels, especially when being connected is so linked to essential services.

- Digitally Together - the growing ubiquity of high-speed Internet, particularly the acceleration of mobile internet, is driving live interactive experiences online and facilitating collaboration on large files instantly. From dating to education, consumers have grown to expect more authentic, life-like interactions online. Growing comfort with sharing friends, location and activities online can be observed which will lead to the development of new ways to engage consumers.

- Age Agnostics - are consumers who don't hold with conforming to demographic expectations - everyone connects. The key to winning and retaining loyalty and trust is to develop products and services that are universally accessible even while designed with older people in mind. Baby boomers have much more in common with the values and priorities of millennials and younger generations then many realise, and it is this inclusive mindset that needs to be better understood and catered for in the future.

\section{RACE planning in managing e-marketing}

Managing and achieving success in e-marketing is not possible without a proper strategy. According to Ryan (2016), components that form the foundation of digital marketing strategy include:

- knowledge about business - having products or services suited to online promotion; having the right technology etc.,

- knowledge about competitors - knowing main competitors in the digital marketplace; which of their activities are worth to benchmark; how to differentiate the current offer from competitors etc.,

- knowledge about consumers - knowing the latest trends; understanding consumers behaviour on the Internet; knowing consumers needs and expectations etc.,

- purpose of e-marketing activities - setting clear, measurable and achievable goals

- measuring effects - tracking everything that happens online and comparing a progress against predefined goals and key performance indicators (KPIs)

It should be noted that abovementioned components are in line with basic managerial functions (Koontz, Weihrich, 2010), and include planning, organizing, staffing, leading and controlling.

One of the most comprehensive approaches to management in e-marketing is the RACE Digital Marketing Planning Framework presented for the first time in 2010 to help digital marketers plan and manage their activities in a more structured way (Chaffey, 2017). It summarises the key online marketing activities that need to be managed 
as part of digital marketing and covers the full consumer lifecycle from the planning phase to the engagement (Fig. 2).

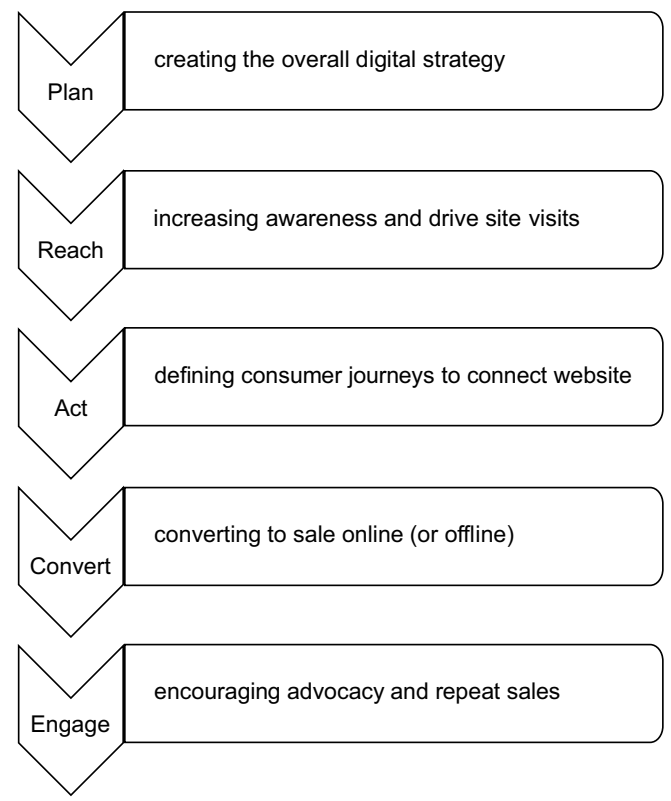

Figure 6. The RACE Digital Marketing Planning Framework

Chaffey D. (2017). Introducing RACE: a practical framework to improve your digital marketing.

The principal aim of the planning phase is to create the overall digital strategy and includes different activities such as those outlined below:

- establishing key operational strategies that will allow the development of an online business. An example of this would be the creation of a plan to achieve interactions, conversion of visitors to a lead and ultimately a sale.

- marketplace analysis on audience and consumers, competitor benchmarking, online partner analysis and SWOT analysis.

- vision and mission setting, creating evaluation system and deciding what KPIs should be used.

Based on the abovementioned, a strategy that covers further e-marketing activities starting with the reach phase, through act and conversion phase and ending with the engagement phase is proposed (Chaffey, 2017).

The reach phase involves building awareness of a brand, its products, and services on other websites and offline media in order to build traffic by driving visits to different web presences like a given company main site, microsites or social media pages. It involves maximising reach over time to create multiple interactions using different paid, owned and earned media touchpoints. Within this phase SEM and Social Marketing 
tools are commonly used. Key measures in the reach phase are: unique visitors, bounce rate, revenue per visit and number of a brand searches (Chaffey, 2017).

The act phase is about engaging the audience through relevant, compelling content and clear navigation pathways so that they do not hit the back button. Persuading site visitors or prospects to take the next step, the next "action" on their journey when they initially reach a given site or social network presence is one of the biggest challenges for online marketers since the bounce rates on many sites is greater than $50 \%$. The main objective of this phase can differ depending on the type of an online business and can include key measures such as number of leads, \% conversion to lead, goal value per visit and/or page views/visit etc. Important strategies in this phase includes content marketing, data collection, research and marketing automation tools (Chaffey, 2017).

The convert phase involves getting an audience to take the vital step into becoming paying consumers. In this phase capitalization of marketing expenditures takes place and includes key measures such as number of sales, \% conversion to sale, sales value and/or average order value etc. Within this phase almost every group of e-marketing tools (Table 3 ) is used to a greater or lesser extent (Chaffey, 2017).

Finally, the main objective of the engagement phase is to create long-term engagement as repeat purchases using communications on a given site, social presence, email and direct interactions boost consumer lifetime value. Key measure within this phase may include: \% of active consumers, \% consumer conversion, \% existing sales value and/or number of brand mentions. The most commonly used e-marketing tools used to engage consumers in this phse are content marketing, social media marketing and e-mail marketing (Chaffey, 2017).

It should be added that the RACE Digital Marketing Planning Framework has been built on the foundation of the REAN model (Reach ,Engage ,Activate and Nurture) created by Satama (now Trainer's House) in 2006 (Jackson, 2009). In turn, the REAN model can be seen as an adaptation of the well-known AIDA model, developed in 1898 by St Elmo Lewis in an attempt to explain how personal selling works (oxfordreference.com) to the online environment. This situation shows that many solutions that find application on the Internet nowadays, in fact, have their sources in well-established marketing knowledge.

\section{Managing e-marketing - the case study of Frisco.pl}

Undoubtedly, one of the sources of business growth is the consumer experiences with the brand throughout the entire purchasing process. E-shops are no longer only a place of transaction, but a tool for building brand image, credibility and a necessary condition for creating bridges that connect consumer needs with offers. The strategic goal for Frisco.pl is to build brand awareness and expand the consumer base by positioning itself as a convenient alternative for hypermarkets when making large and planned grocery shopping. Frisco.pl operates locally in and around Warsaw, but in the category of online grocery shopping it has to compete with such giants as Auchan and 
Tesco. The company has appeared on the e-grocery market much earlier than competitors, has a perspective approach to the category and a good understanding of social changes which are reflected in consumer shopping habits. The main challenge facing Frisco.pl is convincing Poles (who shop 5 times often than those in purchases Western Europe), to change their shopping habits. The first step to change the habits of Polish consumers was to create a communication platform "Do not go shopping", which effectively allowed Frisco to build shares in the e-grocery category and become the leader of the Warsaw online grocery shopping market. Unfortunately, the communication turned out to be insufficient because the need to buy from the shelf is strongly rooted among Poles. As a result, a new approach was necessary and led to the creation of a communication platform "Definition of better purchases", in which the company displayed the troublesome nature of shopping in stationary stores and the specific benefits of online shopping. Among the actions taken by the company, which led to success, it should be emphasized:

- the creation of a precise consumer definition which discovered that the potential consumers are primarily women for whom grocery shopping is an obligation. They give the family what they need (for which relatives are grateful to them) and looking for ways to make the process comfortable and pleasant. For them, a definition of better shopping was created,

- convincing potential consumers about the convenience of online grocery shopping from home through $\mathrm{OOH}$ (out-of-home) campaign, radio and display/programmatic e.g "kitchen* - the perfect place to pick up your purchases" (Pic. 1),

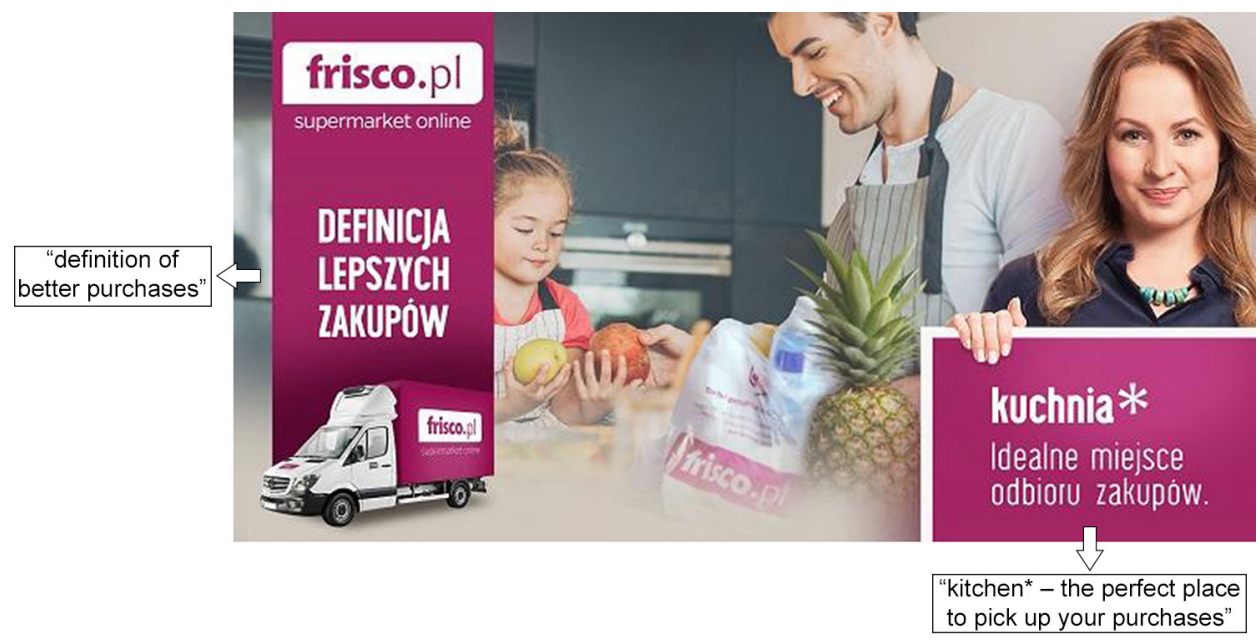

Figure 7. Example of communication in Frisco.pl during the "Definition of better purchases" campaign

Frisco.pl ma nową platformą komunikacji - "Definicja lepszych zakupów". (2018). Retrieved from https://www. wirtualnemedia.pl/artykul/frisco-pl-definicja-lepszych-zakupow-platforma-komunikacji. 
- preparation of creatives based on specific advantages of Frisco.pl, such as the possibility of determining the delivery date with an accuracy of one hour (Pic. 2) and using such benefits as a basis for outreach activities based on $\mathrm{OOH}$ (Out-ofhome), radio, display and recommendations of influencers. This ability to have the groceries delivered at a specific hour has become a key building element for the trial at www.frisco.pl,

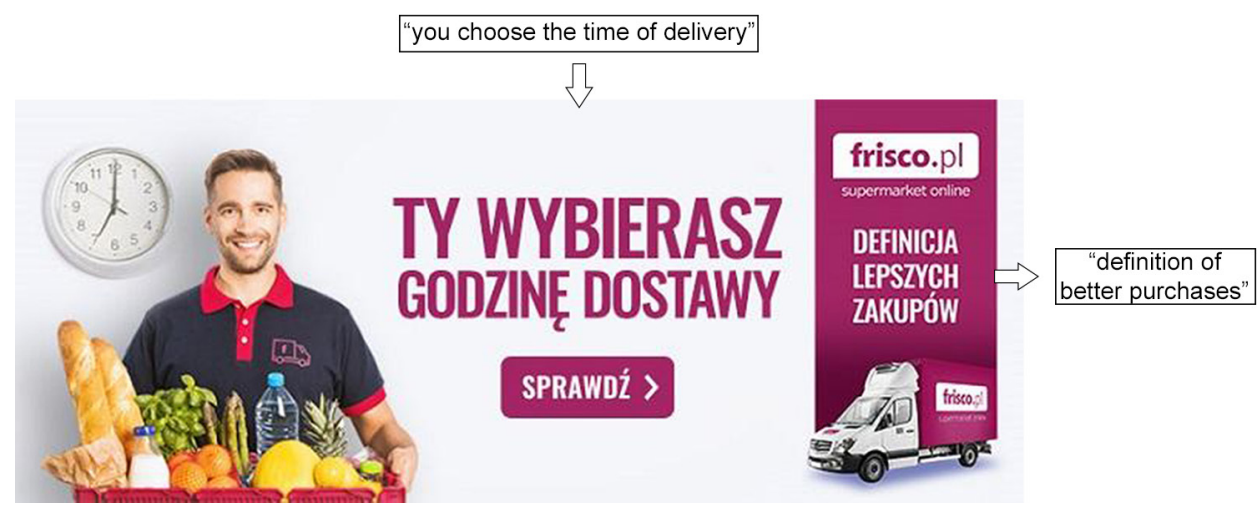

Figure 8. Example of creation based on specific advantages of Frisco.pl in "Definition of better purchases" campaign

Frisco.pl reklamuje się hasłem "Ty wybierasz godzinę dostawy". (2018). Retrieved from https://www.wirtualnemedia.pl/artykul/frisco-pl-kampania-ty-wybierasz-godzine-dostawy.

- the use of an attractive benefit to create the closure of the shopping path in e-commerce channels (mailing, promotional leaflet, landing page and performance). The overall positive experience created in this way - both online and offline - translated into further purchases (Pic. 3).

Actions indicated above has led to the following results:

- a $150 \%$ increase in spontaneous brand awareness,

- among people with knowledge of the e-grocery category, www.frisco.pl has been mentioned most often as a leader in the category (42\%), as a store offering the highest quality and completeness of delivery (37\%) and the best quality of fresh products (40\%),

- the campaign has significantly increased $(+51 \%)$ the number of unique page views at www.frisco.pl,

- the generated traffic has been successfully converted into sales, an unprecedented increase $(+73 \%)$ in the number of new consumers has been obtained.

Understanding consumers' needs and providing a great experience at every stage of the shopping path allowed the company to generate above-average sales results. Thanks to the "Definition of better shopping" platform, supported by the highest quality service and an attractive offer, Frisco.pl generated an enormous increases in the 
base of its consumers and become a leader in the e-grocery category in Poland (Raport strategiczny Internet 2017/2018, p. 20-21).

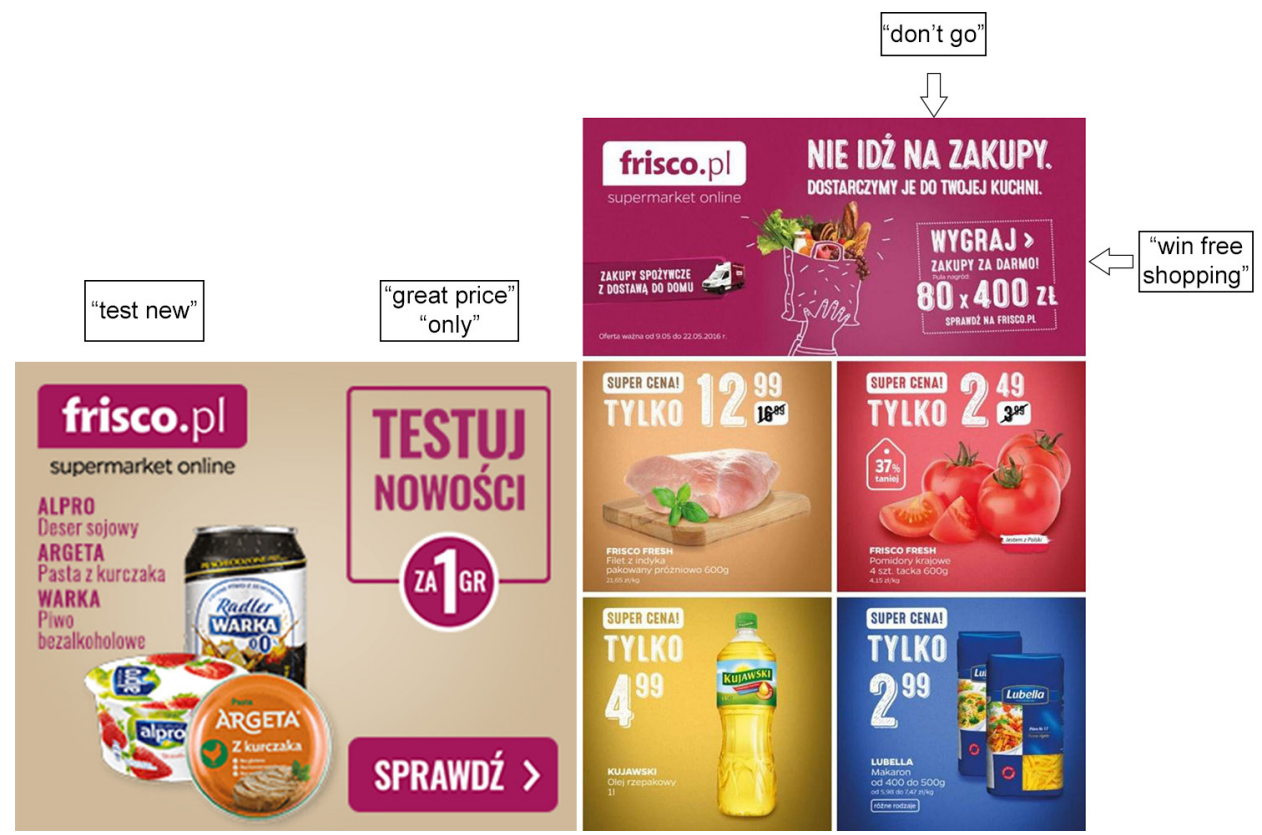

Figure 9. Example of an e-mail (left side) and a promotional leaflet (right side) of Frisco.pl

Retrieved from https://www.wirtualnemedia.pl/artykul/frisco-pl-definicja-lepszych-zakupow-platforma-komunikacji and https://www.wirtualnemedia.pl/artykul/frisco-pl-kampania-ty-wybierasz-godzine-dostawy.

\section{Conclusions}

E-marketing is an important part of the activities of modern enterprises and there are many different tools that can be used within it. While there is no consensus on the universal classification of these tools in the subject literature, the following division has been adopted within the chapter: Search Engine Marketing (SEM) tools, Content Marketing tools, E-mail Marketing tools, Marketing automation tools, Social Media Marketing tools, Data collection and research tools. Such e-marketing tools are valuable in the promotion of good and services, the sale of goods and services and building relations with consumers. Obviously, the above-mentioned purposes are complemented by numerous specific objectives and should be considered as a relatively complex problem that requires knowledge not only about the available tools but consumer behaviour on the Internet. The data presented in the chapter clearly indicate the growing importance of the Internet in the purchasing behaviour of modern consumers and the role e-marketing plays in it. 
The RACE Digital Marketing Planning Framework has been presented as an example of one of the management approaches. The framework not only confirms the complexity of the whole process but also underlines the importance of previously acquired knowledge in the field of marketing. The case study of Frisco.pl served as an example of e-marketing management and proved the importance of conducting research on consumer behaviour. Moreover, it also proved that achieving success in e-marketing often requires using the offline environment $(\mathrm{OOH}$ and radio in the case of Frisco.pl) and requires an organisation to update its knowledege on a constant basis if it is to maintain a competitive edge over rivals.

\section{References}

1. Armstrong G., Kotler Ph. (2012). Marketing. Wolters Kluwer, Kraków.

2. Cambridge Dictionary, https://dictionary.cambridge.org/dictionary/english/manage [accessed: 24.03.2019].

3. Chaffey D. (2019). Global social media research summary 2019. https://www.smartinsights. com/social-media-marketing/social-media-strategy/new-global-social-media-research/ [accessed: 24.03.2019].

4. Chaffey D. (2017). Introducing RACE: a practical framework to improve your digital marketing. https://www.smartinsights.com/digital-marketing-strategy/race-a-practical-framework-to-improve-your-digital-marketing/ [accessed: 24.04.2019].

5. Chaffey D., Ellis-Chadwick F. (2016). Digital Marketing, Strategy, Implementation and Practice. 6th Edition, Pearson.

6. Digital in 2019. https://wearesocial.com/uk/digital-2019 [accessed: 18.04.2019]

7. Digital in 2019 B. https://datareportal.com/reports/digital-2019-poland [accessed: 19.04.2019].

8. gazetki.promocyjne.net.pl https://gazetki-promocyjne.net.pl/gazetka-promocyjna- frisco-pl/09-05-2016/7546/1/ [accessed: 25.04.2019].

9. GlobalWeblndex. https://blog.globalwebindex.com/chart-of-the-day/social-media/ [accessed: 18.04.2019].

10. Euromonitor International, Top 10 Global Consumer Trends 2019. https://www.circularresourceslab.ch/wp-content/uploads/2019/03/10-Global-Consumer-Trends-2019-Euromonitor.pdf [accessed: 19.04.2019].

11. Jackson S. (2009). Cult of Analytics: Driving online marketing strategies using web analytics. Routledge.

12. Kierzkowski A., McQuade S., Waitman R., Zeisser M. (1996). Marketing to the digital consumer. The McKinsey Quarterly, 3, 5-21.

13. Koontz H., Weihrich H. (2010). Essentials of management. Tata McGraw-Hill Education.

14. Maciorowski A. (2013). E-marketing w praktyce. Strategie skutecznej promocji online. Samo Sedno Edgard, Warszawa.

15. oxfordreference.com

http://www.oxfordreference.com/view/10.1093/oi/authority. 20110803095432783 [accessed: 24.04.2019]. 
16. Raport strategiczny Internet 2017/2018. https://iab.org.pl/badania-i-publikacje/raport-strategiczny-internet-20172018/ [accessed: 25.04.2019].

17. Ryan D. (2016). Understanding digital marketing: marketing strategies for engaging the digital generation. Kogan Page Publishers.

18. Stephen A.T. (2016). The role of digital and social media marketing in consumer behavior. Current Opinion in Psychology, 10, 17-21.

19. TechWyse, Internet Marketing Tools, https://www.techwyse.com/infographics/internet-marketing-tools/ [accessed: 18.04.2019].

20. Tian Y., Stewart C. (2006). History of E-Commerce. [In:] Encyclopedia of E-commerce, E-government, and Mobile Commerce. M. Khosrow - Pour, Idea Group Reference, London.

21. Teo T.S. (2005). Usage and effectiveness of online marketing tools among Business-to-Consumer (B2C) firms in Singapore. International journal of information management, 25(3), pp. 203213.

22. wirtualnemedia.pl.

https://www.wirtualnemedia.pl/artykul/frisco-pl-definicja-lepszych-zakupow-platforma-komunikacji [accessed: 25.04.2019].

23. wirtualnemedia.pl. https://www.wirtualnemedia.pl/artykul/frisco-pl-kampania-ty-wybierasz-godzine-dostawy [accessed online: 25.04.2019].

24. zrabatowani.pl. https://zrabatowani.pl/frisco-pl [accessed: 25.04.2019]. 
Romanowski R. (Ed.): Managing Economic Innovations - Methods and Instruments

Bogucki Wyd. Nauk., Poznań 2019. ISBN 978-83-7986-277-1

DOI: $10.12657 / 9788379862771-2$

\title{
Chapter 2
}

\section{Instagram as a New Promotion and Sales Channel}

\author{
Elżbieta Baron, Wiesław Ciechomski
}

\begin{abstract}
This chapter is devoted to content marketing and the significance of social media, with a particular emphasis on Instagram as a promotional tool and a channel for selling goods and services. The advent of social networks is creating an opportunity for companies to reach out to a very wide audience, craft personalised messages and maintain an optimal self image. Instagram takes the lead on this and is fast proving itself to be a novel means through which companies can reach out to their target audience with products and services, convince, sell and garner loyalty.
\end{abstract}

Keywords: Instagram, sales channel, promotion channel, social media

\section{Introduction}

Contemporary marketing is evolving in step with the development of technology. Customers' attention is attracted by the newest media, and marketing specialists must incorporate these changes into their marketing strategies. Traditional marketing was primarily based on a unilateral flow of promotional messages addressed to mass recipients. However, modern customers, especially those from Generation Z, have no intention of being only passive addressees of increasingly aggressive ads and prefer to

Elżbieta Baron: Member of Marketing Students' Society (SKN Marketing), graduate of Management Study Programme at Poznań University of Economics and Business, ORCID: https://orcid.org/0000-0002-0596025X, e-mail: elzbieta.maria.baron@gmail.com

Wiesław Ciechomski: Associate Professor at Department of Commerce and Marketing, Institute of Marketing, Poznań University of Economics and Business, ORCID: https://orcid.org/0000-0002-2310-8378, e-mail: w.ciechomski@ue.poznan.pl 
influence what content and tools are used to reach them. This is how the phenomenon of social media and broadly understood inbound marketing originated.

The aim of this chapter is to discuss selected issues related to the use of social media as an instrument of content marketing management and to present a new channel for selling goods and services. The analysis was based on the example of Instagram, an extremely popular social networking site. Considering the subject undertaken, the chapter is primarily based on foreign language sources, including literature relating to the subject, articles in the professional press, marketing research reports and internet sources.

\section{Content marketing on social media}

Inbound marketing can be defined as "the process of helping potential customers find your company - often before they are even looking to make a purchase - and then turning that early awareness into brand preference and, ultimately, into leads and revenue" (Marketo, 2012). Inbound marketing encapsulates content marketing, social media, websites, blogs, forums and is a preferred form of communication due to its speedy nature.

Inbound marketing is strongly connected with content marketing because it involves the creation of interesting, informative and entertaining content which is then distributed through communication channels on the web. In an environment in which Internet users can find information about products and services on offer, the task of marketing specialists is to focus consumer attention, establish long-term relationships, and achieve a transaction. Content marketing is based on creating materials that help potential customers make a purchase decision and positioning the optimal image of the company in the perception of buyers. For example, to illustrate the multitude of options for promoting the offering of an e-store, the following forms of marketing communication can be mentioned: articles on the products offered; company blog entries; books related to the company's operations; information brochures containing case studies; product demos; free samples; live broadcasts of events such as, for example, a book signing session in a bookshop; additional instructions for the use and potential applications of a product; various types of online courses containing product presentation; interviews, reviews, presentations, press conferences, reports, so-called "plug-ins" put on websites in partner programmes and many more. In this multitude of potential and actual actions, the most difficult challenge is to ensure that the developed and implemented content marketing strategy is internally coherent and original. It must be emphasized that if the requirement of originality and creativity is met, online advertising will function independently in the form of word-of-mouth marketing, also known as viral marketing. Thus, this will be free product promotion by thousands or even millions of social media users.

Content marketing can be considered as "a strategic marketing approach focused on creating and distributing valuable, relevant, and consistent content to attract and retain a clearly defined audience and, ultimately, to drive profitable customer action" 
(Pulizzi, 2014). This content marketing strategy can be implemented at every stage of the purchasing process using a variety of media channels in order to create positive experiences related to a company's brand and its products. Its task is to expand the amount of information available to the selected target group and provide emotional value to the buyers and users of products while positioning the company as a leader in a given field. The published content should engage potential customers and help them to see and understand the benefits of the presented product offer (Rose, 2011).

Creating and distributing content requires good media management, starting from building appropriate marketing channels through which the company intends to establish relationships with potential clients. Content marketing differs from the typical "push" sales approach as it based on building emotional connections with consumers by providing them with professionally prepared information on the product offers, which by definition is part of the "pull" strategy. The main assumption of content marketing is that if a company is able to regularly provide valuable information about a given product, service and market, customers will eventually respond by making purchases and maintaining brand loyalty (Pulizzi, 2014).

The concept of content marketing also implies partial or complete abandonment of classic forms of expensive advertising in favour of publishing marketing materials using free media channels available in the online environment. However, a big challenge for marketing specialists is to ensure that the published content achieves high popularity and motivates them to take actions leading to making a purchase, according to the AIDA model. The online sphere is also crowded with numerous rivals who are undertaking content marketing activities of their own, which is why creating a name for oneself as a trusted expert and advisor is a better strategy that aggressive competition. Thus, instead of spending more and more funds on accessing traditional mass media, marketing staff should create their own media channels to respond more effectively to customer information needs. This strategy makes particular sense in situations where potential customers tend to avoid advertising messages from the mass media or where the use of such media is not the optimal way of reaching the specific target group (Lieb, 2012).

The term content marketing was first used in 2001. Although businesses and institutions engaged in the creation and distribution of various types of content much earlier, other terms such as consumer media, corporate media or brand media were previously used to describe this process. The father of content marketing is thought to be John Deree, the founder of Deree \& Company, an agricultural equipment firm, and The Furrow magazine. In 1895, instead of sending out catalogues with descriptions of available products, Deree launched the magazine, which educated potential clients in the field of agricultural technology. The magazine was not filled with promotional messages aimed at mail-order sales; instead, it contained useful information that helped with, for example, plant cultivation. The owner of the company hired journalists and graphic artists, who in an attractive way presented knowledge relating to agricultural production, which enabled the readers to be successful in this field. Interestingly, despite the passage of time, The Furrow magazine still exists and is delivered monthly to 1.5 million farmers in 40 countries in 12 languages. Other examples in pioneering the use of content marketing include a comprehensive 400-page guide for drivers 
developed in 1900 by Michelin, a recipe book created in 1904 by Jell-O, as well as a design magazine published for the first time in 1913 by the engineering company Burns \& McDonnel (Pulizzi, 2014).

Despite originating over a hundred years ago, it was not until the second decade of the 21 st century that content marketing began to gain extraordinary popularity. This was the result of several main factors:

- consumers find most of the information on market offers themselves, using the Internet;

- content created by companies is more reliable and can compete with mass-circulation publications;

- an increasing proportion of marketing budgets is allocated to promotional activities implemented in the online environment;

- the costs of creating and distributing content have been significantly reduced. In most cases, technologies for publishing content on the web are free. The only cost is the time spent on preparing appropriate materials that support sales and image;

- enterprises can actively cooperate with professional writers, musicians and filmmakers, also in the form of telework and temporary projects (Pulizzi, Berrett, 2009).

The marketing model based on content distribution consists of three basic steps. The first one is attracting the attention of potential customers; the second is converting this interest into taking actual actions that will provide companies with revenues; and the third is analysing the results. Gaining the interest of prospective buyers involves a strong focus on building a positive brand image on the Internet. The fragmentation of recipients' attention usually means that most of them rely on intuition and choose solutions that spontaneously come to mind. Modern consumers usually use the Internet to obtain information about the products they are interested in and can at times be confused due to the information overload one receives from a simple search query. It is for this reason that company managers who employ modern management methods focus their attention on building a strong brand image on the web, which in the long run means that they are able to achieve an advantage over competitors. High spontaneous and aided brand awareness reduces the need for further time-consuming searches and, above all, inspires confidence, which is often a more important purchasing determinant than the price. Content promotion should lead to growing brand recognition, increasing the number of contacts that the prospective customer will have with the organization, and achieving a certain level of trust and loyalty along with activities related to so-called word-of-mouth marketing (Kabani, 2013).

Social media are closely connected with content marketing because they are mainly used for the publication and promotion of marketing materials and other information intended to attract the attention of consumers. Using social media can provide the following benefits:

- increasing the number of visitors to the website; 
- building high brand recognition;

- creating positive brand-related experiences;

- providing social proof

- attracting brand followers who publish positive opinions about the company's products and services (Fishkin, Høgenhaven, 2013).

Social media can be used chiefly for activities at the very top of a traditional marketing funnel - activities whose primary purpose is to familiarize consumers with the brand. The use of portals such as Instagram, Twitter, Facebook, Linkedin or Google+ can lead to initial and incidental interest in the company's products. However, it is only at the next stage of the sales cycle that customers realize their needs, consider alternative purchase options, make the final decision and establish long-term relationships with the company. It is for this reason that the content used on social media belongs to the category of entertainment or education. This approach generates curiosity or even emotional fascination with storytelling. In turn, contacts made by means of other media such as email campaigns or industry reports, can lead to establishing business relationships (Kabani, 2013).

The concept of social commerce is increasingly identified not with supporting sales through virtual community mechanisms, but actual sales on social networking sites. For example, Liang and Turban $(2011$, p. 6) in their definition point out that social commerce is a subcategory of e-commerce which involves the use of social media to support not only e-commerce activities but also transactions. As mentioned earlier, initially social media were identified primarily with activities that did not translate into specific sales results. This began to change when websites introduced the possibility of paid advertising and provided improved analytical tools that made it possible to measure the effects of activities (Miotk, 2016). This led to social networking sites being used to generate traffic to online platforms and stimulate sales (Felix, Rauschnabel, Hinsch 2017 , p. 119) by means of call to action buttons, which encouraged writing messages, visiting the website, and even making a quick purchase (Miotk, 2016).

The gradual introduction of shopping on social platforms consisted of placing tabs and applications imitating the store on Facebook; looking for solutions that would enable the transfer of the store, and preferably also the shopping basket, to a different platform; and creating various applications supporting the implementation of these tasks (Dziegieć, 2014). Store software providers have begun to offer modules to support this format of commerce (Feldy, 2012). This is all the more important as the phase of fascination with changes in the communication process is now over, and social media is under constant and growing pressure to generate increasing revenues. The shopping function is thus the next step, following the strategies for monetizing the content of social media sites and taking advantage of the vast base of potential customers (Smilansky, 2015, p. 16). 


\section{Instagram as an alternative sales channel}

Instagram is an application whose principal feature is sharing attractive photographs with the community. The service has been operating since 2010 and was considered exclusive to iPhone users till an Android and Windows version was released (Todorczuk 2014, p. 61). In 2012 the application was bought by Facebook and since then the two sites have remained strongly integrated, especially in the marketing context (Lisowski 2016 , p. 45). The website brings together users who are looking for inspiration with those who inspire others, connecting people who share the same passions (Instagram dla biznesu..., 2017, p. 3). In terms of the number of users, only Facebook and YouTube come before Instagram (Clarke, 2019) which has over one billion active accounts every month. The main reason for this vast popularity is adapting to the requirements of consumers, which is connected with constantly developing new applications and adding new functions. At the same time, the creators of the website are constantly developing its marketing aspect: first in terms of advertising and then selling. Within the last few years the application has evolved to such an extent that it has begun to set trends in the world of social media.

The pace of technological progress and the constant emergence on the market of new smartphone models, with increasingly better cameras, have further increased the importance of Instagram. New, easy to use, and professional photo-editing applications are being created for mobile devices, making the capture and sharing of attractive photos much easier. This is the reason for the growing popularity of Instagram and, on the other hand, a result of it. Another reason for the applications success is its minimalist interface, limited possibilities and a predominance of visual content. Images are given prominence over text to cater to the increasing pace of life of today's internet users (Grabiwoda, 2018). This is a natural consequence of the development of the "picture civilization", in which icons and other graphic forms replace traditional text.

The essence of Instagram are photographs as well as relatively short videos that can be recorded via the application or shared from the library of a mobile device. In the News Feed section, which is the user's main screen, there are photos and videos with matching descriptions and hashtags from various user profiles. Initially, the posted video materials had to be very short, but over time their length was extended and now they can last up to a minute. After some time the option of posting multiple photos and videos within one post was introduced.

The next section is the Explore tab, a place with photos of other users which can be constantly refreshed. In 2016, the Instagram Stories section was introduced. The content published in it disappears after twenty-four hours. Since 2017, however, they are automatically saved in private Stories Archives. Stories can be permanently shared on the profile in Story Highlights. Photos and videos can last up to 15 seconds and can be enhanced using a wide selection of add-ons such as text, emoticons, filters, animated overlays, music, location, temperature and gifs. Unlike in the case of posts, Instagram Stories allow users to put links and refer to other addresses on the web. In 2017 the live stream feature was added to the Instagram Stories format. In addition, in 2018 Instagram introduced IGTV - an application for watching long-form vertical videos (Our 
Story, n.d.). The selection of posts that the user can see in the application depends on the Instagram algorithm, which is designed to ensure that the content is most closely related to their interests. This is done automatically and is based, for example, on the followed accounts or liked posts. This sort of content sorting was introduced instead of the previously used chronological feed. However, details of the algorithm's mechanism remain confidential and modifications are introduced from time to time (Pollock, 2018). The selection of photos that appear in each user's feed depends not only on the algorithms, but also on promotional budgets. As the number of users and the amount of content increases, Instagram is increasingly monetizing its resources. After the introduction of the algorithmic update, an organic post has only a $2-3 \%$ reach, promoting marketers to move towards paid promotions (Grabiwoda, 2018).

Paid advertising on Instagram was only available to selected large companies initially, a tact Facebook did away with in 2015 when it opened advertising to everyone. First, the possibility of promoting posts in the News Feed was introduced, and later also in Instagram Stories. This enables advertisers to pursue various advertising goals, such as activity relating to posts, application installation, site redirect clicks, or website conversion rates. Advertisers can use various advertising formats and optimization methods as well as precise targeting based on age, gender, place of residence, family status, relationship status, level of education, or even such features as recently starting work in a new workplace, owning a mobile device of a particular brand, and previous visits to a given site or performing a specific action on it. Targeting can also be based on an imported database of phone numbers or email addresses (Lisowski, 2016, pp. 45-46).

For a sizable amount of time, Instagram did not include significant selling activity as its main marketing goal was building brand image. The shopping function appeared in 2016 (Zakupy na Instagramie, 2016) and was tested by several companies in the United States, before being introduced in other selected countries. Today it is available in 46 countries, including Poland (Bringing shopping on Instagram..., 2018).

The shopping function, apart from the links in the bio and in Instagram Stories, is the third possibility of conversion from the application (Chacon, 2018). At the beginning, the option of tagging organic posts with links to the online store was introduced (Zakupy na Instagramie, 2016). This product tagging feature was then added to Instagram Stories, allowing users to tap on a tag or sticker, to see the product's name and price. A double tap on the tag or sticker allowed the user to visit a page with product descriptions, additional images and similar items before making the purchase or browsing some more in the application.

Another improvement is the shopping channel in the Explore tab. The selection of posts visible there is determined by algorithms for personalizing brands and products in terms of the preferences of individual users (Przedstawiamy funkcję zakupów..., 2018). In 2019, Instagram introduced the "Checkout on Instagram" option, which means that users no longer have to go to an external website to make purchases. Billing and shipping data is entered within the application. In addition, payment information is stored so consumers do not have to enter those details again, even when buying from different stores. Currently, the new functionality is available to users from the United States, who can buy from over 20 selected companies. After the testing phase, the application 
will be widely available to all users and companies. Instagram has already announced that further improvements to the shopping function are going to be introduced in the future (Nowość w Zakupach..., 2019). Users have already become accustomed to the presence of brands on Instagram so shopping seems more natural for this platform (A better shopping experience..., 2017). To a certain extent, this is also influenced by the fact that product tags look just like the popular tags for linking to other profiles. On Instagram, all the elements smoothly connect with and complement one another (Fleming, 2018).

With the Instagram shopping function, consumers smoothly go through stages such as searching for a company, reading information about it, and going to the shopping basket - all with just a few taps, without leaving the application (Chacon, 2018). This shopping function on Instagram provides the convenience of quickly purchasing products and services, reducing the search time to the consumers while increasing conversion rates and revenues for retailers. Another interesting feature is the save for later function which allows users to save items they found interesting for a closer look at another time (Zakupy na Instagramie, 2016).

Selling through this channel brings measurable benefits to businesses as it saves time and provides high measurability. New functionalities of the application have improved measuring and monitoring revenues (Inspirujące spostrzeżenia dla firm..., 2018), allowing advertisers to check the compare the product views against its purchases (A better shopping experience..., 2017).

The "Instagram Shopping" function gives companies the opportunity to reach a wide, precisely defined group of recipients in their natural environment. It facilitates direct access to the younger segments of Internet users who often prefer electronic forms of communication over traditional ones because they have had contact with online media from an early age. They treat the Internet as a source of entertainment, knowledge and an environment for developing social bonds. Customers from generation $Y$ do not have problems with using new technologies, to the extent that in their opinion work is almost impossible without them (Kroenke, 2015). Their ability to use new technologies is better than that of their parents, are very creative, willing to undertake new challenges and seek self-fulfilment in their personal lives. In addition, they have an innate ability to function in a multicultural environment, devoted to developing their passions, making new friends, active leisure and exploring the world (Smolbik-Jęczmień, 2013).

After generation $Y$ comes generation $Z$, often called Generation C, from the words change or connected. These are people born after the year 2000, have knowledge of foreign languages, a willingness to meet new people, explore new places, a general lack of respect for what the future holds and deserves to be called the global generation. Such young people as per Waśko (2016) can be described people wanting to lead picture-perfect lives .

Many teenagers consider Instagram to be their favourite medium and use it as their medium of choice (Grabiwoda, 2018). The application is used most often on smartphones and created in a vertical version to suit the mobile first we live in today. It offers 
an attractive and functional space for advertising, with a relatively small number of elements that might distract its recipients.

Instagram is a perfect place for creating customer experiences, as its novelty and innovativeness provides a unique experience for consumers. At the same time, the nature of this site makes it possible to efficiently sell a contextual manner, which makes it more likely to be successful. Instagram facilitates storytelling, which builds a deeper, more intimate, longer-lasting, and thus more valuable relationship between the customer and the brand. An important role in this respect is played by Instagram Stories, which offers a range of possibilities for diversifying the message and influencers who gather highly engaged recipients around their profiles. Their importance on this platform is greater than on most other social networking services (Grabiwoda, 2018).

Instagram is a platform that in its purest form is focused on engagement and creating a community (Todorczuk, 2014, p. 63). It has four times more interaction than on Facebook (Buryan, 2018) and sees the highest engagement rate among all social networking sites. The users of this application willingly interact not only with other individual users, but also with brands. They behave differently than on other websites, with a focus on viewing products, discovering trends and innovations (Inspirujące spostrzeżenia dla firm..., 2018). Eighty percent of them admit that they follow business accounts (A better shopping experience..., 2017), and one-third of the most viewed stories come from brand promoters (Przedstawiamy funkcję zakupów..., 2018). The high engagement is connected with the fact that consumers on Instagram create a special relationship with brands as this makes them feel as part of an elite group. Also, the very nature of the application contributes to the high engagement rate as today's consumers prefer to absorb information from images (Smilansky 2015, p. 16).

Even before the introduction of the shopping function, Instagram played an important role in the purchasing decision process as they were most likely to encourage young consumers to consider and plan purchases. In the 2016 Global Web Index research, $50 \%$ of Instagram users declared that they obtained information about products from this service (Grabiwoda, 2018). Today these rates are much higher with Instagram data showing 130 million users displaying product tags in shopping posts in a month (Nowość w Zakupach..., 2019). It's also important to note that Instagram (14\%) ranks best among all social media sites with regard to the use of the "Shop" button when compared against Pinterest (13\%), Twitter (13\%), and Facebook (9\%) (Business Insider report 2015, as cited in Miotk 2016, p. 50). Instagram also appears to be a great boost for sales as 54\% of consumers declared that seeing a product or service on Instagram prompted them to make a purchase (How Instagram Boosts..., 2019).

After the introduction of the shopping function on Instagram, consumers no longer need to go through the hassle of many buying stages. Many users ask for the names, prices and links to the presented product in comments, send messages via Instagram Direct function, or look for the products on the search engine and on the store's website (Inspirujące spostrzeżenia dla firm..., 2018). Instagram aficionados are eager to buy online and have no reservations about using mobile technologies for this purpose. In 2015 , over a third of users made purchases via m-commerce channel, making them 
more likely to make purchases on mobile devices than people who do not use this application (Buckle, 2015).

Instagram users tend to associate each section of the application with different uses. In the marketing context, therefore, the News Feed and Instagram Stories sections have different roles. Research indicates that Instagram users use the News Feed to search for information and find out about products and brands, as with a storefront. This section is used by brands to present their offers so that consumers can browse the published content and stop at items that they like or are interested in. For this reason, photos and videos published directly in the profile are carefully prepared. Although the News Feed is more strongly associated with discovering brands and products, recipients search for brand-related content and products also in Stories. A characteristic feature of the 24hour stories is their free, authentic and casual nature allowing it to be a great tool for strengthening brand engagement (Jak są postrzegane i używane..., 2018).

Instagram users value highly aesthetic, creative and high-quality posts, as well as those which are created especially for this medium and are not available elsewhere. The application is used primarily in people's spare time (Lisowski, 2016, pp. 46-47) and primarily focused on the consumption of entertainment and lifestyle content. Its most ardent users are people who want to be up to date with global trends (Todorczuk, 2014, p. 62), such as in fashion. The strong relationship between fashion and this social networking site is evidenced by the fact that within its structure, Instagram has a director of fashion partnerships. Since 2015, this position has been held by Eva Chen, former editor of such magazines as Elle, Teen Vogue, Harper's Bazaar and Lucky (The Power of Passions..., 2017). Fashion is also one of the most popular categories in the Explore tab and is the subject of the most popular hashtags, such as \#fashion and \#ootd (outfit of the day) (Tam gdzie pasja spotyka się z modą..., 2017). Also, influencers commonly share on Instagram pictures of the clothes they wear and information about them (Smilansky, 2015, p. 16).

Research confirms the significant role of Instagram in shopping for clothes, especially in the case of women, who tend to be more susceptible to psychological and cultural factors, and attach more importance to the appearance of products (Al Mukhaini, Ismael, Al-Dhuhli 2014, pp. 8-9). Many consumers use Instagram to stay up to date with new products and trends, and to share their own styling. As many as $45 \%$ of users follow a brand or fashion celebrity, looking for image and shopping inspiration (Tam gdzie pasja spotyka się z modą..., 2017). People interested in fashion are the most engaged Instagram users as they open the application 15 times a day and view 5 times more photos than ordinary users. They have on average 3.6 times more followers and they follow 2.2 times more accounts, including those belonging to brand creators. The probability of them publishing something is 16 times higher, 12 times higher for comments, 2.4 times for watching videos and follow it for longer (Fashion on Facebook and Instagram..., 2017).

An interesting example of omnichannel retailing is presented by Rigby (2011) who describes the case of buying a dress for a holiday trip, over the years. A few years ago, this kind of shopping was done at a shopping centre, where customers would walk from store to store and compare the clothes on offer. Stores could then collect data 
based on their loyalty cards, where information about customers' transactions was recorded. Nowadays, this type of shopping begins with browsing the collections available in various stores on a mobile device, comparing the prices, choice of products, reviews, etc. According to Rigby, such web browsing will soon be replaced by a virtual advisor who, being a fashion expert, will compare the clothes available in nearby stores and make some suggestions based on the customer's previous purchases. The customer can then make a decision based on the offers received and go to the nearest store, where the dress will be waiting for her in the changing room with matching accessories. The data gathered from this purchase can then be used to personalize future offers more precisely and accurately.

\section{Conclusions}

We are currently experiencing a revolution in terms of the methods of market communication with customers. Almost everyone who is looking for a product or is seeking advice turns on their mobile device, starts the search engine and begins to search for information. A large proportion of young people treat this as a kind of release from having to use mainstream media. Such aversion to traditional media is a result of, among other things, long commercial breaks, aggressive advertising, or unappealing content in many similar stations. This has given rise to the development of the inbound marketing concept, where the target is clearly defined, attracted and converted into potential customers (Ciechomski, 2015). Inbound marketing strategies make it possible for companies to expand their customer reach as well as increasing brand popularity and recognition.

Over two decades ago, Bill Gates, one of the visionaries of modern business, authored an essay entitled "Content is king" (Gates, 1996), in which he emphasised the fact that consumers are beginning to significantly change their approach to shopping with the advent of the internet. Gates compared this to the television revolution of the 1950s and 60s, which spawned a number of industries and allowed those in the entertainment industry to reap profits. In his opinion, the internet would do the same due to the relative ease with which anyone could be a publisher. Today, over 20 years later, the essay is even more topical than when it was first published as the success of YouTube, Instagram and other social networks proves. In this text, the authors wanted to emphasize the fact that today Instagram is becoming not only a key tool used for content marketing communications, but also an important prospective sales channel for goods and services.

\section{References}

1. A Better Shopping Experience on Instagram. (2017). Retrieved from https://business.instagram.com/blog/a-better-shopping-experience-on-instagram [accessed 17.04.2019]. 
2. Al Mukhaini E., Ismael S., Al-Dhuhli I. (2014). The impact of using social media on consumer buying behavior (unpublished student paper). Sultan Qaboos University, Muskat, pp. 1-12. Retrieved from https://www.researchgate.net/publication/275347329_The_Impact_of_Social_Media_on_Consumer_Buying_Behaviour.

3. Bringing Shopping on Instagram to More Countries. (2018). Retrieved from https://business. instagram.com/blog/shopping-on-instagram-goes-global [accessed 17.04.2019].

4. Buckle Ch. (2015). Profiling Instagram's Future on its Fifth Birthday. Retrieved from https:// blog.globalwebindex.com/trends/profiling-instagram-s-future-on-its-fifth-birthday/ [accessed 17.04.2019].

5. Buryan M. (2018). Instagram Engagement: Everything You Need to Know [Exclusive Stats]. Retrieved from https://www.socialbakers.com/blog/instagram-engagement [accessed 17.04.2019].

6. Chacon B. (2018). How to Make Money with Instagram Shoppable Posts. Retrieved from https:// later.com/blog/instagram-shoppable-posts/ [accessed 17.04.2019].

7. Ciechomski W. (2015). Masowa kastomizacja jako forma komunikacji rynkowej z konsumentami. Prace Naukowe Uniwersytetu Ekonomicznego (AE) we Wrocławiu, 414, p. 77.

8. Clarke T. (2019). 22+ Instagram Stats That Marketers Can't Ignore This Year. Retrieved from https://blog.hootsuite.com/instagram-statistics/ [accessed 17.04.2019].

9. Dziegieć J. (2014). E-commerce. [In:] Królewski J., Sala P. (Eds.), E-marketing. Współczesne trendy. Wydawnictwo Naukowe PWN, Warszawa, pp. 231-243.

10. Fashion on Facebook and Instagram From Top to Toe. (2017). Retrieved from https://www. facebook.com/business/news/insights/fashion-on-facebook-and-instagram-from-top-totoe [accessed 17.04.2019].

11. Feldy M. (2012). Sklepy internetowe. Jak złapać w sieci e-konsumentki i e-konsumentów. Wolters Kluwer, Warszawa.

12. Felix R., Rauschnabel P.A., Hinsch Ch. (2017). Elements of strategic social media marketing: A holistic framework. Journal of Business Research, 70, pp. 118-126. http://dx.doi.org/10.1016/j. jbusres.2016.05.001.

13. Fishkin R., Høgenhaven T. (2013). Inbound Marketing and SEO: Insights from the Moz Blog, Wiley.

14. Fleming M. (2018). Instagram launches shoppable posts as it looks to play a bigger role in ecommerce. Retrieved from https://www.marketingweek.com/2018/03/20/instagram-launches-shoppable-posts-looks-play-bigger-role-ecommerce/ [accessed 17.04.2019].

15. Gates B. (1996). Blog Bill Gates - Microsoft Corporation. [Online] Available at: http://www.microsoft.com/billgates/columns/1996essay/essay960103.asp, [accessed 15.04.2019].

16. Grabiwoda B. (2018). E-konsumenci jutra Pokolenie Z i technologie mobilne. Wydawnictwo Nieoczywiste, Warszawa.

17. How Instagram Boosts Sales and Drives Sales. (2019). Retrieved from https://www.facebook. com/business/news/insights/how-instagram-boosts-brands-and-drives-sales [accessed 17.04.2019].

18. Inspirujące spostrzeżenia dla firm na Instagramie - Facebook Community Boost London (2018). Retrieved from https://www.facebook.com/business/news/instagram/inspirational-insights-for-businesses-on-instagram [accessed 17.04.2019]. 
19. Jak sq postrzegane i używane Instagram Stories oraz Aktualności na Instagramie? (2018). Retrieved from https://business.instagram.com/blog/how-do-people-perceive-and-use-instagram-stories-and-feed/ [accessed 17.04.2019].

20. Kabani S. (2013). The Zen of Social Media Marketing: An Easier Way to Build Credibility. Generate Buzz, and Increase Revenue, Benbella Books Inc.

21. Kroenke A. (2015). Pokolenie $X, Y, Z$ w organizacji. [In:] Organizacja i zarządzanie. Zeszyty Naukowe 1202 (61). Wydawnictwo Politechniki Łódzkiej, Łódź, p. 95.

22. Liang T.-P. i Turban E. (2011). Introduction to the special issue - social commerce: a research framework for social commerce. International Journal of Electronic Commerce, 16(2), pp. 5-13. DOI 10.2753/JEC1086-4415160201.

23. Lisowski S. (2016). Marketing w obrazkach, czyli reklama na Instagramie. Online Marketing Polska, (26), pp. 45-46.

24. Marketo I. (2012). Amplify Your Impact: How to Multiply the Effects of Your Inbound Marketing Program, [http://www.marketo.com/_assets/uploads/Inbound-Marketing.pdf], [accessed 10.04.2019].

25. Miotk A. (2016). Nowy PR. Jak Internet zmienił public relations. Wydawnictwo Słowa i Myśl, Lublin.

26. Nowość w Zakupach na Instagramie: opcja Dokonaj zakupu. (2019). Retrieved from https://business.instagram.com/blog/new-to-instagram-shopping-checkout/ [accessed 17.04.2019].

27. Osom Studio (2017). Instagram dla biznesu. Kompleksowy przewodnik. [e-book] Retrieved from https://osomstudio.com/wp-content/uploads/2018/04/Instagram- dla-biznesu.-Kompleksowy-przewodnik-by-OSOM-STUDIO-v2.pdf [accessed 17.04.2019].

28. Our Story. (n.d.). Retrieved from https://instagram-press.com/our-story/ [accessed 17.04.2019].

29. Pollock S. (2018). Instagram Algorithm Change History. Retrieved from https://powerdigitalmarketing.com/blog/instagram-algorithm-change-history/ [accessed 17.04.2019].

30. Przedstawiamy funkcję zakupów w Instagram Stories oraz kartę Eksploruj. (2018). Retrieved from https://business.instagram.com/blog/announcing-shopping-in-instagram-stories-and-explore/ [accessed 17.04.2019].

31. Pulizzi J. (2014). Epic Content Marketing: How to Tell a Different Story, Break through the Clutter, and Win More Customers by Marketing Less. McGraw Hill Education.

32. Pulizzi J., Berrett. N. (2009). Get Content Get Customers: Turn Prospects into Buyers with Content Marketing. McGraw Hill.

33. Rigby D. (2011). The Future of Shopping - Harvard Business Review. [Online] Available at: https://hbr.org/2011/12/the-future-of-shopping/ar/1 [accessed 15.04.2019].

34. Smilansky O. (2015). Pinterest and Instagram Offer Buy Buttons. Customer Relationship Management, 19(9), p. 16.

35. Smolbik-Jęczmień A. (2013). Rozwój kariery zawodowej przedstawicieli pokolenia X i Y w warunkach gospodarki opartej na wiedzy. [In:] Nierówności Społeczne a Wzrost Gospodarczy. Uniwersytet Ekonomiczny we Wrocławiu, Wrocław, p. 229.

36. Tam gdzie pasja spotyka się z modq. Wybieg na Instagramie. (2017) Retrieved from https:// business.instagram.com/blog/where-passion-meets-fashion/ [accessed 17.04.2019]. 
37. The Power of Passions: A Close-up of the Fashion World on Instagram. (2017). Retrieved from https://www.facebook.com/business/news/insights/the-power-of-passions-a-close-up-ofthe-fashion-world-on-instagram [accessed 17.04.2019].

38. Todorczuk A. (2014). Medium młodych. Press, (4), p. 62.

39. Waśko R. (2016). Wybrane aspekty różniace pokolenie $X, Y I Z$ w kontekście użytkowania nowych technik i Internetu. [In:] Rykiel Z., Kinal J. (Eds.) Socjologia codzienności jako niebanalności. Stowarzyszenie Naukowe Przestrzeń Społeczna i Środowisko, Rzeszów, p. 141.

40. Zakupy na Instagramie. (2016). Retrieved from https://business.instagram.com/blog/shopping-on-instagram [accessed 17.04.2019]. 
Romanowski R. (Ed.): Managing Economic Innovations - Methods and Instruments

Bogucki Wyd. Nauk., Poznań 2019. ISBN 978-83-7986-277-1

DOI: $10.12657 / 9788379862771-3$

\title{
Chapter 3
}

\section{Physiological Measurement as a (Controversial) Research Method}

\author{
Bartłomiej Pierański
}

\begin{abstract}
The chapter presents the essence and specificity of physiological measurements that can only be performed using an appropriate apparatus. It is the only way to obtain physiological data which cannot be directly observed by humans (e.g. brainwaves, eye fixations) and advantageous due to its objectivity, continuity and non-invasiveness of the measurement. One must, however, remember that physiological measurements include a very frequent necessity to create unnatural test conditions (e.g. full immobilisation of the examined person) and can pose difficulties in the interpretation of data. The correct interpretation of data requires specialist knowledge, which very often goes beyond economics or management. The chapter also classifies the methods of physiological measurements, taking the human nervous system structure as a point of reference.
\end{abstract}

Keywords: neuromarketing, eye-tracking, physiological measurement, electrodermal activity

\section{Introduction}

Observation of human physiological reactions gives rise to many controversies, mainly due to the increased optimism manifested in declarations concerning the possibility of reaching the phenomena that have not been directly observable so far (e.g. emotions). Also, the method of interpreting the gargantuan amount of data is not fully determined. Furthermore, due to very restrictive requirements that are necessary to carry

Bartłomiej Pierański: PhD, Assistant Professor at Department of Commerce and Marketing, Institute of Marketing, Poznań University of Economics and Business, ORCID: https://orcid.org/0000-0001-5327-8725, e-mail: bartlomiej.pieranski@ue.poznan.pl 
out certain measurements (e.g. full immobilisation of the examined person), it is not always possible to observe a person in the conditions which are considered natural, both for the person and the situation.

This is the reason for the limited use of methods that are based on physiological measurements in analysing consumer behaviour (including in-store environment). As a consequence, the diagnosis of how the environment influences the consumer behaviour is made mainly on the basis of survey methods. In addition, the limited use of physiological methods is also due to the poor knowledge thereof. Therefore, the purpose of this chapter is to present the essence of physiological measurements as a research method, with its advantages and disadvantages. It also focuses on difficulty and ambiguity in the interpretation of data, collected using complex apparatus, describing the functioning of particular organs in the human body (especially the brain). Interpretation becomes extremely difficult when the empirical material collected must be referred to consumer behaviour. This chapter concludes with an overview of physiological measurement methods. The structure of the human nervous system was used as the basis for classification.

\section{The essence and specificity of physiological measurements}

Physiological measurements are mainly used in biology and medicine (Littlefield, 2009), in order to become familiar, diagnose and treat human diseases. They are, however, becoming adopted by social sciences for the so called biological bases of behaviour, triggered by the nervous system (Plassmann et al., 2012). Such measurements are also used in the study of in-store behaviour, albeit to a relatively limited extent as movements, breathing and perspiration (among other things) constitute an important source of data that can be used in the analysis of consumer behaviour (Schwartzkopf, 2015).

In the context of consumer behaviour research, physiological measurements are considered as a non-survey method of collecting data from primary sources (Kaczmarczyk, 2014, p. 61)1, helping to broaden the scope of observable consumer behaviour manifestations. Reactions to the appearing stimuli (behaviour) can also be observed through the prism of physiological changes taking place in the human body. The non-survey nature of the physiological measurements means that they are not based on conscious and declarative answers as one would obtain from a survey. Physiological measurements, therefore, are considered more objective as they very often concern issues which people are unaware of (e.g. eye fixations), or other problems an individual does not want to or is not able to communicate (O'Connel et al., 2011).

\footnotetext{
The type of stimulus used during the measurement process constitutes the criterion for the division of research methods into survey and non-survey ones. In case of survey methods, data is collected by asking questions in oral and written form. In non-survey methods, on the other hand, the questions are not the main stimulus for data collection. Apart from the physiological measurements, the methods of collecting data from non-survey primary sources include, among other things, monitoring, organoleptic and ethnographic methods (Kaczmarczyk, 2014).
} 
The fundamental issue related to the analysis of physiological measurement methods is that they can only be performed with the use of the appropriate apparatuses (Steward, Furse 1982; Ober et al., 2009) due to unobservable elements such as brainwaves and eye fixations. Reiterating the importance of the apparatus in physiological measurements is Rószkiewicz $(2002$, p. 36) who credits it with possibility to record facts that create reality. This reliance on the apparatus seems to be a source of both advantages and disadvantages of physiological measurements.

Irrespective of the above, it should be stated that technological advancements have led to the development of new devices such as the magnetic tomograph and improvement of existing ones ones such as eye-trackers. Additionally, developments in the area of computer science is now enabling researchers to visualise the data gathered and enhance their analysis. These technological changes, combined with a relative decrease in the acquisition costs of at least some of the devices (Gregor, Wdowiak, 2016), have led to the employment of physiological measurements in many areas, including the area of consumer behaviour observation, as referred to above.

\section{Advantages and disadvantages of physiological measurements}

Observation of consumer physiological responses, based on the appropriate apparatus, has three major advantages: objectivity, continuity and the non-invasiveness of measurement. Such measurements provide an obvious advantage over respondent statements that are of a specific nature, susceptible to subjective distortions and are always made at a specific point in time. The objectivity of physiological measurements, can be understood in two ways as they relate to the behaviour of both the researcher and of the examined person. The researcher in such a study has limited influence on how the apparatus operates or the results obtained as the operation of the apparatus is not dependent on the state of consciousness of the entity performing the measurements (Urbański as cited in Sosnowski, Zimmer 1993). The lack of an appropriate apparatus however might require the researcher to undertake manual recording of specific behaviours. Such recordings as per Hintze et al. (2002) opens the study to the risk of "bending" observations to match research hypotheses, or changes concerning the method of recording the occurring phenomena, caused by fatigue or weariness of a person conducting the experiment.

The objectivity related to the use of the apparatus in the process of obtaining data on the physiological reactions of the consumer is also affected by the modification of the researcher's role. During the data acquisition process, the objectivity concerns the correct preparation of the apparatus and monitoring of its operation (Johnson, Pennypacker, 1993). Thus, active data acquisition by the researcher, which is susceptible to distortion, is replaced by an appropriate device that carry out measurements by mechanical means. On the other hand, the use of an apparatus in observation eliminates the need for the researcher to be present at the test and/or follow the observed person, which undoubtedly influences the modification of the behaviour of the subject (Hintze 
et al., 2002). In view of the above, it would be possible to consider the recording of data - while conducting observations using the apparatus - as non-interfering with the respondents' behaviour (thus, making the behaviour more objective), if it was not for the fact that the use of apparatus makes the participants always aware of the fact that observations are being conducted. As a consequence, it should be assumed that it has a modifying effect on their behaviour. It's also important to note that the behaviour modifications in such instances would not be significant as the only aspects of behavior that can be changed are those of which the examined person is aware of and able to control. Reiterating the same is Steward and Furse (1982) who produced that subjects taking part in physiological measurements are not subject to active influence, such as camouflage or hiding natural reactions.

As it was mentioned above, another advantage of using the measuring apparatus in the process of observation is the continuity of measurements, e.g.: a specific type of physiological reactions accompanying the examined person from the moment he/ she enters the store (sales area) up to the moment he/she leaves it (Larsen et al., 2017). This continuity of measurements enables the analysis of the dynamics of the occurring processes and the detection of speedy processes, thanks to which they can be analysed at very short intervals (Sosnowski, Zimmer, 1993).

Another advantage of conducting physiological measurements with an apparatus is its non-invasiveness. Such measurements are performed on the surface of the skin and are not painful. This non-invasiveness also ensure that the physiological processes are not disturbed by the apparatus used (Sosnowski, Zimmer, 1993), e.g. eye-tracking does not change the eye motor activity.

Nevertheless, the measurement of physiological processes with the apparatus is not free from faults. Such faults are mainly related to the specific nature of conducting the research and require unnatural conditions to be created. These may include the complete immobilisation of the examined person, usually in a lying position (e.g. the brain study using functional MRI (fMRI) or positron-emission tomography (PET) ), or forcing a relatively stable sitting position at a certain distance from the stimulus (e.g. recording facial expressions), or, the creation of uncomfortable conditions for the examination (e.g. the need to wear a EEG cap, or a mask combined with a respirometer). All these factors create the impression that conducting observations on physiological reactions of consumers in normal market conditions seems to be limited and can only be overcome by combining measurements within the scope of the research procedure. It is assumed that only a comprehensive analysis of data obtained from various organs can provide a full and comprehensive answer in the research on consumer behaviour (Smyczek, Turek, 2011). In addition, the apparatus prolongs the time of conducting the research as it requires preparation and can be conducted on one person only over a certain time horizon (Ohme, 2006). Such tests can also be a heavy financial burden on account of the costs in acquisition and maintenance of the apparatus (despite a continuous decrease in the price of apparatuses). 


\section{Problem of (correct) data interpretation}

What seems to be the greatest deficiency of the physiological measurements is the difficulty of the correct interpretation of data obtained with the apparatus. Undoubtedly, the empirical material obtained in this way is extensive (Bremer, 2013) and requires specialist knowledge, which very often goes beyond economy and management, for interpretation. Such knowledge (from neurologists perhaps) is especially important when conducting physiological measurements of brain functions (Diterhaft, Woźniak, 2017). One must, however, also keep in mind that the better we understand the brain, the more insufficient our knowledge of this organ becomes (Rożek, 2011, p. 77). One example could be recent discoveries, in which specific mental processes or emotions were found to be not governed by individual brain areas. On the contrary, the brain activates various parts during its work, which cooperate with each other forming macro connections (Binder, 2018, p. 30).

As per the above, it is clear that the conclusions drawn from the analysis of physiological data should not be overestimated and should be looked at with a greater distance. This also applies to the interpretation of data in behaviour diagnosis, within the context of specific market situations (Ariely, Berns 2010). What does not raise any doubts is that such apparatuses allow us to obtain data on the processes taking place in the body. For example, data from electrodermal activity measurements indicates the secretion activity of the eccrine sweat glands. The data from electroencephalography indicate the bioelectrical brain activity, whereas data from the functional magnetic resonance imaging provide us with a picture of oxygen demand in certain areas of the brain. Such methods make it possible to determine the physiological body response to various stimuli (Szymusiak, 2012).

It seems, however, that it is insufficient to treat physiological measurements as a measure of purely biological processes occurring in the body (under the influence of external stimuli), especially when it comes to brain activity analysis. Therefore, the essence of the problem comes down to answering the question - what are, apart from the described indicators of biological processes, the data collected from the physiological reaction observations? The analysis of literature leads to the conclusion that although it is not directly expressed, some researchers treat the data gathered from physiological measurement as indicators of emotions and thoughts (Szymusiak, 2012). This may result from overinterpretation of findings concerning the functions of the brain (Reimann et al., 2011). As an example, it is stated that the analysis of physiological reactions enables the confirmation of the existence of certain phenomena and even their measurement (Reimann et al., 2011), which until now have been discussed only in probabilistic categories (emotions), thus enabling the possible reconceptualization of these phenomena and identification of the processes taking place at more fundamental (neural) level. Taking the above into consideration, a deeper understanding of the consumer makes it possible to verify the existing theories on his/her behaviour as well as to create new ones (Shiv et al., 2005). In the same vein, it is pointed out that the tests based on physiological measurements enable the identification of phenomena which the examined persons are unaware of, and are significant reasons for their behaviour 
(Falk et. al., 2012). It is a quite common assertion that the apparatus for the study of the brain offers the possibility of 'insight' into the unconscious processes (Kowalski, 2009).

These arguments cannot be fully accepted as the results of research in tests concerning the brain function, put the analysed issue in a different light (Steward, Furse, 1982; Lee et al., 2007). The unquestionable achievement of neurology is the construction of a brain map, as only about $10 \%$ of the human brain has been explored (Rożek, 2011, p. 75). A number of experimental studies made it possible to identify the specific areas of the (known) brain that got activated in specific situations. For example (Sudziński, 2009; Rożek, 2011):

a. it is assumed that focus of attention, solving new problems and innovation are accompanied by the increased activity in prefrontal and parietal cortex,

b. spatial imagination as well as mathematical and analytical reasoning correlate with increased activity of the temporal lobes,

c. while when feeling emotions the amygdaloid nucleus is activated.

Nevertheless, it is emphasised that these are the so called behavioural correlates. Therefore, the analysis of reactions occurring in the brain does not identify the causes of a particular behaviour pattern. It only makes it possible to indicate the co-existence of specific brain region excitation with the stimuli (Ohme, 2006). However, even the mere fact of identifying such correlations raises several controversies. First of all, there is a question whether a specific region of the brain always correlates with only one particular behaviour pattern (Mruk, Jankowiak-Kaczmarek, 2017, p. 83). The tests conducted negate such an assumption (Aron et al., 2007). For example, it turns out that the brain region known as an 'insula' is activated when one has to pay a price which is perceived as high, but it also regulates the process of overcoming a habit such as nicotine addiction (Knutson et al., 2007). Similarly, the amygdaloid nucleus is activated during excitement and during learning (Paton et al., 2006). Notwithstanding the questionable interpretive unambiguity of the correlations discussed, the new findings concerning brain function (the above-mentioned macro connections) seem to completely undermine the reasonableness of linking specific brain areas with particular behaviour patterns. According to the critics of that approach, it is not the particular brain areas themselves but the mutual communication between the brain regions that constitutes the essence of mental processes (Dobbs, 2005). Furthermore, attention is also drawn to some malpractice linked to the use of such correlations. Methodically, they were determined in the following system: stimulus - brain cells response. Therefore, by exposing the examined person to the stimulus of predetermined characteristics (e.g. high level of emotional charge (anger), or an intellectually demanding task), the brain regions which were activated were searched for. Then, knowing the stimulus nature and the correlating brain area, it was concluded in which processes (of what nature) this region is involved (Poldrack, 2006). Meanwhile, knowledge gained in this way constitutes a source of conclusions concerning different, opposite course, which are considered to be not fully justified. Based on the brain reaction (activation of a specific area), conclusions are made concerning the nature of the stimulus presented to the examined person (Reimann, 2011). Such an action is methodically doubtful (Poldrack, 2006), due to the aforementioned multifunctional nature of the individual brain areas (Plassmann et 
al., 2012). Similarly, it is not legitimate to claim that physiological measurements enable detection of unconscious processes. What is indicated is the current stream of research in neurology, focused on the search for the neuronal activity that can be associated with either conscious information processing or unconscious information processing (neural correlate of consciousness). However, there are no clear solutions as regard this issue (Lamme, 2003).

Bearing on the above mentioned findings in mind, it is difficult to justify the statements, appearing in the literature, on the unusual diagnostic power of physiological measurements related mainly to brain function. It seems that the key argument in favour of treating the results of empirical measurements as inference indicators of hidden existence is the lack of diagnosis, and thus the lack of understanding of the emergence phenomenon mechanism. This phenomenon is to explain how the observable, electrochemical reactions occurring in the brain result in intangible and volatile phenomena, such as thoughts or emotions (Ohme, 2017, p. 55).

\section{Classification of the physiological measurement methods}

The structure of the nervous system can be treated as the basis for the physiological measurements classification (String, Turkish, 2011). In other words, when discussing the possibility of physiological measurements, human body should be treated as a certain network of integrated tissues and organs. The nervous system plays here a superior and integrating role in terms of functionality (String, Turkish, 2011) and can be divided into two main parts: the central system and the peripheral system. The central system contains all the neurons of the encephalon and spinal cord, whereas the peripheral nervous system consists of nerves connecting the central nervous system with other parts of the body. The peripheral nervous system, therefore, performs a transmission function, supporting the exchange of information between the brain and the rest of the body. The peripheral nervous system is divided into somatic and autonomic system. A human being is able to influence the somatic system to some extent. as it regulates the physiological functions of the body, which are partially controlled by human (e.g. eye movement, facial expressions). On the other hand, the autonomic system is characterized by the fully automated operation that is beyond any control, and very often outside of any conscious awareness of the human (Bercik, Rybanka, 2017).

Taking into account the structure of the nervous system, the physiological measurements can be divided into two groups: measurements of brain functioning (formed by the central system) and measurements of human body functioning (directly related to the functioning of the peripheral system). A more detailed division of the physiological measurements based on the structure of the nervous system is presented in Figure 1.

Measurements of brain activity are divided into direct and indirect ones. The first group of measurements is based on the fundamental principle of the nervous system - the brain in particular - which releases a continuous electrical discharge of neurons. Therefore, the direct methods are based on detection and recording (imaging) of the electrical activity of neurons. These measurements include: 


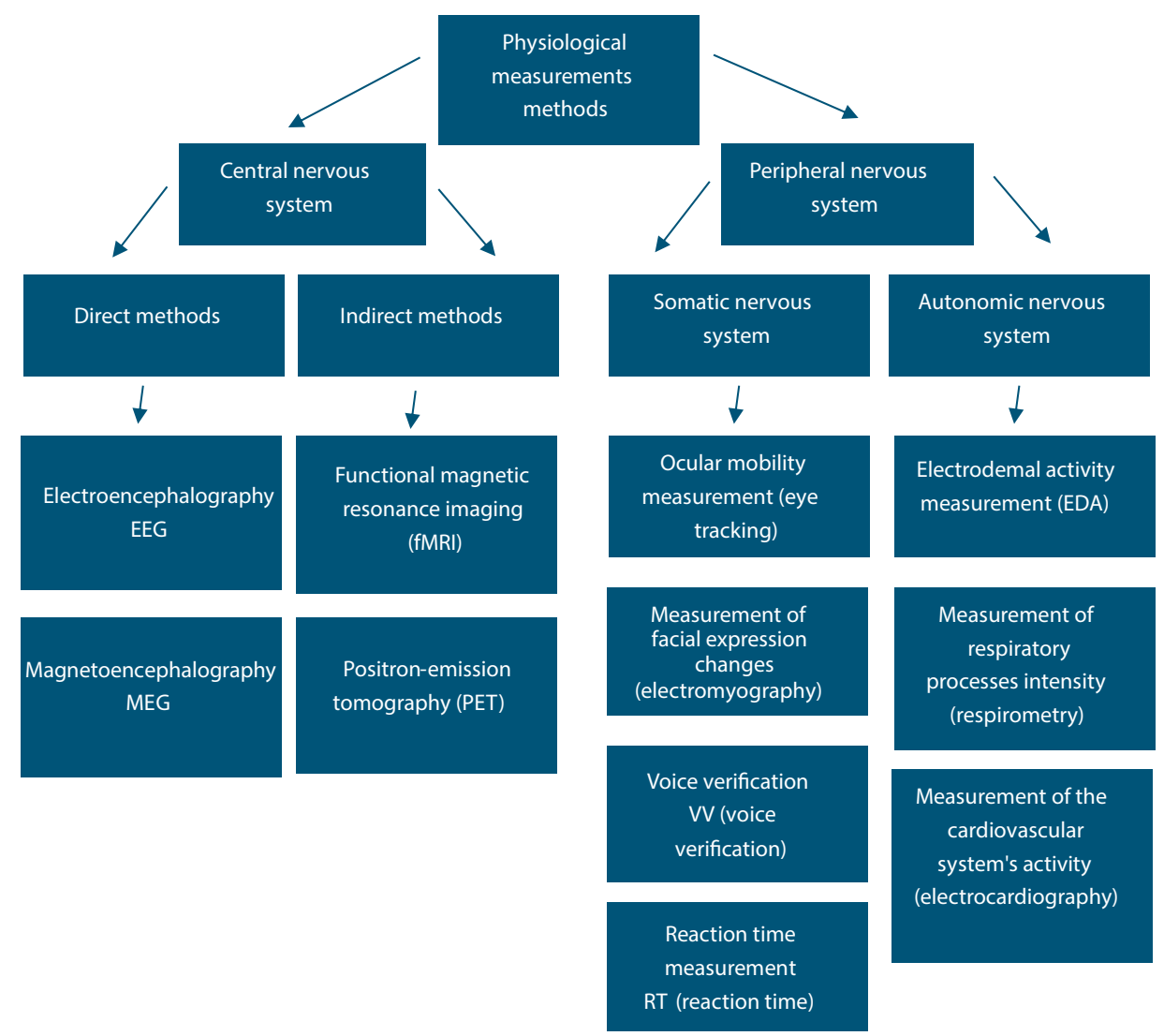

Figure 1. Classification of the physiological measurements methods according to the nervous system structure

Source: own elaboration based on: Bercik and Rybanska, 2017, p. 85.

a. Electroencephalography (EEG), which is one of the most popular and commonly used methods of measuring brain functions (Gregor, Wdowiak, 2016). It is based on two aspects. The first of them as per Bremer (2013) is the analysis of the so called rhythms (also known as waves), in tact with which the electric discharges of neurons occur. Identification of their character makes it possible to determine the state of the brain. Thus, a slow discharge rhythm is a characteristic of a state of relaxation (alpha rhythm), faster discharges indicate a state of excitement (beta rhythm), while delta waves are those found during a period of sleep. The analysis of EEG rhythms enables the detection of some neurological diseases, e.g: ADHD or epilepsy (Ligęza, 2018 , p. 21). In addition to the rhythm analysis, the electroencephalography also examines the event related potentials (ERP). They represent the changes in EEG, the source of which are specific incidents (stimuli) occurring in the environment of the examined person. ERP is used in research on paying attention to stimuli or their recognition. One of the advantages of EEG is a time precision at a very high level, 
allowing to record changes in electrical activity with an accuracy of $1 \mathrm{~ms}$ (Ohme et al., 2011, Rossiter et al., 2001). Additional advantages include a relatively low cost of the research, in comparison to other methods used for the analysis of the brain activity. Moreover, thanks to the use of a cap with built-in electrodes to be put on the head of the examined person, it is possible to conduct tests which require the participants to move as freely as possible (Gregor, Wdowiak, 2016). This method is also non-invasive as the electrodes adhere to the scalp and makes it possible to provide a very approximate location of the brain regions where electron activity changes occur. The EEG is used to analyse the process of processing information provided on websites (Bremer, 2013). Using the possibility of applying EEG measurements in mobile conditions, such equipment is also used to study the consumer behaviour within the in-store environment. However, taking into account the aforementioned low spatial precision of the technique, the results of such research are also quite vague. One of the few examples is the research conducted by Bagdziunaite and colleagues (2014), in which the level of analysis reached only the activation of cerebral hemispheres. It was assumed that higher activation of the left hemisphere in relation to the right hemisphere means positive attitude towards the product (approach motivation), whereas the opposite situation means negative attitude (avoidance motivation).

b. Magnetoencephalography (MEG), in which changes in the magnetic field associated with the activity of neurons are recorded using detectors placed in the area of the skull of an examined person (Gregor, Wdowiak, 2016). Despite the high spatial precision of this method, it requires extremely high costs associated with the purchase and maintenance of the apparatus. In addition, MEG tests require isolation of the room where they are carried out. Due to these inconveniences, this method is not used on the wide scale.

The other type of methods for analysing the brain function is not based on measuring the electrical activity of neurons, but on their demand for energy required by the activity. Therefore, these are the methods that indirectly measure the brain function by focusing on blood flow analysis, in accordance with the assumption that more active parts of the brain require more oxygen or glucose supplied with blood. Within this group of methods, the functional magnetic resonance imaging (fMRI) is mainly used. In contrast to EEG, this method is characterized by very high spatial precision. This is possible thanks to haemoglobins magnetic properties in its transport of oxygen. It turns out that in magnetic resonance, the component's behaviour characteristics differ (the magnetic properties are different) when the blood is being transported and when it is not. The comparison of the image of oxygen-rich haemoglobin with oxygen-poor haemoglobin enables the accurate indication of the brain regions with high oxygen demand (Lizęga, 2018, p. 22), even if such structures are deeply positioned (Bercea, 2012). Therefore, $f M R I$ allows the identification of the brain areas that are activated for specific tasks, especially that brain cells use oxygen ten times faster than other organs when working (Duch, 2008). Thanks to this method, the areas that are active while feeling emotions, learning new skills or making decisions have been identified (Wang et al., 2008; Plassmann et al., 2011). Nevertheless, this method has a number of disadvantages 
which significantly limit its use in research on consumer behaviour. First of all, the relationship between oxygen demand and neurons activity is not fully explained. It is possible that this demand may be a result of other factors that are not directly related to the increased work of specific parts of the brain. There are two reasons for this. The first condition is the fact that the brain at rest consumes as much energy as the brain in the activation state (Binder, 2018, p. 30). In turn, the second premise is based on the research, according to which neurons activate within a few milliseconds after the stimulus is presented, while the increase in oxygen demand and thus the increase in blood flow occurs only after 2-6 seconds (Szymusiak, 2012). A significant time delay of measurement is another disadvantage of this method (Morin, 2011; Kenning, 2007). Bearing in mind the above, this method proves to be of little use in diagnosis of the dynamics of brain function changes. In addition, the requirements that must be met in order to perform magnetic resonance create very unnatural test conditions: the examined person must be immobilised (especially head) and then placed in the lying position (on the back) in a cylinder that emits noises of a high intensity (magnetic resonance). Moreover, the specificity of the measurement performed using that method required multiple repetition of the same stimulus for the same person. It inevitably prolongs the process of data collection. As a result, it is very difficult to create appropriate research conditions that at least to a small extent would reflect everyday shopping conditions (Riedl et al., 2010). Therefore, it is difficult to generalise the research results obtained in this way, and consequently, predict the behaviour of people in the ordinary environment (Bremer, 2013). Moreover, very high cost of this method intensifies limitations in its application with regard to the analysis of consumer behaviour (Gregor, Wdowiak, 2016). There are also opinions that this method is too primitive for the tasks that it should be able to tackle. And since this does not lower the researchers' expectations, it triggers the aforementioned tendency to over-interpret the results obtained (Uttal, 2003).

Intermediate brain activity testing also includes a very sensitive method called positron-emission tomography (PET). Nevertheless, its specificity requires the administration of radioactive substances to the examined persons which significantly limits its usefulness. The half life period of these substances is so short that it coincides with the test period. Nevertheless, these are hazardous substances, thus the tests carried out using this method are considered to be invasive. Awareness that they will be required to take such substance constitutes a significant psychological barrier to people who are to be examined (Kenning et al., 2007) and may impede the acquisition of a sufficient number of participants (Jaśkowski, 2004). If one combines the above with the high costs of apparatus acquisition and maintenance as well as high cost of isotopes, the research method appears so complicated that its usage is limited primarily to medical tests (Szymusiak, 2012).

As it was already mentioned, the physiological measurements do not only cover the brain activity regulated by the central nervous system, but they also concern the body activity directly influenced by the peripheral nervous system. Those measurements indicate the consequences of brain activity observable in different parts (physiological systems) of the body. The body activity is regulated by two nervous systems (two parts 
of the peripheral system): somatic and automatic system. The activities regulated by the somatic system can be controlled by humans to a limited extent. The following measurements are carried out in their scope:

a. Eye movement measurement - a collection of research techniques used for the measurement, recording and analysis of data on the position and movement of the eye in a given period of time. Eye-tracking is based on psycho-physiological processes related to the visual perception of the environment (Rojna, 2003). The most popular technique for recording eye movement is "corneal reflex examination" and uses the reflection of light from the cornea (the so called Purkinje effect). That technique is based on a continuous lighting of the cornea and then on determining the position of the beam of light being reflected. The lights reflection off the cornea is analysed and identified as the movement of the eyeball (Wedel, Pieters, 2006).

b. Measurements of facial expressions (changes in facial expressions) - changes in facial expression can be observable and unobservable (Dimberg, 2000). It is assumed that changes occurring on the face, communicate the existence of specific emotions (both positive and negative) in a correct way. In case of the observable changes, cameras record the examined person face for forty-four possible combinations of facial muscle movements (Ekman, Friesen, 2003). The images from the cameras are then analysed by software designed for that purpose. Necessarily, this type of measurements require that the examined person does not move (it concerns the head in particular), so that the distance from the camera remains unchanged. In turn, measurement of the unobservable changes of facial expressions that last several milliseconds (microexpression) is called electromyography. It consists in attaching electrodes to appropriate places on the face and measuring muscle contractions, which are essentially their bioelectrical signals. Measurement of both observable and unobservable changes of facial expression, due to its specificity makes the examined person focused on the research process despite its impracticality in data collection in non-laboratory conditions (Szymusiak, 2012).

c. Voice verification- consists of the measurement of the volume of speech, the pace of spoken words (speed of speech), the meaning of spoken words (logic of speech), and microvibrations (Klebba, 1985; Haddad et al., 2002). These measurements are good indicators of emotional stimulation (Backhaus et al., 1985) and is one of the simplest measurements to carry out, due to its use of conventional recording equipment, which may remain unrevealed for the examined person. The analysis of the recorded voices, however, must be carried out using specialised software (Klebba, 1985). Although this method is suitable for detecting the emotional stimulation, physiological mechanism that leads to changes in the characteristics of statements made under the influence of emotions is not clearly recognized (Nighswonger, Martin, 1981).

d. Measurements of response time - by comparing the response time of the examined person to specific stimuli, it is possible to determine how such stimuli are received (positive or negative). The test makes it possible to determine the attitude of the examined subject or person - in line with the principle that the faster the reaction to the stimulus presented, the more positive attitude. A great advantage of this 
method is the possibility to conduct the test on persons who remain unaware of the attitudes towards specific stimuli (Barcea, 2012).

The last group of measurements being analysed is related to the functioning of the autonomic nervous system. As mentioned above, the activities of the body regulated by the autonomic nervous system remain beyond the human body control. They take place automatically and out of consciousness. This system activity can be analysed by means of the following measurements:

a. Measurement of secretion activity of the eccrine sweat glands - this activity affects the electrodermal reaction (EDA) and is related to changes in the skin conductance, which is a derivative of perspiration by the eccrine sweat glands. By measuring this activity it is possible to identify the emotional stimulation. Electrodermal activity can be recorded as a reaction to a short-term stimulus (phase reaction) or a chronic stimulus (tonic reaction). Due to the significant accumulation of sweat glands on hands and feet, these body parts are the main area of the physiological measurements focus.

b. Measurement of respiratory processes intensity (respirometry) - in this case, the respiratory frequency (rhythm) as well as inspiration and expiration depth are subject to measurement. It is assumed that respiratory processes can be an important indicator for determining the emotional states. For example, quick and deep breathing is associated with enthusiasm, while shallow breaths can be a sign of fear or even panic. In general, emotional stimulation increases the respiratory frequency, making it irregular (Bercik, Rybanska, 2017) and is measured by a device known as a respirometer. In order to perform the test properly, it is required to place the appropriate mask on the examined person face (including nose and mouth). The mask is connected with the measuring equipment and is usually conducted in laboratory conditions due to their specificity.

c. The measurement of the cardiovascular system activity - measuring the frequency and regularity of heart contractions (Sosnowski, Zimmer, 1993, p. 222) enable the determination of excitement. It has also been noted that the heart rate decreases when people focus on analysing information in their environment. When one does not pay attention to such information, the heart rate increases. This system activity is measured by means of an electrocardiograph or a heart rate monitor.

\section{Conclusions}

Physiological measurements, as a research method are increasingly used in social sciences, including economics. The main reason for this is the technological progress, thanks to which the equipment used for physiological measurements become easier to operate, more accurate and, what is equally important, less costly. Nevertheless, regardless of the level of technological advancement of the apparatus used, the issue of correct interpretation of data obtained remains unchanged. This undoubtedly requires an interdisciplinary approach and needs scientific achievements in consumer behaviour to be combined with knowledge of physiology, neurology, psychology, engineer- 
ing or computer science. Such a multilateral approach, however, can be an obstacle to the correct use of methods discussed and needs to be overcome as they provide an opportunity to acquire knowledge that would be difficult to obtain otherwise.

\section{References}

1. Ariely D., Berns G.S. (2010). Neuromarketing: the hope and hype of neuromarketing in business. Nature Reviews. Neuroscience, 11(4), 284-292.

2. Aron A., Badre D., Brett M., Cacioppo J., Chambers C., Cools R. et al. (2007). Letter: Politics and the brain. New York Times.

3. Backhaus K., Meyer M., Stockert A. (1985). Using voice analysis for analysing bargaining processes in industrial marketing. Journal of Business Research, 13(5), pp. 435-446.

4. Bagdziunaite D., Nassri K., Clement J., Ramsøy T.Z. (2014). An added value of neuroscientific tools to understand consumers' in-store behaviour. (43rd EMAC Conference, Valencia, June 3-6), downloaded from http://www.emac2014.eu/.

5. Bercea M.D. (2012). Anatomy of methodologies for measuring consumer behavior in neuromarketing research. Conference Paper. Dowloaded from http://www.lcbr-archives. com/media/ files/12emc023.pdf

6. Berčik J., Rybanská J. (2017). Methods used in neuromarketing. [In:] Horska E., Berčik J. (Eds.), Neuromarketing in food retailing. Wageningen Academic Publishers, Wageningen, pp. 83102.

7. Binder M. (2018). Psychoodejście. Jak i po co podglądamy mózg. Polityka, 31(11), pp. 26-31.

8. Bremer J. (2013). Czym jest neuromarketing. British Computer Society, Teoretické štúdie, Communication Today, 18, pp. 18-45.

9. Dimberg U., Thunberg M., Elmehed, K. (2000). Unconscious facial reactions to emotional facial expressions. Psychological Science, 11(1), pp. 86-89.

10. Diterhaft A., Woźniak M. (2017). Sytuacja i możliwości wykorzystania badań neuromarketingowych na rynku polskim. Zeszyty Naukowe Wyższej szkoły Bankowej w Poznaniu, 75(4), pp. 193-204.

11. Dobbs D. (2005). Współczesna frenologia? Świat Nauki. Special edition, 16, pp. 23-29.

12. Duch W. (2008). Perspektywy neuromarketingu. [In:] Mruk H., Sznajder M. (Eds.), Neuromarketing. Interdyscyplinarne spojrzenie na klienta. Wydawnictwo Uniwersytetu Przyrodniczego w Poznaniu, Poznań.

13. Ekman P., Friesen W.V. (2003). Unmasking the face. Malor Books Cambridge, MA .

14. Falk E.B., Berkman E.T., Lieberman M.D. (2012). Effects from neural responses to population behavior: Neural focus group predicts population-level media. Psychological Science, 23(5), pp. 439-445.

15. Gregor B., Wdowiak Ł. (2016). Istota oraz metody badań neuromarketingowych. Prace Naukowe Uniwersytetu Ekonomicznego, 459, pp. 50-61.

16. Haddad D., Walter S., Ratley R., Smith M. (2002). Investigation and Evaluation of Voice Stress Analysis Technology, Final Report. National Institute of Justice, NCJRS 193832. http://www. ncjrs.gov/pdffiles1/nij/193832.pdf. 
17. Hintze J.M., Volpe R.J., Shapiro E.S. (2002). Best practices in the systematic direct observation of student behavior. Best Practices in School Psychology IV, 63, pp. 993-1006.

18. Jaśkowski P. (2004). Zarys psychofizjologii. Wyższa Szkoła Finansów i Zarządzania, Warszawa.

19. Johnston J.M., Pennypacker H.S., Green G. (1993). Strategies and tactics of behavioural research. Lawrence Erlbaum, Hillsdale, NJ.

20. Kaczmarczyk S. (2014). Klasyfikacja metod zbierania danych ze źródeł pierwotnych w badaniach marketingowych. Metody ilościowe w badaniach marketingowych, 195, pp. 55-64.

21. Kenning P., Plassmann H., Ahlert D. (2007). Applications of functional magnetic resonance imaging for market research. Qualitative Market Research. International Journal, 10(2), pp. 135-152.

22. Klebba J.M. (1985). Physiological measures of research: A review of brain activity, electrodermal response, pupil dilation, and voice analysis methods and studies. Current Issues \& Research in Advertising, 8(1), pp. 53-76.

23. Knutson B., Rick S., Wimmer G.E., Prelec D., Loewenstein G. (2007). Neural Predictors of Purchases. Neuron, 53(1), pp. 147-156. doi:10.1016/j.neuron.2006.11.010

24. Kowalski J. (2009). Neuromarketing jako wrota do podświadomości konsumenta. [In:] Kozielski R. (Ed.) Nowe media - konkurencja z wyobraźnią. W poszukiwaniu nowych metod komunikacji z klientem. Raport z warsztatów strategicznych. Uniwersytet Łódzki, Mikołajki, p. 20-21.

25. Lamme V. (2003). Why visual attention and awareness are different. Trends in Cognitive Sciences, 7(1), pp. 12-18.

26. Larsen N. M., Sigurdsson V., Breivik J. (2017). The use of observational technology to study instore behavior: consumer choice, video surveillance and retail analytics. Behavioral economics in consumer behavior analysis, pp. 1-29, doi: 10.1007/s40614-017-0121-x.

27. Lee N., Broderick A.J., Chamberlain L. (2007). What is "neuromarketing"? A discussion and agenda for future research. International Journal of Psychophysiology, 63, pp. 199-204.

28. Littlefield M. (2009). Constructing the organ of deceit: The rhetoric of fMRI and brain fingerprint in post-9/11 America. Science, Technology \& Human, 34(3), pp. 365-392, doi:10.1177/0162243908328756.

29. Ligęza T. (2018). Przyrządy do narządu, Poradnik Psychologiczny. Jak i po co podglądamy mózg. Polityka 31(11), pp. 18-24.

30. Morin Ch. (2011). Neuromarketing: The New Science of Consumer Behavior. Society, 48(2), pp. 131-135.

31. Mruk H., Jankowiak-Kaczmarek A. (2017). Wiedza o konsumentach z perspektywy ekonomii behawioralnej. [In:] Bartosik-Purgat M. (Ed.), Zachowanie konsumenta. Globalizacja. Nowe Technologie. Aktualne trendy. Otoczenie społeczno-kulturowe. Wydawnictwo Naukowe PWN S.A., Warsaw, p. 79-98).

32. Nighswonger N.J., Martin C.R. (1981). On using voice analysis in marketing research. Journal of Marketing Research, 18(3), pp. 350-355.

33. Plassmann H., Ramsøy T.Z., Milosavljevic M. (2012). Branding the brain: A critical review and outlook. Journal of Consumer Psychology, 22(1), pp. 18-36.

34. Ober J., Dylak J., Gryncewicz W., Przedpelska-Ober E. (2009). Sakkadometria - nowe możliwości oceny stanu czynnościowego ośrodkowego układu nerwowego. Nauka 4, pp. 109-135.

35. O'Connell A.F., Nichols J.D., Karanth K.U. (2011). Camera Traps in Animal Ecology. Methods and Analyses. Springer. 
36. Ohme R. (2006). Kontrowersje wokół neuromarketingu. Downloaded from: https://wiadomosci.Onet. pl/kiosk/kontrowersje-wokol-neuromarketingu/kmj1s.

37. Ohme R. (2017). Emo sapiens. Harmonia emocji i rozumu. Bukowy Las, Wrocław.

38. Ohme R., Matukin M., Pacula-Lesniak B. (2011). Biometric measures for interactive advertising research. Journal of Interactive Advertising, 11(2), pp. 60-72.

39. Paton J.J., Belova M.A., Morrison S.E., Salzman C.D. (2006). The primate amygdala represents the positive and negative value of visual stimuli during learning. Nature, 439, pp. 865-870.

40. Poldrack R.A. (2006). Can cognitive processes be inferred from neuroimaging data? Trends in Cognitive Sciences, 10(2), pp. 59-63.

41. Riedl R., Hubert M., Kenning P. (2010). Are there neural gender differences in online trust? An $f M R I$ study on the perceived trustworthiness of eBay offers. Society for Information Management and The Management Information Systems Research, 34(2), pp. 397-428.

42. Reimann M., Schilke O., Weber B., Neuhaus C., Zaichkowsky J. (2011). Functional magnetic resonance imaging in consumer research: A review and application. Psychology \& Marketing, 28(6), pp. 608-637 doi:10.1002/mar.20403.

43. Rossiter J.R., Silberstein R.B., Harris P.G., Nield G. (2001). Brain-imaging detection of visual scene encoding in long-term memory for TV commercials. Journal of Advertising Research, 41(2), pp. 13-21. doi:10.2501/JAR-41-2-13-21.

44. Rożek T. (2011). Nauka po prostu. Demart S.A., Warszawa.

45. Rószkiewicz M. (2002). Metody ilościowe w badaniach marketingowych. Wydawnictwo Naukowe PWN, Warsaw.

46. Schwartzkopf S. (2015). Measurement devices and the psychophysiology of consumer behaviour: A posthuman genealogy of neuromarketing. BioSocieties, 10(4), pp. 465-482. doi:10.1057/biosoc.2015.3.

47. Shiv B., Bechara A., Levin I., Alba J.W., Bettman J.R., Dube L., Mcgraw A.P. (2005). Decision neuroscience. Marketing Letters, 16(3-4), pp. 375-386.

48. Smyczek S., Turek A. (2011). Możliwość zastosowania diagnostyki medycznej w badaniach zachowań konsumentów. [In:] Mazurek-Łopacińska K., Sobocińska M. (Eds.), Badania marketingowe w zarządzaniu przedsiębiorstwem. Prace Naukowe Uniwersytetu Ekonomicznego we Wrocławiu, 237, Wydawnictwo Uniwersytetu Wrocławskiego, Wrocław, pp. 65-74.

49. Sosnowski T., Zimmer K. (1993). Metody psychofizjologiczne w badaniach psychologicznych. Wydawnictwo Naukowe PWN, Warsaw.

50. Stewart D.W., Furse D.H. (1982). Applying psychophysioological measures to marketing and advertising research problems. Journal of Current Issues and Research in Advertising 5(1), pp. 138. doi:10.1080/01633392.1982.10505319.

51. Studziński J. (2009). Z markq do mózgu. [In:] Kozielski R. (Ed.), Branding. Nowe możliwości. Nowe rozwiq̨zania. Raport z warsztatów strategicznych, Uniwersytet Łódzki, pp. 15-16.

52. Szymusiak H. (2012). Neurobiologiczne techniki stosowane w biznesie. Wydawnictwo Uniwersytetu Ekonomicznego w Poznaniu, Poznań.

53. Urbański M. (1993). Podstawy pomiarów w psychofizjologii. [In:] Metody psychofizjologiczne w badaniach psychologicznych. Wydawnictwo Naukowe PWN, Warsaw, pp. 42-100.

54. Uttal D. (2003). On the relation between play and symbolic thought. The Case of Mathematics manipulatives. [In:] Saracho O.N., Spodek B. (Eds.). Contemporary Perspectives in Early Childhood Education. Age Publishing Inc., pp. 97-114. 
55. Wang Y.J., Minor M.S. (2008). Validity, reliability and applicability of psychophysiolgical techniques in marketing research. Psychology \& Marketing, 25(2), pp. 197-232.

56. Wedel M., Pieters R. (2006). Eye-tracking for visual marketing. Foundations and Trends in Marketing, 1(4), pp. 231-320. 
Romanowski R. (Ed.): Managing Economic Innovations - Methods and Instruments

Bogucki Wyd. Nauk., Poznań 2019. ISBN 978-83-7986-277-1

DOI: $10.12657 / 9788379862771-4$

\title{
Chapter 4
}

\section{An Overview to Neuromarketing Research Methods}

\author{
Urszula Garczarek-Bąk
}

\begin{abstract}
Neuroscience research methods provide a deeper understanding of the cognitive processes and underlying mechanisms that help explain consumer behaviors. The human brain that controls intelligence, senses, body movements and behavior is the most complex organ and the place where emotions are generated and controlled (Abhang, Gawali, Mehrotra, 2016). It yields two kinds of signals that scientist has exploited "to get a better look at what is going on under the hood" (Genco, Pohlmann, Steidl, 2013). Namely, the first is blood flow in the brain, and the second - the electrical activity in the brain. Although both have produced robust bodies of research, they are not without controversies as emerging fields. What is clear, however, is that understanding what is happening in the neuromarketing techniques is essential for anyone who believes that marketers can change the probability of a favorable response from consumers (as a valid measure of consumers' attitude towards products, packaging, design, price, promotion, etc.), more accurate that self-reports. Therefore, the aim of this systematic review is to summarize the techniques, contributions and limitations of the main neuromarketing measures.
\end{abstract}

Keywords: neuromarketing, PET, fMRI, fNIR, EEG, MEG, TMS

\section{Introduction}

Currently, consumer neuroscience is a growing approach to research that is garnering increased attention among academic researchers in the fields of marketing (Lin et al.,

Urszula Garczarek-Bąk: PhD, Assistant Professor at Department of Commerce and Marketing, Institute of Marketing, Poznań University of Economics and Business, ORCID https://orcid.org/0000-0002-3979-7964, urszula.garczarek-bak@ue.poznan.pl 
2018). In 2002, the Dutch marketing researcher Smidts coined a term "neuromarketing" (NM) that continues to both enthral and enrage neuroscientists, psychologists, marketers, market researchers and consumer advocates. According to Schwarzkopf (2015), this term mainly acts as a promise, for it conjures up visions of startlingly new 'insights' into consumers' minds and a grand unification of disparate approaches to the research of consumer behavior. Neuromarketing is a new discipline that uses medical techniques to understand how the central nervous system reacts to marketing stimuli. Lin et al. (2018) point out that by using NM techniques, researchers can overcome the biases inherent in self-reported data derived from surveys and qualitative methods and discover real emotions, feelings, expectations and even hidden restraints of the consumer. The purpose of this chapter is to provide an integrative overview of neuromarketing using brain imaging techniques, separated into recording metabolic and electrical activities. To clarify, apart neuromarketing measures, the neuroscience literature distinguish also psychophysiological measures as well (Table 1).

Table 1. Classification of Neuromarketing and Psychophysiological Tools

\begin{tabular}{|c|c|c|c|}
\hline \multirow{6}{*}{$\begin{array}{l}\text { Neuromarket- } \\
\text { ing Measures }\end{array}$} & \multirow{3}{*}{$\begin{array}{l}\text { Recording Metabolic } \\
\text { Activities in Brain }\end{array}$} & PET & Positron Emission Tomography \\
\hline & & fMRI & Functional Magnetic Resonance Imaging \\
\hline & & fNIR & Functional Near-Infrared Spectroscopy \\
\hline & \multirow{3}{*}{$\begin{array}{l}\text { Recording Electrical } \\
\text { Activities in Brain }\end{array}$} & EEG & Electroencephalography \\
\hline & & MEG & Magnetoencephalography \\
\hline & & TMS & Transcranial Magnetic Stimulation \\
\hline \multirow{7}{*}{$\begin{array}{l}\text { Psychophys- } \\
\text { iological } \\
\text { Measures }\end{array}$} & \multirow{7}{*}{$\begin{array}{l}\text { Without Recording } \\
\text { Brain Activities }\end{array}$} & ET & Eyetracking \\
\hline & & EDA & Electrodermal Activity (formerly called GSR) \\
\hline & & fEMG & Facial Electromyography \\
\hline & & FACS & Facial Action Coding System \\
\hline & & IAT & Implicit Association Test \\
\hline & & MPR & Measuring Physiological Responses \\
\hline & & $\mathrm{SMH}$ & Somatic Marker Hypothesis \\
\hline
\end{tabular}

Note. own elaboration based on Zurawicki (2010) and Holmqvist et al. ( 2011).

\section{Recording Metabolic Activities in Brain}

Nowadays, two main measurement technologies are used in neuroscience to derive images of brain activity by measuring blood flow in the brain (fMRI and PET). They are based on the anatomical principle that mental activity increases demand for oxygen or glucose in activated regions in the brain (and this need is met by increased blood flow to the region) (Genco, Pohlmann, Steidl, 2013). Brig and Cole (2009) notice that medical imaging continues to evolve at a blistering pace and recent developments in molecular imaging have created a lot of excitement not only in the medical fraternity, but also in neuromarketing field. 


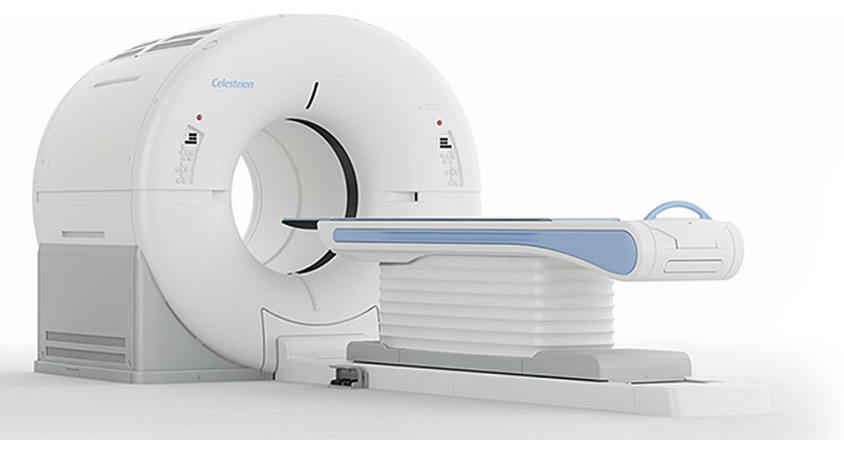

\section{Celesteion}

PUREVISION Edition PET/CT

Figure 1. PET scanner

Retrieved from https:/eu.medical.canon/product-solutions/computed-tomography/celesteion-pet-ct/.

Note: The most recent innovation in PET scanners is the dual-modality PET/CT. By combining nuclear medicine and radiological imaging modalities it is possible to add anatomical to functional information (Langer, 2010).

\section{PET}

Positron emission tomography (PET) is a three-dimensional diagnostic imaging technique using compounds labelled with positron-emitting radioisotopes to measure cell metabolism (Langer, 2010). PET uses radiolabeled molecules to image molecular interactions of biological processes in vivo, and has been widely adopted as an important clinical modality for neurological oncological and cardiovascular applications. PET imaging is based on detecting two time-coincident high-energy photons from the emission of a positron-emitting radioisotope. According to Vaquero and Kinahan (2015) it offers more translational possibilities than any other modality due to its combination of sensitivity and quantitative accuracy. Similarly, Jones and Townsend (2017) indicate that PET is the most specific and sensitive means for imaging molecular interactions and pathways within the human body.

This molecular imaging technique is based on the detection of radioactivity emitted after a small amount of a radioactive tracer is injected into a peripheral vein' (the used dose is similar to this one used in computed tomography) (Lai, Yen, Chang, 2007). The tracer after being absorbed by the body travels through the subject's blood and collects in organs and tissues (the investigation begins after at least one hour). Then a narrow table slides patient into a large tunnel-shaped PET scanner that detects signals from the tracer and a computer changes the signals into 3D pictures that shows how organs and tissues are working (MedlinePlus, 2018). A common analytical approach in PET imaging is to statistically compare a patient's PET images on a voxel-by voxel basis to a database of healthy individuals matched for age and gender (called normative database) (Slough, Masters, Hurley, Taber, 2016). Voxels in which the patient differs by more than 2.5 standard deviations indicate areas of significantly altered function (Shokouhi, Claassen, Riddle, 2014).

The tracer is administered as an intravenous injection usually labelled with oxygen-15, fluorine-18, carbon-11, or nitrogen-13. 
PET is an instrument which is capable of pointing out various phenomena such as brain blood flow, blood volume, glucose and last but not least oxygen consumption. That is because the brain structures which have higher concentration of injected radiopharmaceutical emit higher amount of radiation - meaning they are more active in terms of the cell metabolism or blood circulation (more actively working areas are highlighted) (Zurawicki, 2010).

PET is a very costly method, quite uncomfortable for the subject (mainly due to the stationary position and noise generation), and less and less used in neuromarketing specific research (Sebastian, 2014). Due to the fact that PET involves radioactive material injection, it is not suitable for everyone (especially it is not recommended to conduct PET scan in case of pregnant women and infants, and individuals who have an allergic reaction to the tracer). Moreover, the spatial resolution may be seen as a next limitation, determined by the variability in estimating the interaction point of the $511 \mathrm{keV}$ photon in the scintillator (Vaquero, Kinahan, 2015). The temporal resolution is poor, because it takes time before enough radioactive "ticks" can be counted (the greater activity in the brain region, the more radioactive tracer is present in that region, and the stronger PET signal at that location).

\section{fMRI}

Nowadays, due to the constant changes in consumer behavior in the world full of sophisticated technologies, functional magnetic resonance imaging (fMRI) is definitely a promising alternative research method (Ruanguttamanun, 2014). According to Genco, Pohlmann and Steidl (2013) fMRI is at present the most popular neuroimaging technique for academic neuroscience research. It is a class of imaging methods developed in order to demonstrate regional, time-varying changes in brain metabolism that can be consequent to task-induced cognitive state changes or the result of unregulated processes in the resting brain (Glover, 2011). fMRI aims to determine the neurobiological correlation of human behavior by locating the active parts of the brain during the experiment (Kulich, Maciewicz, Scrivani, 2009) and require the subject to perform a particular action in order to trigger a dynamic uptake of oxygen into the brain. This is because fMRI recordings are based on the subsequent increase in oxygen demand from the brain tissue upon the execution of a certain stimulus, whether it is motor, sensory or emotional.

There are two principal techniques of functional MRI: the blood-oxygen-level dependent (BOLD) technique and the dynamic or exogenous technique (Hare et al., 1998). The first technique is the favored method because no intravenous contrast medium is required. Chow et al. (2017) note that the majority of $\mathrm{FMRI}$ studies make use of BOLD contrast imaging, which involves mapping particular regions of a functioning brain, from the changes in blood oxygen. Blood flow in the brain is very locally controlled in response to oxygen and carbon dioxide tension of cortical tissue. As with a PET scanner, in the fMRI experiment, the subject is scanned while lying on their back in a narrow, long tube and remains still throughout the testing ${ }^{2}$, in order not to compromise the

2 If the person moves his or her head as little as two millimeters, the resulting image is blurred into meaninglessness. And because speaking causes head movement, verbal responses are impossible to collect. 
collected data. This tube is surrounded by magnets that generate electric fields when activated. This method offers very accurately identifying increased activity in a certain brain area while a stimulus situation is being presented (Sebastian, 2014).

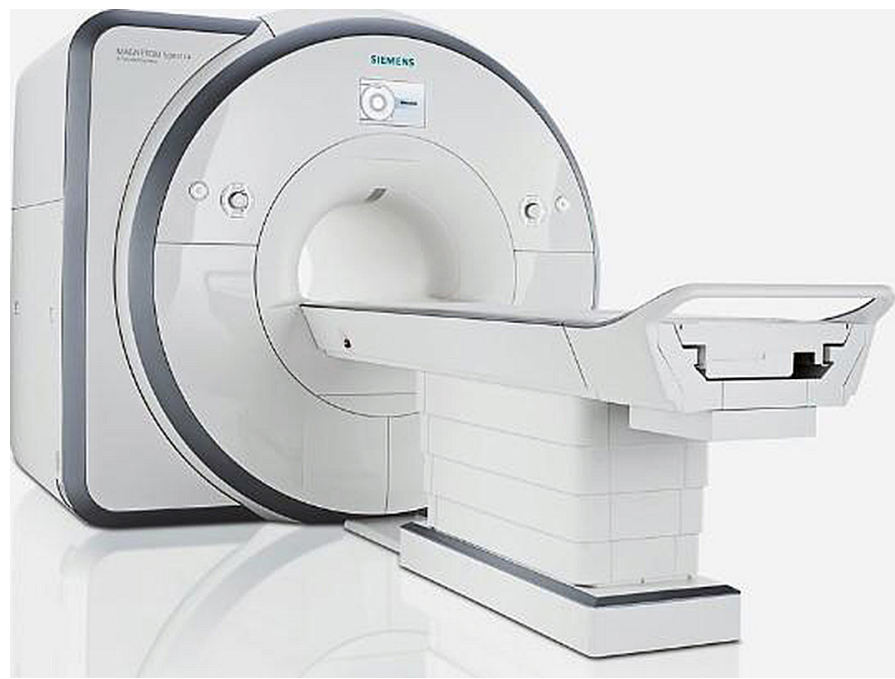

Figure 2. fMRI scanner

Retrieved from https://www.siemens-healthineers.com/en-ca/magnetic-resonance-imaging.

In order to understand how the fMRI works, it is imperative to mention that blood contains iron, which is part of hemoglobin, which transports oxygen throughout the bloodstream. Iron atoms are capable of generating changes in the magnetic field around them (Sebastian, 2014). When a specific region of the cortex increases its activity in response to a task, the extraction fraction of oxygen from the local capillaries leads to an initial drop in oxygenated hemoglobin (oxyHb) and an increase in local carbon dioxide (CO2) and deoxygenated hemoglobin (deoxyHb). Following a BOLD response lags (of 1 to 2 seconds behind the stimulus - in order for the vascular system to respond), cerebral blood flow increases (it peaks at 5 seconds after the stimulus) delivering a surplus of oxygenated hemoglobin, washing away deoxyhemoglobin and in this large rebound in local tissue oxygenation which is imaged ${ }^{3}$. So the reason $\mathrm{fMRl}$ is able to detect this change is due to a fundamental difference in the paramagnetic properties of oxyHb and deoxyHb (Glover, 2011). Interestingly, the voxel representing the area of activation is usually defined as covering a few million neurons (Heuttel, Song, McCarthy, 2009).

\footnotetext{
3 The different levels of oxygen usage are frequently illustrated with a pseudocolor scale in the images acquired. In the commonly used four-color scale, red indicates the highest level of oxygen uptake, yellow is an intermediate level of uptake, green indicates the normal level of oxygen, and blue indicates oxygen levels that are lower than normal (Glover, 2011).
} 
Since scanners produce strong magnetic fields, subject will need to remove all metal objects before having a scan (therefore, metal objects and certain medical devices - such as hearing aids, surgical implants, clips, and pacemakers, are not allowed in the vicinity of the MRI scanner for safety reasons). In the case of neuromarketing research individuals with claustrophobia should not be signed up to take part in an fMRI study. Moreover, participants need to be free from current psychological and neurological diagnoses and have normal hearing, and normal, or corrected-to-normal, vision.

Whereas only limited conditions can be tested in the fMRI-scanner (and only specific types of stimuli can be shown while the participant is lying in the scanner), many researchers question whether economic decision making can truly be measured (and generalized) in such a restricted situation (a.o. Shimokawa et al., 2009; Ariely, Berns, 2010; Ayaz et al., 2013). fMRI usage has been relatively limited due to the high cost of machinery (in terms of installation, training and maintenance) and the high level of required technical expertise. Furthermore, some subjects may find the experience claustrophobic, or at least highly agitating due to the noise and still position required, not mentioning the novelty of medical research. As mentioned by Genco, Pohlmann and Steidl (2013), in case of consumer and marketing research, focused on identifying subtle variations in emotional response, this method can produce a confounding effect difficult to disentangle from participants' responses to the stimuli themselves.

\section{fNIR}

The third metabolic recording method opens a promising new avenue for studying and understanding shopper's behavior, since mobile fNIR enables marketing management to collect neural data from shoppers and analyze neural activity associated with real-life settings (Krampe, Strelow, Haas, Kenning, 2018). Similarly, Kopton and Kenning (2014) persuade that fNIR is a new and promising tool for investigating economic decision making both in field experiments and outside the laboratory.

Functional near-infrared spectroscopy ( $\mathrm{fNIR}$ ) is an optical brain imaging technique that enables monitoring of changes in cerebral blood oxygenation related to human brain functions (Ayaz et al., 2011). Subjects wear an fNIR sensor (infrared light sources and detectors mounted in a flexible band $)^{4}$ on the forehead - that detects oxygen levels in the prefrontal cortex and provides real-time values for oxy-hemoglobin ( $\mathrm{HbO})$ and deoxygenated hemoglobin $(\mathrm{HbR})$ - due to the hemodynamic response - the rapid delivery of oxygenated blood to active cortical areas through neurovascular coupling ${ }^{5}$ (Ayaz et al., 2013).

Although, recordings from fNIRS are similar to $\mathrm{FMRI}$, the measurement area is limited to the outer cortex and has lower spatial resolution ( $\mathrm{mm}$ versus $\mathrm{cm}$ ) (Batula, Mark,

\footnotetext{
4 Near-infrared light, with a wavelength spectrum of circa 650-950 nm, passes through biological tissue without difficulty, and can non-invasively illuminate several centimeters of the tissue (Jackson, Kennedy, 2013; Scholkmann et al., 2013).

When a group of neurons are more active, local blood flow changes in response (and in turn, changes the local oxy-/deoxy-hemoglobin concentrations) - this is known as neurovascular coupling.
} 
Kim, Ayaz, 2017). However, fNIRS can measure at a higher temporal resolution to capture additional frequency bands and does not require subjects to lay down in a supine position in restrictive and artificial lab environments with the loud noises generated by $\mathrm{fMRI}$. As noted by Batula et al. (2017), despite the lower temporal resolution and time delay of the hemodynamic response compared to EEG measurements, fNIRS provides a unique trade-off between temporal and spatial resolution and moreover, it is free from most artifacts, such as muscle activity and eye blinks. In the common configuration, light sources and detectors are placed on the scalp and two wavelengths of light are transmitted through the top layer of the cerebral cortex. Picture 3 shows fNIR sensor pad that contains 4 light sources (middle row) and 10 light detectors (black spots) forming 16 optodes (measurement locations - four for each light source).

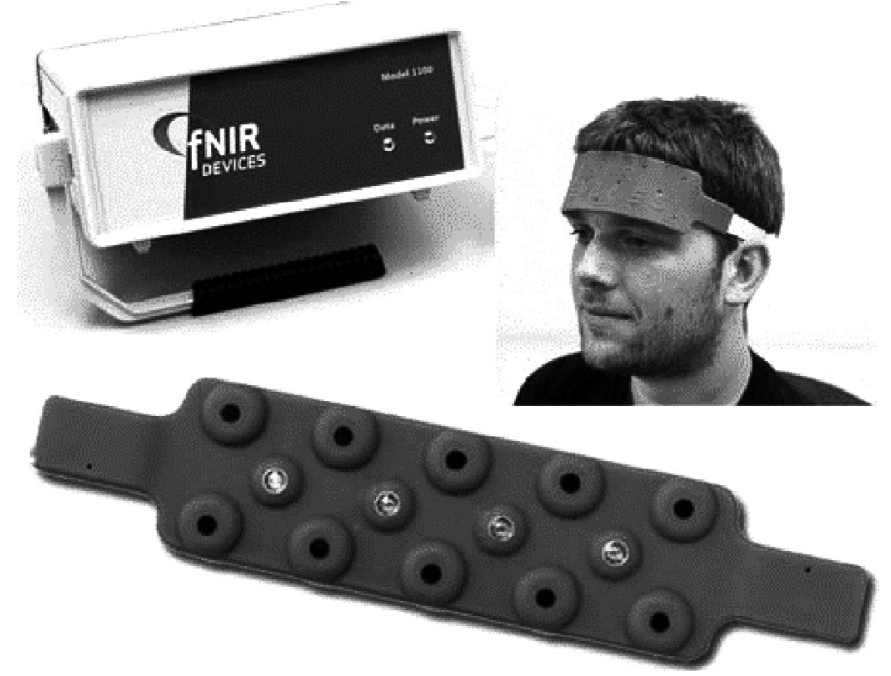

Figure 3. fNIR devices (data acquisition control box and fNIR sensor pad)

Retrieved from https://biopac.com/product-category/research/fnir-optical-brain-imaging.

According to Ayaz et al. (2011), light at wavelengths between approximately 700 and $900 \mathrm{~nm}$ can pass through skin, bone, and water, but it is absorbed primarily by oxy- and deoxy-hemoglobin ( $\mathrm{HbO}$ and $\mathrm{HbR}$ respectively). Due to the fact that $\mathrm{HbO}$ and $\mathrm{HbR}$ have different light absorption properties, the relative changes in $\mathrm{HbO}$ and $\mathrm{HbR}$, and therefore the change in oxygenation of the tissue, can be calculated from changes in the reflected dual-wavelength light using the modified Beer-Lambert law ${ }^{6}$ (Cope, 1991). However, fNIR does have some limitations. Particularly, it enables to examine only cortical activity, with the limited depth penetration of near-infrared light into the skull. Moreover, hair can interfere with the transmission of light among the source, the scalp, and the detector, so researcher must be prepared to avoid this possibility (Seraglia et al., 2011).

6 Also known as Beer's law, relates the attenuation of light to the properties of the material through which the light is travelling. 


\section{Recording Electrical Activities in Brain}

The second basic class of mapping technique is localizing the underlying electrical activity of the brain. Such techniques enable the recording of brain activity directly through scalp-surface detection of electrical and magnetic signals emitted by the brain (Genco, Pohlmann, Steidl, 2013). Electrical measurement techniques compared to blood flow provide much poorer spatial resolution, because they measure only signals at the scalp surface where the sensors are located.

\section{EEG}

The electroencephalogram (EEG) is an efficient and relatively inexpensive method for the study of changes in brain-behavior relations (Bell, Cuevas, 2012). The change in the human brain signal and its main spectral bands of Delta $(0-4 \mathrm{~Hz})$, Theta $(3-7 \mathrm{~Hz})$, Alpha (8-12 Hz), Beta (13-30 Hz), and Gamma (30-40 Hz) is observed to examine consumers' cognitive or affective processes in response to presented marketing stimuli (Mostafa, 2012). The applications of this method are extremely wide-reaching, as they allow investigators to explore a nearly infinite number of domains where it is of interest to understand the relative timing of neural events (Light et al., 2010). The recording of EEG signals is done by placing several electrodes on the participant's scalp (usually in form of a cap) and to improve the conduction of impulses to electrode, a gel is recommended to be applied.

The electric current produced by a normal human brain has order of a few microvolts. These voltage fluctuations are the result of ionic current that flows between brain and the neurons. Neurons communicate with each other via electrical impulses. The electric potential picked up by a single neuron is very small and thus it is impossible to detect. Each electrode reflects the summation of the synchronous activity of thousands or millions of neurons that have similar spatial orientation, so the EEG determines the summation of the synchronous activity of a large number of neurons present in the brain (Kaur, Kaur, 2015).

The amplitude of EEG signal may vary from 10 to 100 micro volts with a frequency range of $1-100 \mathrm{~Hz}$. The signal extracted from electrodes - called raw EEG signal - may include some non-cerebral signals called artefacts. The EEG signals may be contaminated mainly by movement related potentials, eye blinks, movement of facial muscles as well as by the environmental artefacts like line noise, pulse and electrode stabilization (Kaur, Kaur, 2015). So in order to possess readable EEG signal, the raw signal must undergo various processes, including filtration. When planning a recording session, an investigator must balance the need to obtain a sufficient quantity of data to provide reliable estimates of EEG signal while minimizing participant burden, because with longer sessions, emotional state can change within session (Smith, Reznik, Stewart, Allen, 2017). Having in mind this constraint, when projecting EEG research - among two main methods presented in the literature - such as evoked potentials (EP) ${ }^{7}$ recording

7 Meanwhile Abhang, Gawalin, Mehrotra (2016) did not distinguish evoked potential (EP) from the event related potential (ERP), one remark specifying the difference between EPs and ERPs is necessary. An 
and calculating asymmetry - the later seems to be more attractive for participant. In the first case, there is a need to apply repeated stimuli (many trials are required because the waveform is extracted by averaging across all trials of the same stimulus) - because evoked potential is an electrical potential recorded from the nervous system of a human following presentation of a stimulus, as distinct from spontaneous potentials as detected by EEG.

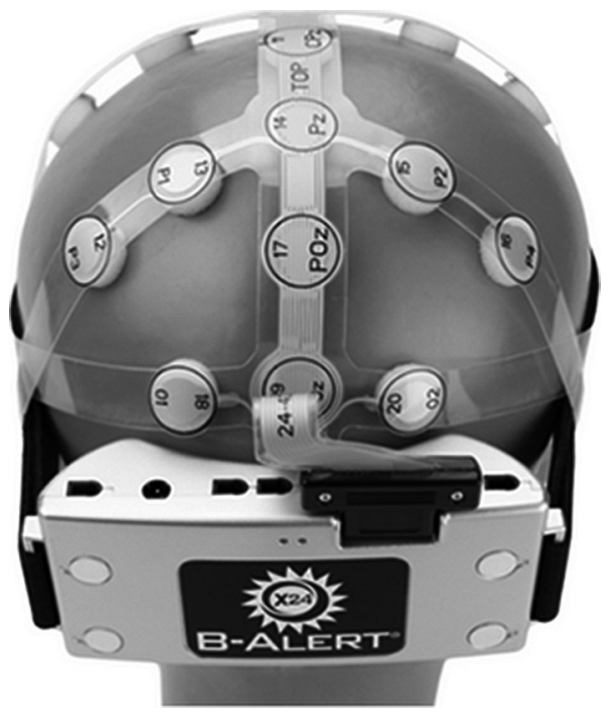

Figure 4. Wireless EEG headset

Retrieved from https://imotions.com/hardware/abm-b-alert-x24/.

Note: B-Alert X24 has 20 channels of high-quality EEG, plus 4 optional channel for ECG, EMG, or EOG.

One commonly cited metric which neuromarketing companies focus on is the degree of "emotional engagement", that is measured by the frontal asymmetry ${ }^{8}$ in the EEG output (index can be computed in a fairly simple manner from raw frontal EEG data). This measure involves computing the difference in activity between left frontal and right frontal regions, generally in the alpha band (but many recent research include also beta and gamma band - for further information see Garczarek, Disterheft, 2018). Neuropsychologists have consistently found that higher engagement of the left - relative to the right frontal brain - is related to positive feelings and higher engagement

event-related potential (ERP) is any stereotyped electrophysiological response to an internal or external stimulus. In simple terms it is any measured brain response that is the direct result of a thought process or perception. ERPs were originally called evoked potentials (EPs) because they were electrical potentials that were evoked by stimuli (as opposed to the spontaneous EEG rhythms. In many cases EP = ERP, but it is important to emphasize that EPs are time locked and averaging typically brings them out, whereas ERPs are not time locked and averaging may hide the potential (KCE 2009).

8 The frontal lobe is the emotional control center of the brain, responsible for problem solving, judgment and motor function. It controls thinking, planning, organizing, short-term memory and movement (Abhang, Gawalin, Mehrotra 2016). 
(Coan, Allen, 2003), that may serve as an index of approach motivation or related emotion (that is activated when an individual is moving towards goals or experiences positive emotions). Conversely, relatively increased right-frontal activity may serve as an index of withdrawal motivation or related emotion (a lateralized withdrawal system is involved in negative affect or the motivation to move away from potentially dangerous situations or stimuli) (Davidson, 1998).

Frontal EEG asymmetry is now employed by scientists worldwide to study constructs such as temperament and personality, various types of psychopathology, motivation, emotion, and cognitive control. Although, according to Pizzagalli (2007) EEG is one of the more favorable brain imaging methods, (especially for use with infants and children), there is one major caveat of this methodology. The EEG signal has excellent temporal resolution, but it has poor spatial resolution. Apart from this issue, when conducting EEG research, scientists must prepare proper questions (as well as relevant stimuli), and the patient must be given instructions when the EEG is scheduled (including: not to consume alcohol, caffeine and cigarettes before the test, to avoid using hair styling products, sleep at least 8 hours, etc.).

It is worth to mention also about technology patented and used by Neuro-Insight (2019), known as Steady-State Topography (SST), that records and measures electrical signals at the scalp in order to build a second by second picture of activity in the brain. It is essentially a refinement of EEG, that offers serious advantages for marketing (a derivation of EEG/ERPs using an evoked potential to an ongoing oscillating stimuli). This method for observing and measuring human brain activity uses presence of a dim sinusoidal visual flicker presented in the visual periphery. The sinusoidal flicker elicits an oscillatory brain electrical response called Steady State Visually Evoked Potential (SSVEP), and neural speed can be calculated by measuring the delay between the visual flicker and the SSVEP response (Seixas et al., 2015). So task related changes in brain activity are determined from the SSVEP measurement and decreases in the magnitude of this potential are correlated with an increase in cognitive processing demand (Gordon, Ciorciari, 2017). Making the important distinction between EEG and SST, one must remember that EEG measures neural amplitude, which ambiguously describes a subject's brain activity, while SST measures the speed of electrical activity and has a higher signal to noise ratio. This means it provides clear insight into precise brain activity after only one test showing of an ad, while the other methods require 6 to 10 trials. SST overcame the short-comings of raw EEG which has "the potential for errors that is, interpreting spurious signals as real" (Neuro-insight, 2019).

And last but not least, the term quantitative EEG ( $q E E G$ ) requires further explanation. The qEEG is an extension of the analysis of the visual EEG interpretation which may assist and even augment our understanding of the EEG and brain function. This multi-channel EEG data is processed with various algorithms, such as the "Fourier" classically, or in more modern applications "Wavelet" analysis and the digital data is statistically analyzed. The processed EEG is commonly converted into color maps of brain functioning called "Brain maps". qEEG gives the ability to view the dynamic changes taking place throughout the brain during cognitive processing tasks, and this novel approach can be used to assist us in determining which areas of the brain are engaged 
and processing efficiently. The QEEG method is finding increasingly more users because it supports the biomarker hypothesis and allows for more precise information about the respective clinical picture (Qeegsupport, 2018).

\section{MEG}

Magnetoencephalography (MEG) is the measurement of the magnetic field generated by the electrical activity of neurons (Singh, 2014). MEG directly records the magnetic fields associated with synchronous activity of neuronal populations, and picks up transient and sustained evoked activity. It also records the magnetic fields rhythms with millisecond-range temporal resolution (Hari, Puce, 2017). As noticed by Singh (2014), the magnetic permeability of biological tissues is almost the same as that of empty space and so the magnetic field is not distorted by scalp or skull. Moreover, MEG is a noninvasive imaging technique that does not involve exposure to ionizing radiation, does not make any operational noise, and does not requires the complete absence of subject movement during recording. However, this expensive method requires a magnetically shielded room and superconducting quantum interference detectors to measure the weak magnetic signals in the brain.

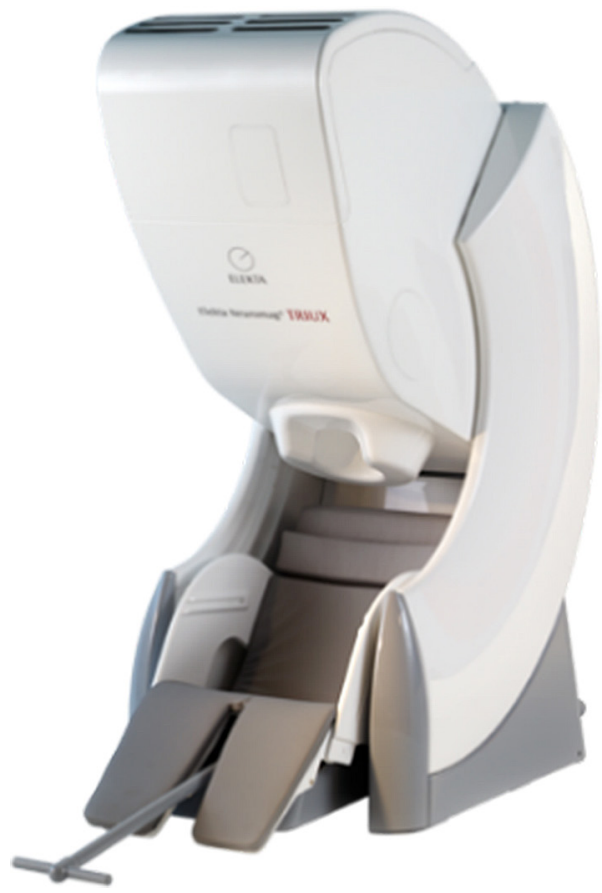

Figure 5. Latest generation MEG system

Retrieved from https://elekta.com/diagnostic-solutions. 
It is performed using a dewar that contains multiple sensor coils (the helmet looks like a large hair dryer), which do not touch the patient's head. At the cellular level, individual neurons in the brain have electrochemical properties that result in the flow of electrically charged ions through a cell, and the electromagnetic fields are generated by the net effect of this slow ionic current flow. While the magnitude of fields associated with an individual neuron is negligible, the effect of multiple neurons excited together $(50,000-100,000)$ in a specific area generates a measureable magnetic field outside the head. Due to the fact that these neuromagnetic signals generated by the brain are extremely small (a billionth of the strength of the earth's magnetic field), MEG scanners require superconducting sensors - SQUID, superconducting quantum interference device (that are bathed in a large liquid helium cooling unit at approximately -269 degrees $C$, and due to low impedance at this temperature, they can detect and amplify magnetic fields generated by neurons a few centimeters away from the sensors). A magnetically shielded room houses the equipment, and mitigates interference (Ilab.wahsington, 2018). This sophisticated instrument and computer software work together to detect and record the activity of neurons as the patient lies still or completes a series of tasks, such as listening to a series of words or looking at pictures (Radiologyinfo, 2018). Patients with a vagus nerve stimulator (VNS), pacemaker or similar device may not be able to undergo an MEG study. Furthermore, jewelry and other accessories should be removed prior to the MEG exam and participant should not wear makeup (which could include metallic substances) or hair products on the day of the procedure.

MEG is usually combined with a magnetic resonance imaging (MRI) to get a good structural perspective. This combination of MEG and MRI is called magnetic source imaging (MSI). Future MEG breakthroughs in understanding brain dynamics are expected through advanced signal analysis and combined use of MEG with hemodynamic-imaging ( $\mathrm{fMRI}$ ).

\section{TMS}

Transcranial Magnetic Stimulation (TMS) is a noninvasive method for local stimulation of cerebral cortex. TMS can be used not only to demonstrate causal brain-behavior relations, but by varying the duration and onset of the virtual lesion - TMS can also reveal the time course of normal processing. When applied to the scalp, the magnetic field induces electrical activity in the underlying brain tissue, temporarily disrupting local cortical information processing. This transient interference effectively creates a short-lasting "virtual lesion" (Sliwinska, Vitello, Devlin, 2014). Stimulation that interferes with task performance indicates that the affected brain region is necessary to perform the task normally.

This method relies upon the properties of electromagnetic induction - a rapidly changing magnetic field is generated when a high-voltage current is passed through a coil. As explained by Bolognini and Ro (2010), when this coil is held in close proximity to any electrically conducting medium, such as the brain, this time-varying magnetic field induces current in a direction opposite to the original current in the coil. So, through time-varying current in a stimulation coil, TMS generates strong alternating 
magnetic field pulses that can permeate the electrically poorly conducting skull and evoke action potential of neurons in the focus of the stimulation coil. Attenuated in the tissues of the head, a TMS pulse can effectively reach at least $3-4 \mathrm{~cm}$ below the scalp and this depth allows TMS to be used to probe, or treat, virtually the entire area of the human cortex (Goetz, Deng, 2017).

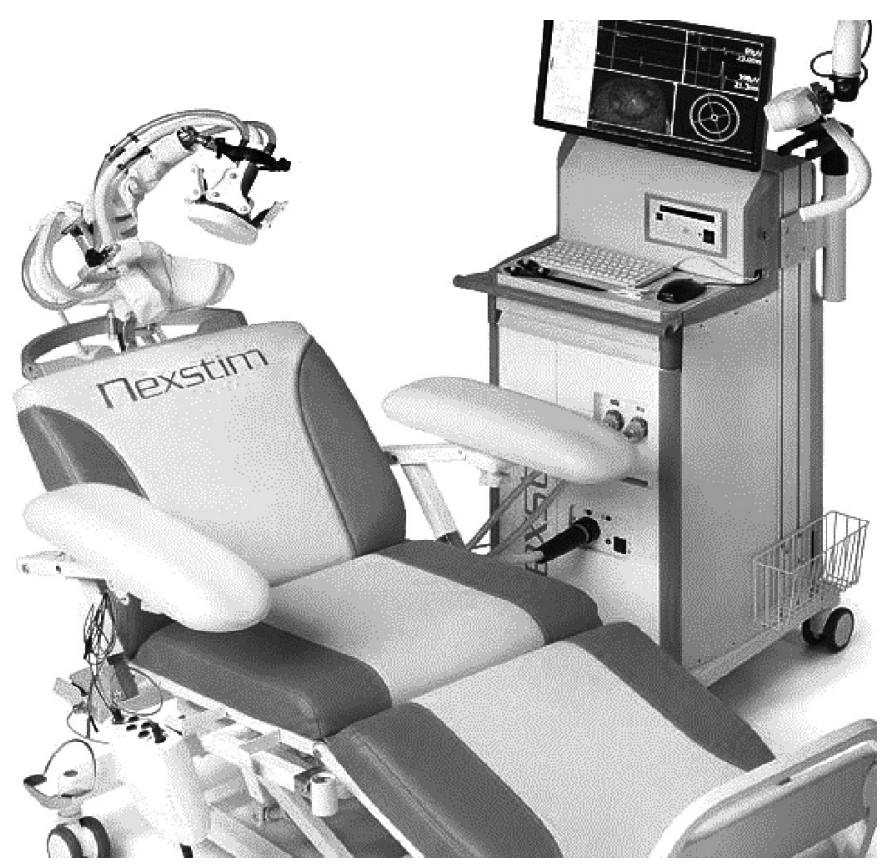

Figure 6. TMS + The NBT System

Retrieved from https://nexstim.com/healthcare-professionals/technology/.

Note: The Navigated Brain Therapy (NBT ${ }^{\oplus}$ ) System is a device that uses navigated transcranial magnetic stimulation (nTMS) for use in stroke rehabilitation. Navigation is achieved by visualizing the electric field (e-field) generated by the TMS coil in a 3D image rendered from the patient's MRI scan.

This technique offers a non-invasive method for drawing causal brain-behavior inferences and investigating the temporal dynamics of online neural information processing in both healthy adults and neurological patients. Depending on stimulation parameters, TMS can excite or inhibit the brain, allowing functional mapping of cortical regions and creation of transient functional lesions (Hallett, 2000). As indicated by Volz et al. (2014), unlike subthreshold neuromodulation techniques, TMS pulses can trigger a neuron's endogenous signal transmission mechanism, which amplifies the stimulus and transmits the signal to other neurons. Advantages of the technique over lesion-deficit studies include better spatial-temporal precision of the disruption effect, the ability to use participants as their own control subjects, and the accessibility of participants (since only individuals that have a pacemaker fitted or have any metal in or on their bodies and pregnant woman are unable to take part). Limitations listed 
Table 2. Neuromarketing Research Aims and Results Examples

\begin{tabular}{|c|c|c|c|c|}
\hline Method & $\begin{array}{l}\text { Au- } \\
\text { thors }\end{array}$ & Field & Research goal & Results \\
\hline PET & 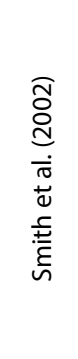 & 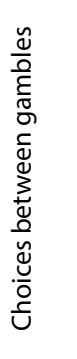 & 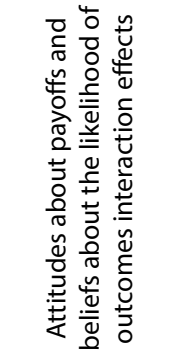 & $\begin{array}{l}\text { The interaction between belief structure (ambiguity/risk) } \\
\text { and payoff structure (gain/loss) shapes the distribution of } \\
\text { brain activity during choice. A simple manipulation of belief } \\
\text { structure and payoff structure produces focal activations } \\
\text { and deactivations that suggest two disparate, but func- } \\
\text { tionally integrated, choice systems with sensitivity to loss: a } \\
\text { neocortical dorsomedial system related to loss processing } \\
\text { when evaluating risky gambles, and a more primitive ven- } \\
\text { tromedial system related to processing of other stimuli. }\end{array}$ \\
\hline
\end{tabular}

\begin{tabular}{|c|c|c|c|c|}
\hline fMRI & 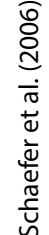 & 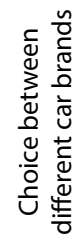 & 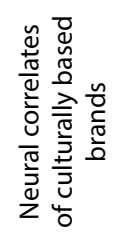 & $\begin{array}{l}\text { Activation of a single region in the medial prefrontal cortex } \\
\text { is related to the logos of the culturally familiar brands. The } \\
\text { results were interpreted as self-relevant processing induced } \\
\text { by the imagined use of cars with familiar brands, which } \\
\text { suggest that the prefrontal cortex plays a crucial role for } \\
\text { processing culturally based brands. }\end{array}$ \\
\hline
\end{tabular}

fNIR $\begin{array}{lll}\text { for } \\ \end{array}$

\begin{tabular}{llll}
\hline & & &
\end{tabular}




\begin{tabular}{lllll}
\hline Method $\begin{array}{c}\text { Au- } \\
\text { thors }\end{array}$ & Field & Research goal & Results \\
\hline MEG & & & &
\end{tabular}

Note. own elaboration.

by Sliwinska, Vitello and Devlin (2014) include concurrent auditory and somatosensory stimulation that may influence task performance, limited access to structures more than a few centimeters from the surface of the scalp, and the relatively large space of free parameters that need to be optimized in order for the experiment to work.

\section{Conclusions}

The increasing popularity of using neuroscientific methods as a tool in new domains is due to the limited possibilities available in classical market research. Although understanding how customers think, feel, and respond to a company's offerings has always been rather difficult (Hsu, 2017), consumer neuroscience helps obtain a more complete and objective understanding of consumer desires, which may consequently assist companies to adjust their marketing strategies (Hubert, 2010). The field of neuromarketing should be considered a legitimate and important area for future research, despite the publics lack of knowledge on its practice by companies, physicians, and scientists. What is more, lack of validation of neuromarketing techniques in controlled academic studies has been a sore spot for years (Fisher, Chin, Klitzman, 2010) with neuromarketing companies bearing no special duty towards transparency. Since neuromarketing has socially and ethically relevant implications it is important to raise considerations for the responsible conduct of research and the public understanding of neuroscience. This is all the more important when descriptions of neuroscience research are accompanied by images of the brain - even though these images may have no actual impact on the objective validity of those findings (the colorful results appear as such only after 
extensive image processing and statistical analyses, and in the context of a specific experimental paradigm).

\section{References}

1. Abhang P.A., Gawali B.W., Mehrotra S.C. (2016). Introduction to EEG-and Speech-based Emotion Recognition. Academic Press.

2. Ariely D., Berns G.S. (2010). Neuromarketing: the hope and hype of neuroimaging in business. Nat. Rev. Neurosci., 11, pp. 284-292.

3. Ayaz H., Shewokis P.A., Curtin A., Izzetoglu M., Izzetoglu K., Onaral B. (2011). Using MazeSuite and functional near infrared spectroscopy to study learning in spatial navigation. JoVE, 56, pp. $1-13$.

4. Aya H., Onaral B., Izzetoglu K., Shewokis P.A., McKendrick R., Parasuraman R. (2013). Continuous monitoring of brain dynamics with functional near infrared spectroscopy as a tool for neuroergonomic research: empirical examples and a technological development. Frontiers in human neuroscience, 7, p. 871.

5. Batula A.M., Mark J.A., Kim Y.E., Ayaz H. (2017). Comparison of brain activation during motor imagery and motor movement using fNIRS. Computational intelligence and neuroscience, 4.

6. Bell M.A., Cuevas K. (2012). Using EEG to study cognitive development: Issues and practices. Journal of Cognition and Development, 13(3), pp. 281-294.

7. Biopac. (2019, May 21). Continuous wave fNIR spectroscopy: affordable cognitive assessment. Retrived from https://biopac.com/product-category/research/fnir-optical-brain-imaging

8. Bolognini N., Ro T. (2010). Transcranial magnetic stimulation: disrupting neural activity to alter and assess brain function. Journal of Neuroscience, 30(29), pp. 9647-9650.

9. Brig S.A., Col H.S.L. (2009). Clinical applications of PET and PET-CT. Medical Journal Armed Forces India, 65(4), pp. 353-358.

10. Chow M.S., Wu S.L., Webb S.E., Gluskin K., Yew D.T. (2017). Functional magnetic resonance imaging and the brain: A brief review. World Journal of Radiology, 9(1), p. 5.

11. Coan J.A., Allen J.J. (2003). Frontal EEG asymmetry and the behavioral activation and inhibition systems. Psychophysiology, 40(1), pp. 106-114.

12. Cope M. (1991). The Development of a near Infrared Spectroscopy System and Its Application for Non Invasive Monitory of Cerebral Blood and Tissue Oxygenation in the Newborn Infants. University of London, London, UK.

13. Davidson R.J. (1998). Affective style and affective disorders: Perspectives from affective neuroscience. Cognition, Emotion, 12(3), pp. 307-330.

14. D'Hondt F., Lassonde M., Collignon O., Lepore F., Honore J., Sequeira H. (2013). Emotions guide us: behavioral and MEG correlates. Cortex, 49(9), pp. 2473-2483.

15. Elekta (2019). Diagnostic Solutions. Retrived from https://elekta.com/diagnostic-solutions

16. Eu.medical.canon (2019). Canon medical systems Europe B.V. Retrived from https://eu.medical.canon/product-solutions/computed-tomography/celesteion-pet-ct/

17. Fisher C.E., Chin L., Klitzman R. (2010). Defining neuromarketing: Practices and professional challenges. Harvard Review of Psychiatry, 18(4), pp. 230-237. 
18. Garczarek-Bąk U., Disterheft A. (2018). EEG frontal asymmetry predicts product purchase differently for national brands and private labels. Journal of Neuroscience, Psychology, and Economics, 11(03), 182-195..

19. Genco S., Pohlmann A., Steidl P. (2013). Cheat sheet. Neuromarketing for Dummies.

20. Glover G.H. (2011). Overview of functional magnetic resonance imaging. Neurosurgery Clinics, 22(2), pp. 133-139.

21. Goetz S.M., Deng Z.D. (2017). The development and modelling of devices and paradigms for transcranial magnetic stimulation. International Review of Psychiatry, 29(2), pp. 115-145.

22. Gordon R., Ciorciari J. (2017). Social marketing research and cognitive neuroscience. [In:] Formative Research in Social Marketing. Springer, Singapore, pp. 145-163.

23. Hallett M. (2000). Transcranial magnetic stimulation and the human brain. Nature, 406(6792), p. 147.

24. Hare R.D., Smith A.M., Forster B.B., MacKay A.L., Whittall K.P., Kiehl K.A., Liddle P.F. (1998). Functional magnetic resonance imaging: the basics of blood-oxygen-level dependent (BOLD) imaging. Canadian Association of Radiologists Journal, 49(5), p. 320.

25. Hari R., Puce A. (2017). MEG-EEG Primer. Oxford University Press.

26. Holmqvist K., Nyström M., Andersson R., Dewhurst R., Jarodzka H., Van de Weijer J. (2011). Eye tracking: A comprehensive guide to methods and measures. OUP Oxford.

27. Hsu M. (2017). Neuromarketing: inside the mind of the consumer. California Management Review, 59(4), pp. 5-22.

28. Hubert M. (2010). Does neuroeconomics give new impetus to economic and consumer research? Journal of Economic Psychology, 31(5), pp. 812-817.

29. Huettel SA, Song AW, McCarthy G. (2009). Functional Magnetic resonance imaging. Mass: Sinauer Associates, Sunderland.

30. Ilab.wahsington (2018). Retrived from https://ilabs.washington.edu/what-magnetoencephalography-meg

31. Imotions (2019). Hardware specifications. Retrived from https://imotions.com/hardware/ abm-b-alert-x24/

32. Jackson P.A., Kennedy D.O. (2013). The application of near-infrared spectroscopy in nutritional intervention studies. Front. Hum. Neurosci, 7, p. 473.

33. Jones T., Townsend D.W. (2017). History and future technical innovation in positron emission tomography. Journal of Medical Imaging, 4(1), 011013.

34. Kaur J., Kaur A. (2015). A review on analysis of EEG signals. International Conference on Advances in Computer Engineering and Applications, pp. 957-960.

35. KCE (2009). The value of EEG and evoked potentials in clinical practice KCE reports 109C. Retrived from https://kce.fgov.be/sites/default/files/atoms/files/d20091027323.pdf

36. Kopton I.M., Kenning P. (2014). Near-infrared spectroscopy (NIRS) as a new tool for neuroeconomic research. Frontiers in human neuroscience, 8, p. 549.

37. Krampe C., Strelow E., Haas A., Kenning P. (2018). The application of mobile fNIRS to "shopper neuroscience" - first insights from a merchandising communication study. European Journal of Marketing, 52(1/2), pp. 244-259.

38. Lai C.H., Yen T.C., Chang T.C. (2007). Positron emission tomography imaging for gynecologic malignancy. Current Opinion in Obstetrics and Gynecology, 19(1), pp. 37-41. 
39. Langer A. (2010). A systematic review of PET and PET/CT in oncology: A way to personalize cancer treatment in a cost-effective manner? BMC Health Services Research, 10(1), p. 283.

40. Light G.A., Williams L.E., Minow F., Sprock J., Rissling A., Sharp R., Braff D.L. (2010). Electroencephalography (EEG) and event-related potentials (ERPS) with human participants. Current Protocols in Neuroscience, 52(1), pp. 6-25.

41. Lin M.H., Cross S.N., Jones W.J., Childers T.L. (2018). Applying EEG in consumer neuroscience. European Journal of Marketing, 52(1/2), pp. 66-91.

42. Medlineplus (2018). PET scan. Retrived from https://medlineplus.gov/ency/article/003827. htm

43. Meyerding S.G., Mehlhose C.M. (2018). Can neuromarketing add value to the traditional marketing research? An exemplary experiment with functional near-infrared spectroscopy (fNIRS). Journal of Business Research.

44. Mostafa M.M. (2012). Brain processing of vocal sounds in advertising: A functional magnetic resonance imaging (fMRI) study. Expert Systems with Applications, 39(15), pp. 12114-12122.

45. Neuro-insight (2019). SST methodology. Retrived from https://www.neuro-insight.com/science-and-technology.

46. Nexstim (2019). TMS solutions based on science. Retrived from https://nexstim.com/healthcare-professionals/technology/.

47. Ohme R., Reykowska D., Wiener D., Choromanska A. (2010). Application of frontal EEG asymmetry to advertising research. Journal of Economic Psychology, 31(5), pp. 785-793.

48. Pitcher D., Goldhaber T., Duchaine B., Walsh V., Kanwisher N. (2012). Two critical and functionally distinct stages of face and body perception. Journal of Neuroscience, 32(45), pp. 1587715885.

49. Pizzagalli D.A. (2007). Electroencephalography and high-density electrophysiological source localization. [In:] Cacioppo J.T., Tassinary L.G., Berntson G.G. (Eds.) Handbook of Psychophysiology. 3. Cambridge University Press, Cambridge, pp. 56-84.

50. Qeegsupport (2018). What is qEEG/Brain Mapping? Retrieved from https://qeegsupport. com/what-is-qeeg-or-brain-mapping/.

51. Radiologyinfo (2018). Magnetoencephalography. Retrived from https://www.radiologyinfo. org/en/info.cfm?pg=meg

52. Ruanguttamanu, C. (2014). Neuromarketing: I put myself into a fMRI scanner and realized that I love Louis Vuitton ads. Procedia-Social and Behavioral Sciences, 148, pp. 211-218.

53. Schaefer M., Berens H., Heinze H-J., Rotte M. (2006). Neural correlates of culturally familiar brands of car manufacturers. Neuroimage, 31, pp. 861-865.

54. Scholkmann F., Kleiser S., Metz A.J., Zimmermann R., Pavia J.M., Wolf U. (2013). A review on continuous wave functional near-infrared spectroscopy and imaging instrumentation and methodology. Neuroimage 85, pp. 6-27.

55. Schwarzkopf S. (2015). Measurement devices and the psychophysiology of consumer behaviour: A posthuman genealogy of neuromarketing. BioSocieties, 10(4), pp. 465-482.

56. Sebastian V. (2014). Neuromarketing and evaluation of cognitive and emotional responses of consumers to marketing stimuli. Procedia-Social and Behavioral Sciences, 127, pp. 753-757.

57. Seixas S.A., Nield G.E., Pynta P., Silberstein R.B. (2015). The Neuroscience of Social Television. [In:] Handbook of Research on Integrating Social Media into Strategic Marketing. IGI Global, pp. 153-166. 
58. Seraglia B., Gamberini L., Priftis K., Scatturin P., Martinelli M., Cutini S. (2011). An exploratory fNIRS study with immersive virtual reality: a new method for technical implementation. Frontiers in Human Neuroscience, 5, p. 176.

59. Siemens-healthineers. (May, 14). Magnetic Resonance Imaging. Retrived from https://www. siemens-healthineers.com/en-ca/magnetic-resonance-imaging

60. Sliwinska M.W., Vitello S., Devlin J.T. (2014). Transcranial magnetic stimulation for investigating causal brain-behavioral relationships and their time course. Journal of Visualized Experiments, 89.

61. Smith K., Dickhaut J., McCabe K., Pardo J.V. (2002). Neuronal substrates for choice under ambiguity, risk, gains, and losses. Management science, 48(6), pp. 711-718.

62. Smith E.E., Reznik S.J., Stewart J.L., Allen J.J. (2017). Assessing and conceptualizing frontal EEG asymmetry: An updated primer on recording, processing, analyzing, and interpreting frontal alpha asymmetry. International Journal of Psychophysiology, 111, pp. 98-114.

63. Shimokawa T., Suzuki K., Misawa T., Miyagawa K. (2009). Predictability of investment behavior from brain information measured by functional near-infrared spectroscopy: a Bayesian neural network model. Neuroscience, 161, pp. 347-358.

64. Shokouhi S., Claassen D., Riddle W.R. (2014). Imaging brain metabolism and pathology in Alzheimer's disease with positron emission tomography. Journal of Alzheimer's disease, Parkinsonism, 4(2).

65. Singh S.P. (2014). Magnetoencephalography: basic principles. Annals of Indian Academy of Neurology, 17(1), S107.

66. Slough C., Masters S.C., Hurley R.A., Taber K.H. (2016). Clinical Positron Emission Tomography (PET) Neuroimaging: Advantages and Limitations as a Diagnostic Tool. The Journal of Neuropsychiatry and Clinical Neurosciences, 28(2), pp. 4-71.

67. Vaquero J.J., Kinahan P. (2015). Positron emission tomography: current challenges and opportunities for technological advances in clinical and preclinical imaging systems. Annual Review of Biomedical Engineering, 17, pp. 385-414.

68. Volz L.J., Hamada M., Rothwell J.C., Grefkes C. (2014). What Makes the Muscle Twitch: Motor System Connectivity and TMS-Induced Activity. Cerebral Cortex, 25(9), pp. 2346-2353.

69. Zurawicki L. (2010). Neuromarketing: Exploring the brain of the consumer. Springer Science, Business Media. 
Romanowski R. (Ed.): Managing Economic Innovations - Methods and Instruments

Bogucki Wyd. Nauk., Poznań 2019. ISBN 978-83-7986-277-1

DOI: $10.12657 / 9788379862771-5$

\title{
Chapter 5
}

\section{Measurement of Electrodermal Activity in Marketing Research}

\author{
Sylwester Białowąs, Adrianna Szyszka
}

\begin{abstract}
The paper presents the method of measuring electrodermal activity (EDA), its essential elements, assumptions related to the concept, and its possibilities in marketing research. The article also discusses examples of using EDA, together with other measurement methods. The aim of this chapter is also to present the methods of EDA measurement and to discuss the basic indicators and their interpretation.
\end{abstract}

Keywords: electrodermal activity, measurement, EDA, GSR, Galvanic Skin Response, marketing research, psychophysiological methods, consumer behaviour

\section{Introduction}

The subject of consumer research is the best possible understanding of consumer behaviour in response to specific stimuli. The existing methods of measuring such reactions, i.e. self-descriptive and behavioural methods, despite their undeniable advantages, also have their limitations. For this reason, psychophysiological methods have been used in marketing research in order to thoroughly examine the mechanisms of the human mind, taking into account the role of psychological processes. An unques-

Sylwester Białowąs: Associate Professor at Department of Market Research and Services Management, Institute of Marketing, Poznan University of Economics, ORCID: https://orcid.org/0000-0003-4575-5346, sylwester.bialowas@ue.poznan.pl

Adrianna Szyszka: PhD Student at Department of Market Research and Services Management, Institute of Marketing, Poznan University of Economics, ORCID https://orcid.org/0000-0002-1389-2365, adrianna. szyszka@ue.poznan.pl 
tionable advantage of psychophysiological methods is the fact that they enable the examination of such reactions of an individual that are not subject to its volitional control. One of these methods is the measurement of electrodermal activity as changes in the electrical properties of the skin are an autonomous reaction of the human body to the action of external stimuli. For this reason, the EDA measurement is also used in marketing as it allows us to examine consumer reactions concerning advertisements, products or trade fair stands. The purpose of this chapter is to present the EDA measurement and to determine its applicability in marketing research.

\section{Electrodermal activity (EDA) - essence and a short history}

Electrodermal activity (EDA) is considered as all electrical reactions generated by the skin and registered on its surface (Sosnowski, 1993). The term was first introduced in 1966 by Johnson and Lubin, but research in this field dates back to the 19th century (Boucsein, 2012). EDA is a measure of psychophysiological activity, which is an indicator of changes in the arousal of the sympathetic system. It is worth noting that it is the only psychophysiological parameter sensitive to changes in emotional states or cognitive activity, that is not affected by the activity of the parasympathetic system (Braithwaite, Watson, Jones, Rowe, 2013). Electrodermal activity is connected with the stimulation of the sympathetic system that operates during heightened alertness. This is accompanied by specific physiological reactions, such as sweat production, pupil enlargement or a change in breathing rate (Bell et al., 2018).

The first studies on electrodermal activity date back to 1879 when Vigoroux observed changes in the level of skin resistance while examining patients suffering from hysteria. The achievements of the French neurologist Charles Féré, who is considered a pioneer in galvanic skin reflex (GSR) research, were also particularly outstanding. In his research, Féré also focused on hysterical patients, noticing that a low current flow between two electrodes placed on the surface of the skin makes it possible to observe changes in resistance depending on the implied stimuli. Féré also pointed out that in the presence of an external stimulus, the skin becomes a better current conductor (Dawson, Schell, Filion, 2007; Neumann, Blanton, 1970). The physiologist Ivan Tarchanoff conducted his research on the electrical properties of the skin simultaneously, with a focus on the mechanisms behind the changes in skin conductance. Tarchanoff noticed that the electrodermal phenomena are determined by the activity of sweat glands and compared the reactions resulting from the current flow in places of different density of these glands. Tarchanoff also proved that it is possible to study changes in the electrical potential of the skin using two electrodes placed on its surface, without using an external power source (Neumann, Blanton, 1970).

Electrodermal activity is also present in the literature under the concept of galvanic skin response (GSR) or galvanic skin reflex (GSR). This term implies that the skin works exclusively as a galvanic cell, i.e. it generates an electric current through the chemical reaction resulting from the electrical contact of two different metals. However, the term is no longer used as it does not fully reflect the complexity of electrodermal skin 
reactions (Boucsein, 2012). Using the concept of galvanic skin reflex may also indicate that the observed electrodermal phenomena are reflective and do not include psychologically induced reactions (Handler, Nelson, Krapohli, Honts, 2010). Moreover, the ambiguity of the concept of galvanic skin reaction results from the fact that this term was used not only to describe phase responses, but also the whole electrodermal activity, including, among others, tonic reactions (Boucsein, 2012).

Changes in the electrical properties of the skin result from the activity of eccrine sweat glands and the processes occurring in the outer layer of the skin (Jagielnicki, 2010). Due to the fact that sweat is an electrolyte solution, the more pores are filled with sweat, the more skin conductance increases (Figner, Murphy, 2011). Thermoregulation is the main function of most eccrine sweat glands. However, it is believed that glands on the palmar and plantar surface are more sensitive to psychological stimuli than to thermal stimuli. In spite of the fact that eccrine glands are thought to be involved in mental sweating, this kind of sweating is usually most apparent on the palm and foot surfaces due to the high density of sweat glands in these areas (Dawson et al., 2007). From the point of view of marketing research, the focus is on the measurement of the electrical activity of the skin associated with the psychologically induced activity of sweat glands. While considering the importance of skin conductance as an indicator of emotional stimulation, it is particularly interesting that parts of the brain such as the amygdala, hippocampus and prefrontal cortex, which are responsible for higher mental activity, are involved in the control of eccrine gland activity as well. It is worth noting that these are parts of the limbic system, which is particularly important in the regulation of affective processes. Additionally, it has been observed that reflex skin conductance responses caused by emotionally uncharacterized stimuli do not require the involvement of designated brain areas responsible for higher mental functions (Figner, Murphy, 2011; Naqvi, Bechara, 2006).

\section{Measurement methods, tonic and phase activity}

The research conducted by Féré and Tarchanoff allowed for the separation of two primary methods of measurement of electrodermal activity:

- exosomatic method;

- endosomatic method.

The object of measurement in the exosomatic method is skin conductance or skin resistance. The measurement of electrodermal activity is performed by applying an external current source (Dawson et al., 2007; Handler et al., 2010). In the case of constant voltage, the electrical activity of the skin is recorded in units of skin conductance (SC). On the other hand, skin resistance (SR) can be studied if the current is maintained at a constant level (Boucsein, 2012).

The endosomatic method, on the other hand, examines electrical potential of the skin without the use of an external source of current, i.e. solely based on the electrical activity of sweat glands. This measurement depends on determining the difference in 
potentials between a selected measurement point and a reference point (i.e. between a place with higher and lower electrodermal activity) (Handler et al., 2010; Jagielnicki, 2010).

Concerning electrodermal activity, two basic elements can be distinguished: tonic and phase activity (Sosnowski, 1993). Tonic activity is an expression of changes occurring in the general level of autonomous stimulation (Bazarnik, 2016) and refers to the characteristics of the background signal (i.e. general level, slow increase or slow decrease in time) (Braithwaite et al., 2013). In the case of the tonic level, there are only slight changes over several dozen seconds or several minutes. Moreover, there are significant individual differences in this parameter, limiting the usefulness of tonic activity in marketing and other analyses (IMotions, 2017). From this point of view, much broader interpretative possibilities exist in the case of the second component of electrodermal activity - phase activity. This term refers to any rapid reactions in the skin conductance, usually caused by external or internal stimuli (Sosnowski, 1993). It should be noted, however, that some phase electrodermal reactions occur without stimuli and are referred to as non-specific or spontaneous electrodermal reactions (Boucsein, 2012). They can be observed in the body generally every 1-3 minutes. Unlike non-specific reactions, changes in skin conductance caused by specific stimuli occur within 1-5 seconds after their occurrence (IMotions, 2017).

\section{The subject of measurement}

Depending on the method of measurement and the component of electrodermal activity, it is possible to measure a number of parameters. The exosomatic method is used to measure the skin conductance, the unit of which is siemens, and the skin resistance, which is expressed in ohms. Within the tonic activity, the subject of measurement is, therefore, the skin conductance level ( $\mathrm{SCL}$ ) and skin resistance level (SRL). Phase activity parameters measured in this way include the skin conductance response (SCR) and skin resistance response (SRR). The endosomatic method is used to measure the skin potential, which is expressed in microvolts. In terms of tonic activity, the skin potential level (SPL) is measured and in the case of phase activity - the skin potential response (SPR) (Boucsein, 2012; Handler et al., 2010; Shaffer, Combatalade, Peperi, Meehan, 2016; Sosnowski, 1993).

The most popular way of measuring electrodermal activity is an exosomatic method. It may be divided into two types - with direct current (DC) and alternating current (AC) (which is rarely used). Measurement of EDA while using the direct current method may be performed using two techniques - direct voltage or direct current. The constant current method allows for the measuring of skin resistance - if a constant current of low intensity is applied to two electrodes placed on the skin, it is possible to measure changes in voltage, which are directly proportional to changes in resistance. In the case of constant voltage technology, skin conductance is measured (Boucsein, 2012; Handler et al., 2010). Direct current measurement using a DC voltage system is the most 
widely used method for observing both phase and tonic electrical activity of the skin (Boucsein et al., 2012).

\section{EDA measurement indicators}

For the purposes of marketing research, it is worth looking at the indicators to interpret and compare during the EDA measurement. Due to the fact that the most frequently tested property is skin conductance, the most popular parameters describing this characteristic will be presented below. The basic parameter is the signal value, which gives information about the signal level at a given point. The recording of electrodermal activity provides information about the mean and standard deviation of the skin conductance response (SCR) - these measures include converting raw SCR into a standardised Z-result (with a normal distribution, a mean of 0 and a standard deviation of 1 ). The most commonly used measure of phase activity is amplitude, which is calculated as the difference between peak skin conductance response (SCR) and the low point before this peak (BIOPAC, 2017; Braithwaite et al., 2013; Naqvi, Bechara, 2006). In other words, it is a phase increase in skin conductance shortly after the onset of the stimulus (Dawson et al., 2007). With this technique, it is possible to measure the change in the skin conductance response to a stimulus over a specific time period (Naqvi, Bechara, 2006). The programs accompanying the measurement equipment provide the possibility to determine the maximum ( $\max$ ) and minimum ( $\min$ ) values, i.e. the highest or lowest amplitude of data samples between the endpoints of the selected area (BIOPAC, 2017). The interpretation of the results also may include the information on the frequency of the response, which refers to the number of single responses triggered by the stimulus presentation or to non-specific reactions in a given period of time not triggered by stimulus (NS-SCR) (Braithwaite et al., 2013). The basic parameters of electrodermal changes include latency, i.e. the period from the moment the stimulus is triggered to the moment the reaction occurs. The rise time is the interval between the beginning of the skin conductance response (SCR) and its peak. A commonly used measure is also the half recovery time, which means the time between the occurrence of the SCR peak and the point at which $50 \%$ of the SCR amplitude occurs, i.e. the time when the signal decreases by 50\% (Dawson et al., 2007; Figner, Murphy, 2011). When a stimulus occurs several times during measurement, and the mean skin conductance response (SCR) can be calculated, it is also possible to determine the mean amplitude or magnitude of the skin conductance response. Magnitude is defined as the mean value calculated for all observed stimuli, including those with a zero measurement value (i.e. including cases where no response occurred), while amplitude refers to the mean value calculated only for those with a measurable, i.e. non-zero response (Dawson et al., 2007; Sosnowski, 1993). A less frequently used parameter is the delta, which indicates the difference between the amplitude values at the endpoints of a selected area. If the cycles are defined (this can be done using "Find cycle" software functions), it allows the observing of the difference between the values if the onset and skin conductance response are defined as an initial and final event. In this case, it is the equivalent of the amplitude value in the analysis panel of a specific event (BIOPAC, 2017; Braithwaite et al., 2013). 


\section{Principles of conducting research on electrodermal activity}

Electrodermal activity measurement is carried out with the use of special electrodes, electrode gels and recording devices. Most researchers record EDA by placing electrodes on the surface of the fingers or hands. It is particularly recommended to place the electrodes at the middle phalanges of the index and middle finger. This is due to the fact that these are areas of high electrodermal activity where the electrodes can be easily attached and which, at the same time, are not susceptible to interference by motion. Another recommended location is the palm at the wrist and the middle of the foot (Boucsein, 2012; Handler et al., 2010). Electrodes made of metal are most often used to perform the test while those made of other materials (e.g. carbon electrodes) are used less often. Usually, the measurement is performed with silver electrodes or silver electrodes covered with silver chloride, i.e. electrodes made of metal in contact with the solution of its own ions. In a DC system, it is particularly important to use the same metal for both electrodes - otherwise, the potential difference generated by different metals will polarise the electrodes. It is recommended that the contact surface of the electrodes with the skin should be one $\mathrm{cm}^{2}$ (Fowles et al., 1981). There should also be a conductive gel between the electrodes and the skin as it is important to use a substance that preserves the electrical properties of the system. Since current flows through the skin when measuring electrodermal activity and the conductive gel interacts with the tissue on which it is placed, it is recommended to use a product with a similar salinity level to the skin (Dawson et al., 2007; Fowles et al., 1981). EDA is measured basically using an electrode gel containing chloride salt, with sodium chloride $(\mathrm{NaCl})$ being the most commonly used (Boucsein et al., 2012).

The proper use of psychophysiological methods - including measurement of electrodermal activity - requires the application of several fundamental principles. Improper test procedure carries the risk of excessive simplification and may lead to erroneous conclusions. When analysing the electrical activity of the skin in response to the stimulus exposure, it is important to remember about additional sources of information necessary for its interpretation. It is crucial to understand the context in which the stimulus is applied, to know the psychophysiological properties of the body and to identify other events that may influence the observed processes (Stewart, Furse, 1982). When designing a study of electrodermal activity, one should bear in mind the risk of artefacts i.e. changes in the recorded signal that does not originate from its source, but are the result of the recording procedure or physiological reactions not related to the electrical properties of the skin. One of the most frequent sources of interference in the measurement of electrodermal activity is motion - this applies not only to the areas where the electrodes are placed but also to muscle work in areas not adjacent to the apparatus, e.g. as a result of violent gestures (Boucsein, 2012; Boucsein et al., 2012). Further sources of artefacts include ambient noise, speech and physiological reactions such as coughing, sneezing or irregular and deep breathing (Boucsein et al., 2012). When measuring the electrodermal activity, care must be taken to ensure that the skin is properly prepared. Even washing hands with soap before the procedure may cause swelling of the skin and reduce its conductance (Lajante, Droulers, Dondaine, Amarantini, 2012). The result can be unreliable if the electrodes break away from the skin, if they are too 
loosely attached or if there are problems with the cable connections. Avoid additional wrapping of the electrodes placed on the skin - this can put pressure on the skin and cause additional stimulus. Artefacts also occur when a test is performed in a magnetic field or outside a laboratory. Disturbances in measurement may also result from the placement of the test equipment on the dominant hand - the skin of the dominant hand is more often physically burdened, and its stratum corneum is usually thicker, which may affect the precision of measurement (Boucsein, 2012; Boucsein et al., 2012). When performing an electrodermal activity test, it should be remembered that the result may also depend on factors such as room temperature and humidity, daily rhythm and time of day, caffeine, medication or nicotine intake, as well as a previous exercise by the participant (Bell et al., 2018).

When making the analysis, it is worth considering that the source of variability of the obtained EDA results can also be demographic factors such as age, gender or culture (Boucsein et al., 2012). For example, when it comes to age-related differences, a significant negative relationship between age and skin conductance was observed in the studies of Barontini, Lázzari, Levin, Armando, Basso (1997). The level of skin conductance for older people is lower than for young adults. The study of Zelinski, Walsh, Thompson (1978) showed a lower phase activity in older people - comparison of mean skin conductance reactions (SCR) during the memory test resolution indicated that the level of this indicator was higher in young people.

Conducting electrodermal activity testing requires control of factors that may be potential sources of deviation in recording the results. When it comes to environmental conditions, among others, proper ambient temperature should be provided. It is recommended that the room where the test is performed should have a temperature of $22-24^{\circ} \mathrm{C}$. However, this range is not appropriate for all conditions - it is recommended to adjust the temperature to the season of the year and the type of activity the participant performs during the study). Keeping the balance between too high (excessive sweating) and too cold (insufficient sweating) temperature is necessary. It is worth remembering that the EDA measurement is most often carried out in the laboratory, with participants most often being passive - higher temperatures are then recommended (Boucsein, 2012; Braithwaite et al., 2013).

\section{Use of measuring electrodermal activity in marketing research}

The specific electrical properties of the skin are the subject of analyses due to its dynamic changes and their relationship with psychological processes associated with sympathetic stimulation. Thus, measuring the electrical activity of the skin can provide information on the emotional aspects of decisions or assessments made (Figner, Murphy, 2011). EDA can be used as a measure of hidden emotional reactions, appearing without the participation of consciousness or going beyond cognitive control, in a situation of danger, anticipation, news or confrontation with a distinctive stimulus (Braithwaite et al., 2013). EDA finds application as an indicator of processes such as attention, habituation, arousal and cognitive effort, which is used in research in many disciplines 
(Figner, Murphy, 2011). Studies on the electrical activity of the skin are used, among others in research in the field of psychopathology, personality disorders, conditioning or neuropsychology, as well as in marketing (Braithwaite et al., 2013).

What is particularly worth emphasising is that in recent years, there has been a noticeable increase in the number of publications on electrodermal activity (Figure 1). The number of searches for the phrase "electrodermal activity" in the EBSCO database indicates that the term appeared in 2020 publications from 1963 to 2018 . Almost 35\% of these sources (i.e. 705 publications) come from the last five years. An upward trend is observable when it comes to the number of search results for the concept of electrodermal activity in the last 25 years - this indicates that there are more and more publications about this method or research using it. EDA measurement is also a tool used in marketing research as EBSCO provides information on 18 such publications (the search criteria were the phrases "electrodermal activity" and "marketing"). It is worth noting that as many as 13 sources were created in the last five years. Considering that electrodermal activity has been present in literature for a long time under the term galvanic skin response, it is also worth looking at the number of searches for this phrase. This phrase appears in 10,741 publications, and the first sources come from 1945. Over 30\% of searches (i.e. 3531) relate to works created in the last decade (Figure 2, note: the chart has a different scale than Figure 1) - this is more than half more than a decade earlier. The measurement of galvanic skin response has also been used in marketing research - since 1970 the term appears in 43 sources, of which over $80 \%$ have appeared in the last ten years (information applies to the simultaneous search for "galvanic skin response" and "marketing").

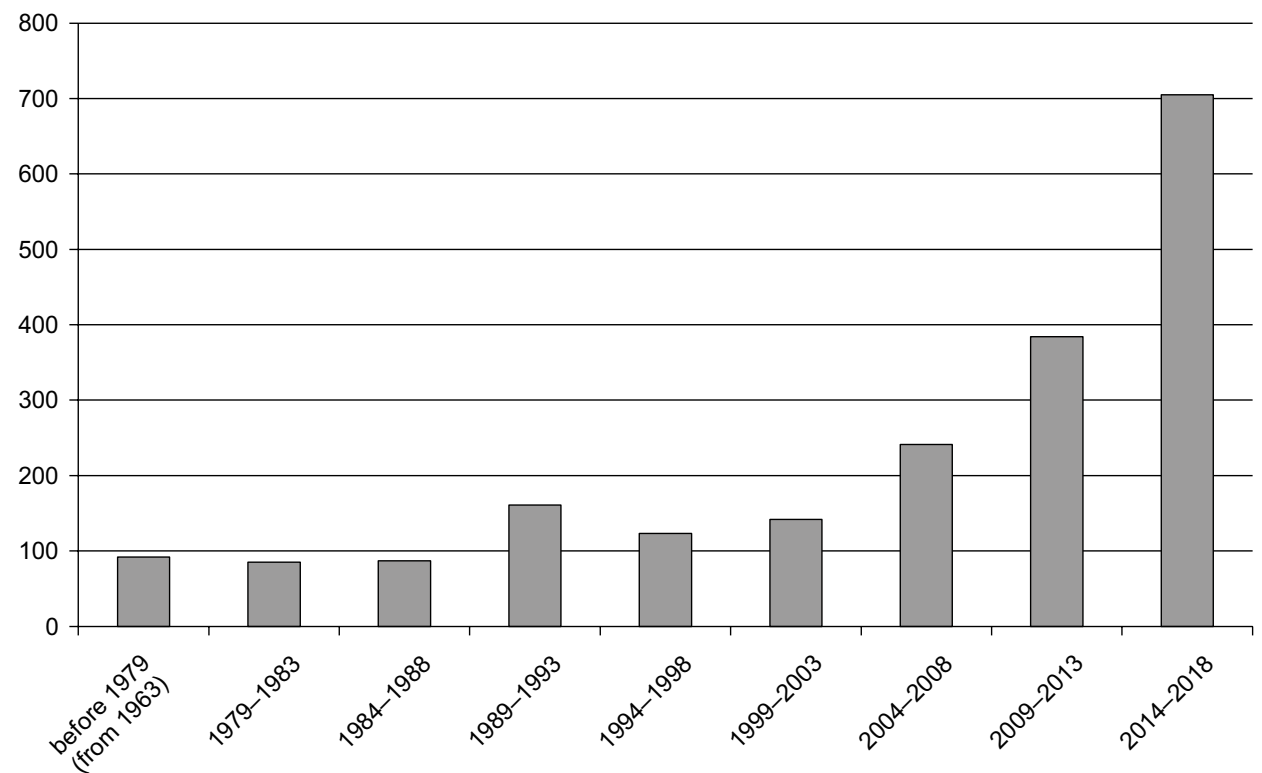

Figure 1. The number of searches for the phrase electrodermal activity in the EBSCO database 


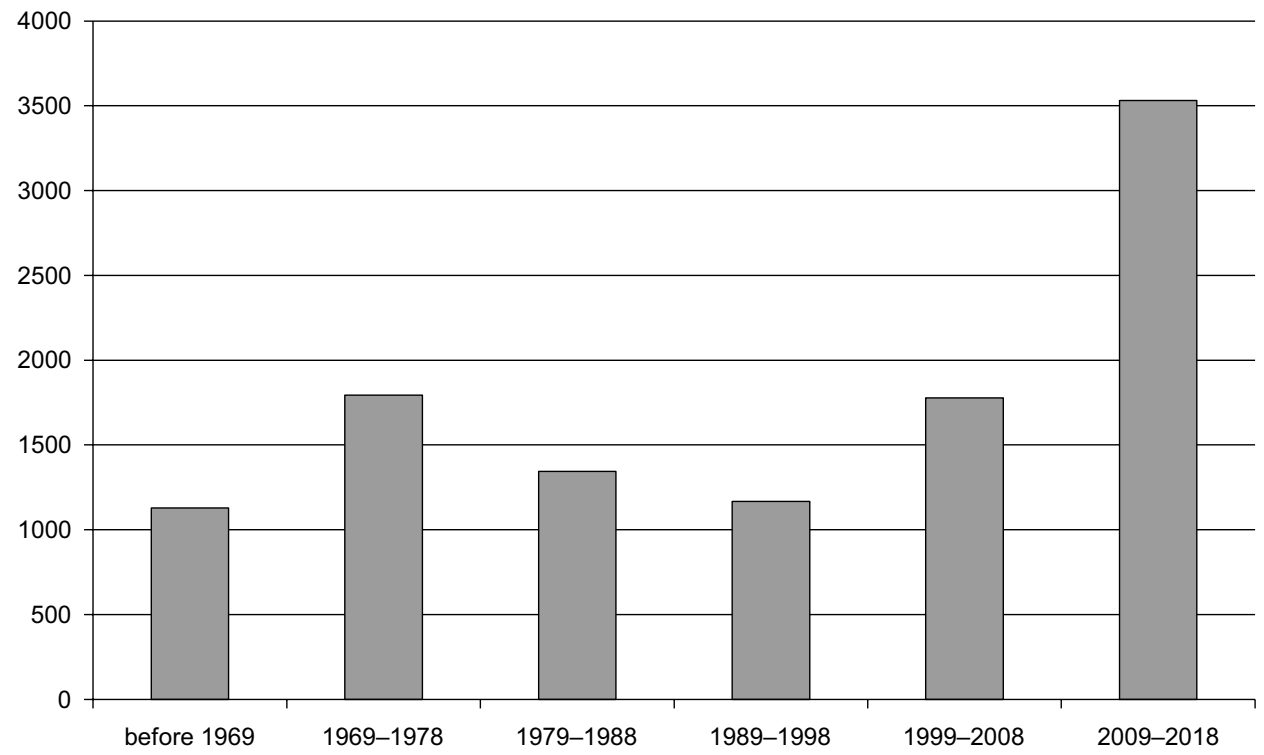

Figure 2. The number of searches for the phrase galvanic skin response in the EBSCO database

The increase in the popularity of psychophysiological methods in marketing research was due to the limitations of the methods used to measure consumer reactions, i.e. self-report measures for assessing intentions, attitudes or emotions, and behavioural measures including actual buying behaviour, amount of money spent or time spent (Stewart, Furse, 1982; Wang, Minor, 2008; Wiles, Cornwell, 1991). In self-description techniques, there is a risk of providing socially acceptable answers (Wang, Minor, 2008). On the other hand, in the case of behavioural methods, it is difficult to determine the process that occurs between stimulus exposure and subsequent behaviour (Wiles, Cornwell, 1991). The premise for using psychophysiological techniques in marketing research is the ability to measure the objective and sensitive response of an individual to a stimulus that does not yield to conscious control. Thanks to this method, the subjects are not able to "mask" their real feelings (Stewart, Furse, 1982). Therefore, psychophysiological methods - including the measurement of electrodermal activity - have found their application in marketing research due to the need for a broader understanding of the mechanisms of the human mind. A particularly important area in this context measures the consumer response to external stimuli (Wang, Minor, 2008).

In marketing research, EDA was widely used as a measure of stimulation. A study by Groeppel-Klein and Baun (2001) investigated how different environmental settings in the stores affect consumer arousal and emotions when shopping. The study was carried out in fruit and vegetable stores, one of which was designed in accordance with the principles of environmental psychology, taking into account the special exposure of products. In the analysis of phase electrodermal activity, the sum of amplitudes was compared during a store visit, average amplitude per minute, skin conductance response frequency and duration of stay in a given store. Significant differences were observed in all parameters except average amplitude per minute. In the store with special 
product display, customers stayed for a long time, and a higher level of arousal was observed.

In a study by Lajante et al. (2012) physiological arousal was measured as an indicator of emotional activation triggered by seven different television commercials (Coca-Cola, McDonald's, Spä, Bose, Pantoloc, Nikon, and Philadelphia). The authors of the study focused on how to most accurately examine the skin's conductance in the context of research on consumer behaviour. The following methods were distinguished: comparison of the overall level of skin conductance under various experimental conditions, comparison of mean changes of skin conductance before and after stimulus exposure and the sum of SCR amplitudes (which is considered one of the most popular indices). As an alternative, an integrated skin conductance response (ISCR) which reflects cumulative phase activity over a specific time period (e.g., from start to end of stimulus exposure) was found. The index correlates directly with the activation level of the sweat glands and allows the integration of both the spatial and temporal dimensions of SCR. For many authors, it is considered the most precise way to determine the phase activity associated with stimulus exposure.

In turn, the study by Gakhal and Senior (2008) concerned differences in the response of psychophysiological activity after the exposure of advertisements depicting celebrities or non-celebrities who were attractive or average-looking. It turned out that popularity - not attractiveness - is the factor that triggers a stronger electrodermal response. The study compared measurements based on the placement of electrodes on the right and left hands - but no significant differences in the levels of individual parameters were observed. The analysis was based on comparisons of the magnitude of EDA changes (expressed as a percentage) in relation to the highest amplitude estimated for each test condition.

In a study by Ohme, Reykowska, Wiener and Choromanska (2009), skin conductance was measured to determine the level of arousal resulting from the emission of two TV commercials of a skin care product that differed only in the presence of the gesture made by the model. The average skin conductance response between 21.5 and 24.5 seconds of the advertisement was recorded, i.e. when the gesture appeared in one version of the commercial. However, no significant difference in the level of stimulation was observed (only an outline of the trend). The study also used other neurophysiological methods (such as EEG), so it was possible to determine not only the level of arousal but also its direction. Other studies using the measurement of EDA to determine emotional arousal as a result of watching ads include Li, Walters, Packer, and Scott (2018) and Bolls, Muehling, and Yoon (2003), that examined the commercials in the tourism industry.

One of the first studies on the effectiveness of commercials using skin resistance measurement was conducted by Kohan (1968) who measured galvanic skin response and mean galvanic skin response in 10-second intervals. By comparing the GSR records with the analysis of experimental ads, it was observed that greater advertising interest is accompanied by higher peaks in skin resistance. The amplitudes and the exact moments of resistance increases varied between subjects, which may be due to the difference in skin resistance among individuals. 
In a study conducted by Belch, Holgerson, Belch, and Koppman (1982), the physiological response of viewers to advertising was verified using sexually-oriented content. For this purpose, the galvanic skin response was examined and the results indicated that nudity and suggestibility of advertisements are associated with an increase in arousal among the subjects. A similar issue was verified by Kilbourne, Painton and Ridley (1985) in a study focusing on the effectiveness of sexual embedding in advertising. For this purpose, a galvanic skin response was measured - skin resistance was calculated based on the amplitudes of the reactions at intervals of 5 seconds. It was observed that a higher level of arousal appeared in response to advertisements containing sexual embeds.

Advertisements were also the subject of a study conducted by AAker, Stayman and Hagerty (1986) in which the relationship between the sense of warmth induced by advertising and physiological stimulation was measured. To this end, the level of skin resistance was verified for warrmth-sensitive ads with respect to humorous, irritating or informative ads. It turned out that warmth is associated with the occurrence of physiological arousal in recipients.

Electrodermal activity is used not only in studies regarding the physiological reactions in response to a specific stimulus but also in relation to consumer purchase decisions. Groeppel-Klein (2005) measured the electrodermal response (EDR) as the indicator of customer arousal at the point-of-sale (POS). The study assumed that the atmosphere of the store should attract customers and thus - induce phase electrodermal activity. Research has shown that arousal has proved to be a significant variable explaining consumers' shopping behaviour. It turned out that a store with a special design and display of goods caused a higher level of arousal compared to a store with a typical exposition - more purchases have been made in it as well. In addition, the level of arousal was higher for people who decided to buy. The conclusions were made on the basis of such EDA parameters as the sum of amplitudes and the frequency of responses (Groeppel-Klein, 2005). The use of EDA in relation to customers' choices also appeared in the study of Somervuori and Ravaja (2013), who analysed emotional processes and purchase decisions made in the context of changes in prices of the products of various brands. It was assumed that a higher level of electrodermal activity (and thus - increased arousal) while viewing the product image would allow concluding about its purchase. However, this hypothesis has not been confirmed as emotional arousal turned out not to have a significant impact on the purchase decision (Somervuori, Ravaja, 2013). Purchase decisions were also investigated in the Guerreiro, Rita and Trigueiros (2015) study, which aimed to explain how cognitive and emotional responses can influence the decision to purchase cause-related products of two categories - utilitarian and hedonistic. To this end, EDA was measured - the average skin conductance response and mean skin conductance response time was estimated. It turned out that a higher level of skin conductance or reduced time to reach the maximum level of arousal is associated with a greater likelihood of choosing a socially responsible product. Attention and emotional arousal are therefore autonomous reactions that affect the marketing effectiveness of this type of products (Guerreiro, Rita, Trigueiros, 2015). 
The measurement of electrodermal activity in marketing research was also used to determine the physiological and verbal responses of consumers in relation to product packaging - these reactions were treated as indicators that allow predicting product selection. In the Vila-López and Küster-Boluda (2018) study, the electrical reactions generated by the skin were examined for six packaging designs of different colours and containing different information. During the analysis, EDA parameters such as the average EDA value, minimum and maximum values in specific time intervals and the peak (maximum) value were used to create the stimulation index. The study found that packaging of different colours (blue, red and black) and with different messages (simple or reinforced) lead to different physiological and cognitive responses that can ultimately influence the consumer's decision to try the product. Compared to self-report measures, it turned out that physiological responses are better indicators of anticipated consumer behaviour when choosing packaging (Vila-López and Küster-Boluda, 2018).

The electrodermal activity has also been used in examining consumer preferences for products. In a study by Walla, Brenner and Koller (2011), the attitude towards liked and disliked brand names was checked using skin conductance and other measures (including heart rate). For the purposes of analysing emotional aspects of brand attitudes, the average values of skin conductance were compared when reading their names. It turned out that the value of skin conductance associated with visual presentations of names of liked brands is significantly lower than that of disliked brands (Walla, Brenner, Koller, 2011). Different results were obtained in the Ohira and Hirao (2015) study which examined the skin conductance response (SCR) as a psychophysiological indicator to assess the affective aspects of consumer preferences for cosmetic products. The study procedure consisted of presenting images and descriptions of the combinations of two cosmetic products while recording skin conductance responses (SCRs), which were then evaluated by study participants. For the purpose of analysis, comparisons of mean and amplitudes of skin conductance reactions were made. The results of the analysis indicated that the average SCR amplitude elicited by preferred products was significantly higher than that elicited by non-preferred items. It is worth emphasising that one year later, the study was repeated with the same participants - their product preferences and corresponding SCR patterns remained stable. This means that the skin conductance response can be an indicator of consumer preferences in the long run (Ohira and Hirao, 2015).

Electrodermal activity was also used in the Hurley, Hutcherson, Tonkin, Dailey and Rice (2015) study on customer preferences for packaging. Electrodermal activity as a measure of emotional arousal was planned to be expressed in the form of an EDA arousal ratio constructed on the basis of minimum and maximum EDA value and the peak value (due to the low number of peak values, the mean normalised EDA value was used). The aim of the study was to check the relationship between the level of electrodermal activity and the data obtained from the eye-tracker. The study was conducted in a place reminiscent of a real retail environment - it proved difficult to engage the consumer in a natural way in experiencing emotional stimuli in such an environment. The results of the study conducted using eye-tracking technique turned out to be statistically insignificant. Also, EDA has not proved to be an important tool for measuring 
arousal with regard to packaging in a purchasing environment (Hurley, Hutcherson, Tonkin, Dailey, Rice, 2015).

There have also been studies using the measurement of electrodermal activity in relation to the e-commerce market. Teubner, Adam and Riordan (2015) reviewed the affective processes and bidding behaviour of people participating in electronic auctions - due to the growing importance of computerized agents in this type of auctions and their impact on bidder decision-making. A laboratory experiment was carried out in which participants bid against other people and against computer opponents. The analysis used skin conductance response (SCR) measurement and compared the average SCR amplitude. It was observed that the level of intensity of immediate emotions of participants in response to events such as submitting a bid, winning or losing an auction, and the general level of arousal of bidders during the auction was mitigated in the case of a bid against computerized agents (Teubner, Adam, Riordan, 2015).

Attention measurement is another application of electrodermal activity in marketing research. For example, in the study of Bolls, Muehling and Yoon (2003), the impact of the advertising pacing on the voluntary and automatic attention of viewers was measured. Emotional stimulation measured by the skin conductance response was treated as one of the indicators of attention. It turned out that fast-paced ads caused significantly more skin conductance reactions than slow-paced ads. Thus, they can potentially increase the involuntary attention of TV viewers (Bolls, Muehling, Yoon, 2003).

To sum up, one should point to the spectrum of research using the measurement of electrodermal activity in marketing. Researchers used this tool to measure consumer emotional arousal, attention and affective responses associated with various stimuli (including warmth or anxiety) (Wang, Minor, 2008). Recording of the electrical activity of the skin was used to measure the effectiveness of advertisements, consumer preferences towards products or their purchase decisions.

\section{Combining measurement of electrodermal activity with other methods}

The measurement of electrodermal activity raises the potential to use it in marketing research along with other methods. In this regard, we can distinguish, among others eye-tracking, electroencephalography, facial electromyography, heart rate measurement, as well as self-description methods.

One of the first studies on the combined use of eye-tracking and measurement of electrodermal activity was conducted by Kahneman, Tursky, Shapiro and Crider (1969). Based on the measurement of heart rate, skin resistance and pupil size (using an eye-tracker), a similar pattern of autonomic responses was observed when solving tasks for all parameters - an increase in the collection and processing of information and their decrease in the reporting phase (Kahneman, Tursky, Shapiro, Crider, 1969). The issue of pupil size and electrodermal activity in marketing research appeared in the study of Rosa, Oliveira, Alghazzawi, Fardoun and Gamito (2017), in which a similar 
pattern of pupil reaction and skin conductance in response to exposed stimuli was observed. For this research, the authors set out to discover whether there is a correlation between peak pupil diameter and skin conductance response (SCR) amplitude. The results indicated a relationship between these variables (Rosa, Oliveira, Alghazzawi, Fardoun and Gamito, 2017). In marketing research, eye-tracking is also used to measure eye fixation time at a specific point. This application of eye-tracking along with the measurement of electrodermal activity appeared, among others, in the study of Guerreiro, Rita and Trigueiros (2015) and Hurley, Hutcherson, Tonkin, Dailey and Rice (2015). The combined use of tracking eye movement and EDA can lead to a better perception of the role of pleasure, arousal and attention in predicting consumer behaviour (Guerreiro et al., 2015). The technique of tracking eye movements also allows assigning individual electrodermal reactions (including peak values) to specific objects on which the eyesight of the examined person is focused. Eye-tracking was used in such a way in the study of Colomer, Naranjo, Guixeres and Ausín (2014), where brain activity during commercial ad observation was analysed. Although skin conductance reactions were correlated with the level of brain activity, eye-tracking was used to depict the places where the eyes were directed by subjects during the moments where the peak values of these reactions occurred (Colomer, Naranjo, Guixeres, Ausín, 2014).

Neurophysiological methods used in marketing research along with electrodermal activity include measuring brain bioelectrical activity by means of electroencephalography (EEG). In marketing research, EEG is often applied to advertisements as it enables a precise description of the emotional response while viewing and identification of scenes generating the strongest emotional involvement, as well as describing the reaction to particular images, sounds, words or effects. By combining the EEG measurement with the analysis of the galvanic skin reaction it is possible to determine the nature of the energisation in response to a specific stimulation, i.e. to indicate whether the observed stimulation is positive (aspiration) or negative (avoidance) (Rafał Ohme, Pleszczyńska, Osiecki, Reykowska, Szczurko, 2010). The measurement of skin conductance in marketing research together with EEG was used in the Ohme, Reykowska, Wiener and Choromanska study (2009), where not only the level of stimulation while watching ads but also its direction was determined (Ohme et al., 2009). Other studies using both tools include Colomer, Naranjo, Guixeres and Ausín (2014).

The technique used in marketing research with the EDA is electromyography (EMG). This method records the electrical activity of the facial muscles as the movements of these muscles are part of the emotional response to exposure to the stimulus. They are spontaneously evoked and vary according to the type of stimulus and are consistent with the autonomous responses of the body (Dimberg, 1990). Also, in marketing studies, EMG is used as an indicator of emotional reactions (Wąsikowska, 2013). The measure was used together with the measurement of electrodermal activity in the following studies: Li, Walters, Packer and Scott (2018), Ohme, Reykowska, Wiener and Choromanska (2009), Somervuori and Ravaja (2013) and Wall, Brenner and Koller (2011).

Research has also been conducted using heart rate and EDA measurement. It is believed that the measurement of skin conductance more often reflects the level of arousal, while changes in heart rate include aspects related to the value of emotions 
(Walla et al., 2011). In the Walla, Brenner and Koller study (2011) it was assumed that heart rate reflects the physiological response to popular and disliked brands. Bolls, Muehling and Yoon study (2003), on the other hand, treated heart rate as the measure of voluntary attention, while skin conductance was treated as an indicator of involuntary attention (Bolls et al., 2003).

The measurement of electrodermal activity as an expression of emotional arousal in response to external stimuli is often supplemented by self-descriptive measures. These measures include package evaluation scales (Vila-López, Küster-Boluda, 2018), advertising evaluation scales (Belsch, 1982; Kilbourne, Painton, Ridley, 1985;) and subjective measures of affective state (Rosa, Oliveira, Alghazzawi, Fardoun, Gamito, 2017). Verbal scales were also used in the Groeppel-Klein study (2005). Along with the measurement of electro-verbal activity, non-verbal scales are also used, such as the Manikin Self-Assessment Scale (SAM), which measures the pleasure and arousal during the decision-making process (Guerreiro, Rita, Trigueiros, 2015), while watching advertisement (Li, Walters, Packer, Scott, 2018) or during product package evaluation (Hurley, Hutcherson, Tonkin, Dailey, Rice, 2015). A non-verbal scale used in marketing research along with the registration of electrodermal activity is also the Warmth Monitor scale, which is a tool for measuring the sense of warmth induced by advertising (AAker, Stayman, Hagerty, 1986).

In marketing research, psychophysiological methods are widely used and combined as emotional reactions, thoughts and actions of participants are measured by the electrodermal activity, the activity of the eyes, facial muscles, the heart or the brain. Supplementing these techniques with self-descriptive measures allows for a holistic examination of the analysed problem. The studies presented above may, therefore, be an inspiration for combining various techniques with the measurement of electrodermal activity.

\section{Conclusions}

The paper presents the method of measurement of electrodermal activity, its use and popularity in scientific literature. Basic indices and their interpretation are discussed, and examples of the possibilities of using the method in marketing research are presented. The article also discusses the possibilities and examples of combining EDA with other methods of measurement. Measurement of electrodermal activity is a tool for understanding the mechanisms underlying consumer behaviour. It allows us to learn about involuntary, unconscious reactions of consumers to products or advertisements. EDA - due to its connection with psychological processes - may be an indicator of arousal, attention or cognitive effort, as well as hidden emotional reactions that the respondents may want to mask. In marketing, EDA recordings are used to measure the effectiveness of advertising, preferences to packaging design and decision-making processes related to purchase behaviours. 


\section{References}

1. AAker D.A., Stayman D.M., Hagerty M.R. (1986). Warmth in Advertising: Measurement, Impact, and Sequence Effects. Journal of Consumer Research, 12(4), pp. 365-381. https://doi. org/10.1086/208524

2. Barontini M., Lázzari J.O., Levin G., Armando I., Basso S.J. (1997). Age-related changes in sympathetic activity: biochemical measurements and target organ responses. Archives of Gerontology and Geriatrics, 25(2), pp.175-186. https://doi.org/10.1016/S0167-4943(97)00008-3

3. Bazarnik A. (2016). Aktywność elektrodermalna $w$ metodzie biofeedback - zastosowanie kliniczne na przykładzie padaczki. Nauki Ścisłe, 12(1), pp. 157-176. Pobrano z https://ruj. uj.edu.pl/xmlui/bitstream/handle/item/27792/bazarnik_aktywnosc_elektrodermalna_w_ metodzie_biofeedback.pdf?sequence=1\&isAllowed=y

4. Belch M.A., Holgerson B.E., Belch G.E., Koppman J. (1982). Psychophysiological and Cognitive Responses to Sex in Advertising. Advances in Consumer Research, 9(1), pp. 424-428. Pobrano z http://search.ebscohost.com.00002bwy0b53.han3.ue.poznan.pl/login.aspx?direct $=$ true \&db=bsu\&AN=6430757\&lang=pl\&site=ehost-live

5. Bell L., Vogt J., Willemse C., Routledge T., Butler L.T., Sakaki M. (2018). Beyond self-report: A review of physiological and neuroscientific methods to investigate consumer behavior. Frontiers in Psychology, 9, pp. 1-16. https://doi.org/10.3389/fpsyg.2018.01655

6. BIOPAC (2017). Acq Knowledge 5 Software Guide. https://www.biopac.com/wp-content/uploads/AcqKnowledge-5-Software-Guide.pdf

7. Bolls P.D., Muehling D.D., Yoon K. (2003). The effects of television commercial pacing on viewers' attention and memory. Journal of Marketing Communications, 9(1), pp. 17-28. https://doi. org/10.1080/1352726032000068032

8. Boucsein W. (2012). Electrodermal activity: Second edition. Electrodermal Activity: Second Edition. Springer Science + Business Media, New York. https://doi.org/10.1007/978-1-46141126-0

9. Boucsein W., Fowles D.C., Grimnes S., Ben-Shakhar G., Roth W.T., Dawson M.E., Filion D.L. (2012). Publication recommendations for electrodermal measurements. Psychophysiology, 49(8), pp. 1017-1034. https://doi.org/10.1111/j.1469-8986.2012.01384.x

10. Braithwaite J., Watson D., Jones R., Rowe M. (2013). A Guide for Analysing Electrodermal Activity (EDA), Skin Conductance Responses (SCRs) for Psychological Experiments. https://doi. org/10.1007/s10948-012-1909-2

11. Colomer A., Naranjo V., Guixeres J., Ausín J.M. (2014). Biosignal Analysis for Advertisement Evaluation. [In:] XXIX Simposium Nacional de la Unión Científica Internacional de Radio. Walencja. https://www.researchgate.net/publication/270880230_Biosignal_Analysis_for_Advertisement_Evaluation

12. Dawson M.E., Schell A.M., Filion D.L. (2007). The Electrodermal System. [In:] Cacioppo J.T., Tassinary L.G., Berntson G. (Eds.) Handbook of psychophysiology. Third, pp. 159-181. Cambridge University Press, New York. https://doi.org/https://doi.org/10.1017/9781107415782

13. Dimberg U. (1990). Facial Electromyography and Emotional Reactions. Psychophysiology, 27(5), pp. 481-494. https://doi.org/10.1111/1469-8986.ep11032582

14. Figner B., Murphy R.O. (2011). Using skin conductance in judgment and decision making research. [In:] Schulte-Mecklenbeck M., Kuehberger A., Ranyard R. (Eds.) A handbook of process tracing methods for decision research: A critical review and user's guide. Psychology Press, New York, pp. 163-184). 
15. Fowles D.C., Christie M.J., Edleberg R., Grings W.W., Lykken D.T., Venables P.H. (1981). Committee report: Publication recommendations for electrodermal measurements. Psychophysiology, 18(3), pp. 232-239. https://doi.org/https://doi.org/10.1111/j.1469-8986.2012.01384.x

16. Gakhal B., Senior C. (2008). Examining the influence of fame in the presence of beauty: an electrodermal "neuromarketing" study. Journal of Consumer Behaviour, 7(4-5), pp. 331-339. https://doi.org/10.1002/cb.255

17. Groeppel-Klein, A. (2005). Arousal and consumer in-store behavior. Brain Research Bulletin, 67(55), pp. 428-437. https://doi.org/10.1016/j.brainresbull.2005.06.012

18. Groeppel-Klein A., Baun D. (2001). The Role of Customers'Arousal for Retail Stores-Results from An Experimental Pilot Study Using Electrodermal Activity as Indicator. Advances in Consumer Research, 28(1), pp. 412-419. Pobrano z http://search.ebscohost.com.00002bwy0b8d.han3. ue.poznan.pl/login.aspx?direct=true $\& \mathrm{db}=\mathrm{bsu} \& A \mathrm{~N}=6686451 \&$ lang=pl\&site=ehost-live

19. Guerreiro J., Rita P., Trigueiros D. (2015). Attention, emotions and cause-related marketing effectiveness. European Journal of Marketing, 49(11-12), pp. 1728-1750. https://doi.org/10.1108/ EJM-09-2014-0543

20. Handler M., Nelson R., Krapohl D., Honts C.R. (2010). An EDA Primer for Polygraph Examiners. Polygraph, 39(2), pp. 68-108. https://www.researchgate.net/publication/265107219_An_ EDA_Primer_for_Polygraph_Examiners

21. Hurley A., Hutcherson D., Tonkin C., Dailey S., Rice J.C. (2015). Measuring Physiological Arousal Towards Packaging: Tracking Electrodermal Activity within the Consumer Shopping Environment. Journal of Applied Packaging Research, 7(5), pp. 76-90.

22. IMotions (2017). GSR Pocket Guide: Everything you need to know about Galvanic Skin Response to push your insights into emotional behavior. pp. 1-36.

23. Jagielnicki R. (2010). Biomedyczne urzq̨dzenie do monitorowania zmian rezystancji skóry. Pomiary Automatyka Kontrola, 56(12), pp. 1568-1570. http://yadda.icm.edu.pl/yadda/element/bwmeta1.element.baztech-article-BSW4-0088-0049/c/Jagielnicki.pdf

24. Kahneman D., Tursky B., Shapiro D., Crider A. (1969). Pupillary, heart rate, and skin resistance changes during a mental task. Journal of Experimental Psychology, 79(1), pp. 164-167. https://doi.org/10.1037/h0026952

25. Kilbourne W.E., Painton S., Ridley D. (1985). The Effect of Sexual Embedding on Responses to Magazine Advertisements. Journal of Advertising, 14(2), pp. 48-56. https://doi.org/10.1080/ 00913367.1985 .10672946

26. Kohan X. (1968). A Physiological Measure of Commercial Effectiveness. Journal of Advertising Research, 8(4), pp. 46-49. http://search.ebscohost.com.00002bwy0bc0.han3.ue.poznan.pl/

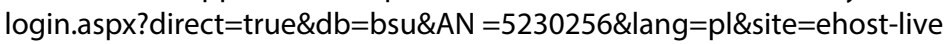

27. Lajante, M., Droulers, O., Dondaine, T. i Amarantini, D. (2012). Opening the "black box" of electrodermal activity in consumer neuroscience research. Journal of Neuroscience, Psychology, and Economics, 5(4), pp. 238-249. https://doi.org/10.1037/a0030680

28. Naqvi, N. H. i Bechara, A. (2006). Skin Conductance: A Psychophysiological Approach to the Study of Decision Making. [In:] Senior C., Russell T., Gazzaniga M.S. (Eds.) Methods in mind. Cambridge, pp. 103-122.

29. Neumann E., Blanton R. (1970). The early history of electrodermal research. Psychophysiology, 6(4), pp. 453-476. https://doi.org/https://doi.org/10.1111/j.1469-8986.1970.tb01755.x

30. Ohira H., Hirao N. (2015). Analysis of skin conductance response during evaluation of preferences for cosmetic products. Frontiers in Psychology, 6, pp. 1-5. https://doi.org/10.3389/ fpsyg.2015.00103 
31. Ohme R., Pleszczyńska I., Osiecki K., Reykowska D., Szczurko T. (2010). Nowa generacja badań konsumenckich: eksperyment, czasy reakcji i fale mózgowe. [In:] Nowe trendy w reklamie. Między naukq a praktykq. Wydawnictwo SWPS, Warszawa, pp. 76-96.

32. Ohme R., Reykowska D., Wiener D., Choromanska A. (2009). Analysis of Neurophysiological Reactions to Advertising Stimuli by Means of EEG and Galvanic Skin Response Measures. Journal of Neuroscience, Psychology, and Economics, 2(1), pp. 21-31. https://doi.org/10.1037/ a0015462

33. Rosa P.J., Oliveira J., Alghazzawi D., Fardoun H., Gamito P. (2017). Affective and physiological correlates of the perception of unimodal and bimodal emotional stimuli. Psicothema, 29(3), pp. 364-369. https://doi.org/10.7334/psicothema2016.272

34. Shaffer F., Combatalade D., Peper E., Meehan Z.M. (2016). A Guide to Cleaner Electrodermal Activity Measurements. Biofeedback, 44(2), pp. 90-100. https://doi.org/10.5298/1081-593744.2.01

35. Somervuori O., Ravaja N. (2013). Purchase Behavior and Psychophysiological Responses to Different Price Levels. Psychology and Marketing, 30(6), pp. 479-489. https://doi.org/10.1002/ mar

36. Sosnowski T. (1993). Aktywność elektrodermalna. [In:] Sosnowski T., Zimmer K. (Eds.) Metody psychofizjologiczne w badaniach psychologicznych. PWN, Warszawa, pp. 182-216.

37. Stewart D.W., Furse D.H. (1982). Applying Psychophysiological Measures to Marketing and Advertising Research Problems. Current Issues, Research in Advertising, 5(1), pp. 1-38. https:// doi.org/10.1080/01633392.1982.10505319

38. Teubner T., Adam M., Riordan R. (2015). The Impact of Computerized Agents on Immediate Emotions, Overall Arousal and Bidding Behavior in Electronic Auctions. Journal of the Association for Information Systems, 16(10), pp. 838-879. https://aisel.aisnet.org/jais/vol16/iss10/2

39. Vila-López N., Küster-Boluda I. (2018). Consumers' physiological and verbal responses towards product packages: Could these responses anticipate product choices? Physiology and Behavior, 200, pp. 166-173. https://doi.org/10.1016/j.physbeh.2018.03.003

40. Walla P., Brenner G., Koller M. (2011). Objective Measures of Emotion Related to Brand Attitude: A New Way to Quantify Emotion-Related Aspects Relevant to Marketing. PLoS One, 6(11), pp. 1-7. https://doi.org/10.1371/journal.pone.0026782

41. Wang Y.J., Minor M.S. (2008). Validity, Reliability, and Applicability of Psychophysiological Techniques in Marketing Research. Psychology, Marketing, 25(2), pp. 197-222. https://doi. org/10.1002/mar

42. Wąsikowska B. (2013). Współczesne technologie eksploracji danych w marketingu. Zeszyty Naukowe SGGW w Warszawie. Polityki Europejskie, Finanse i Marketing, 9(58), pp. 588-599. http://www.wne.sggw.pl/czasopisma/pdf/PEFIM_2013_T9_nr58.pdf

43. Wiles J.A., Cornwell B.T. (1991). A Review of Methods Utilized in Measuring Affect, Feelings, and Emotion in Advertising. Current Issues, Research in Advertising, 13(1-2), pp. 241-275. https:// doi.org/10.1080/01633392.1991.10504968

44. Zelinski E.M., Walsh D.A., Thompson L.W. (1978). Orienting Task Effects on EDR and Free Recall in Three Age Groups. Journal of Gerontology, 33(2), pp. 239-245. https://pdfs.semanticscholar.org/a8c5/260d66b7f5e32120611e05b795130a0ed65b.pdf 
Romanowski R. (Ed.): Managing Economic Innovations - Methods and Instruments Bogucki Wyd. Nauk., Poznań 2019. ISBN 978-83-7986-277-1

\title{
Chapter 6
}

\section{Eye-tracking in Marketing Research}

\author{
Sylwester Białowąs, Adrianna Szyszka
}

\begin{abstract}
Understanding the cognitive processes of consumers, such as attention or perception, can help orient marketing activities in such a way that the information provided to recipients is delivered in the most effective way possible. Neuromarketing methods - in contrast to conventional methods - enable scientists to measure the subconscious reactions in response to stimuli, thereby giving insight into decision-making processes, consumer preferences or motivations. One of the most commonly used methods of this type is eye-tracking. In recent years, there has been a noticeable increase in the popularity of using this technique as it provides valuable information regarding the visual processing of stimuli. The purpose of this publication is to present the possibilities of using eye-tracking in marketing research, including identifying the main research areas and insights from previous research. In the beginning, necessary information about the method will be presented, providing context for further considerations, such as eye movement characteristics and fundamental measurement indicators. Then a review of the studies conducted using eye-tracking will be carried out. A broad spectrum of the use of eye-tracking provides the opportunity for future studies to combine this method with other neuromarketing techniques (including the electroencephalography or magnetic resonance imaging).
\end{abstract}

Keywords: eye-tracking, measurement, eye movements, marketing research, psychophysiological methods, consumer behaviour

Sylwester Białowąs: Associate Professor at Department of Market Research and Services Management, Institute of Marketing, Poznan University of Economics, ORCID: https://orcid.org/0000-0003-4575-5346, e-mail: sylwester.bialowas@ue.poznan.pl

Adrianna Szyszka: PhD Student at Department of Market Research and Services Management, Institute of Marketing, Poznan University of Economics, ORCID https://orcid.org/0000-0002-1389-2365, e-mail: adrianna.szyszka@ue.poznan.pl 


\section{Eye-tracking - what is it?}

Eye-tracking is a set of research techniques and methods intended for measuring, analyzing and interpreting data on the position and movement of eyeballs (Rojna, 2003). Thanks to this method, it is possible to check where the subject's eyesight falls at a given moment, how long the eyesight focuses on a specific point and what path it follows (Schall, Bergstrom, 2014). In addition to observing eye movement, the technique also allows measuring its characteristics, including pupil size (Bojko, 2013). The need to track eye movements arose as a result of the desire to learn about the relationship between the brain and visual system (Schall, Bergstrom, 2014). One of the first studies in this area dates back to the 19th century, when Louis E. Javal registered eye movements using an apparatus placed on the patient's eye surface (Wawer, Pakuła, 2012). Tracking eye movements is used in various fields of science, among others in psychology, medicine or ergonomics (Wąsikowska, 2016). This technique has also been applied to marketing research.

As part of the visual activity, two types of eye movement can be distinguished - fixations and saccades. Fixations are relative pauses in the movement of the eye during which the retina stabilizes at a specific point in the visual field. Saccades, in turn, are quick eye movements occurring between fixations that rely on sight moving from place to place. In other words, these eye movements are responsible for the rapid transfer of the line of sight to those points of the visual environment in which the information needed for the current cognitive task is available (Garczarek-Bąk, Disterheft, 2018; Ober, Dylak, Gryncewicz, Przedpelska-Ober, 2009; Schall, Bergstrom, 2014). The fixations are from $150 \mathrm{~ms}$ to $600 \mathrm{~ms}$ long and constitute $90 \%$ of the looking time as they include the smallest eye movements, such as tremor, drift or microsaccades. Saccades last from 10 $\mathrm{ms}$ to $100 \mathrm{~ms}$ and are seen as a manifestation of the desire for voluntary changes of attention. From research on visual attention, a relevant category of movements are also smooth pursuits, which enable to track moving objects. In the context of the analysis of eyeball movement, it is, therefore, crucial to isolate fixations, saccades and smooth pursuits as they are an expression of voluntary visual attention (Duchowski, 2007).

The eye-tracking method based on tracking the motion of eyeballs allows for detailed follow-up of the subject's vision path, and in fact - the path of the attention. Thanks to this, it is possible to isolate the focus areas of the participant's vision, which gives an image of the content that the subject considers interesting or that has attracted the attention. Such information is a starting point for reflection on how a person perceived the viewed material (Duchowski, 2007). Researchers have always been interested in brain function in response to stimuli exposure, and thanks to eye-tracking, it is possible to understand how a human visual system works, as well as how the mind processes visual stimuli (Schall, Bergstrom, 2014). The studies conducted so far indicate a link between visual attention and eye movement. There are hypotheses according to which the same neural circuits mediate both attention and eye movements - changes in attention depend on the activation of brain structures that are closely involved in moving the eyes. In the study of Hoffman and Subramaniam (1995), it was proved that it is impossible to direct attention to one place and simultaneously perform a saccade 
in another place. This, in turn, may mean that focusing attention can be an essential element in the preparation or execution of saccades. One explanation for the relationship between sight and recognition is that eye movements require the involvement of the attention system to choose which stimuli in the visual field are to take control of the oculomotor system.

\section{The measurements of eye movement}

An eye-tracker is a tool that enables to get an accurate representation and understanding of the eye motion. Most modern eye-trackers follow the position and movements of the eye using the corneal reflection method. The technique is based on the use of light sources (infrared) directed into the eye, followed by a reflection of the camera with high resolution. The image captured by the camera is used to identify the source of light reflection on the cornea, which allows determining the location of the subject's sight (Garczarek-Bąk, 2017; Schall, Bergstrom, 2014). In the analysis of the visual activity while using the eye-tracker, three main attributes can be distinguished, i.e. the location, duration and movement. The basic measure of location is the fixation, which reflects the position of the eyes captured in a given time. When interpreting this parameter, it should be remembered that the mere fact of recording the fixation does not mean that the subject actually saw or cognitively processed the recorded image (Schall, Bergstrom, 2014). Fixation measurement indicators include the number and distribution of fixations, which may be a reflection of the subject's engagement with the object. Another parameter is the total fixation time in a given area and the fixation time per unit area of the visual element being viewed (Bylinskii, Borkin, 2015). Measurement of visual activity using an eye tracker also enables to estimate the first fixation duration as well as the time to first fixation, which helps determine how much time it takes the user to notice a particular element. Additionally, the average fixation duration can be obtained by dividing the total time by the number of fixation. It is also possible to identify revisits defining all cases in which the eyesight again returns to the area in which the fixation had previously occurred (Garczarek-Bąk, Disterheft, 2018; Tullis, Albert, 2008). The analysis can be augmented with such parameters as the diversity of fixations (the number of unique points for which the fixation occurred) and inter-element fixations, which represents the number of cases in which fixation are attributable to different sets of elements (Bylinskii, Borkin, 2015). Using the eye-tracking apparatus, you can also extract parameters that take into account other types of eye movements, including dwell time - the total time of all fixations and saccades (Garczarek-Bąk, Disterheft, 2018).

As for the indicators related to saccades - they are particularly related to the sequence of searching different areas of interest by the observer. Since - unlike fixations - visual information is not processed during saccades, the measurement indicators associated with this type of eye movement are not crucial for examining visual attention. However, it is possible to obtain such indicators as the number of saccades or the saccade duration. Besides, it should also be noted that there are indicators affecting both fixation and saccades measurement as any combination of these movements is 
called a scanpath. Frequently used measurement parameters based on the scanpath include scanpath length, spatial density, transition matrix, scanpath regularity and scanpath direction, which indicates the searching strategies of the participants (Borys, Plechawska-Wójcik, 2017). Information obtained during the test, therefore, can be present in the form of scanning path, reflecting the order of directing sight for each space. At the same time, it helps identify areas of withdrawing the attention from the essential content of the message during the testing procedure. Specific points that the subject looks at are represented in the form of circles, together with numbers indicating the order of observation and lines demonstrating the movement of sight from place to place. The data can also be visualized as a heat map, which allows to identify areas that received the most attention and those that have been overlooked by the participants. Places of longer concentration are marked with warm colours, while areas of shorter focus - using cool colours. On the other hand, the elements that the subject did not look at are not marked in any colour. The heat map can also be presented in an inverted form, showing the places of the presented content to which the subject directed the eyesight. Another way to present the results of measuring eye movements are areas of interest, which contain information about the extent to which a given picture attracted the attention of the subject. This information is presented in the form of a number, which allows for calculating the statistics (Garczarek-Bak, 2016; Wąsikowska, 2016).

\section{The use of eye-tracking in marketing research}

One of the reasons for using the eye-tracking in marketing research is the intention to understand the actions of consumers. The goal of marketing activities is to provide consumers with product information in an efficient enough way to increase awareness among potential buyers and to identify the needs that can be met through it. Consequently, awareness of product availability increases the likelihood of buying it. Eye-tracking can provide insight into at least one aspect of the internal model of the consumer attention: how the consumer distracts visual attention to various forms of advertising (Duchowski, 2007). Visual attention is essential in examining the consumer behavior and understanding its role in the decision-making process can provide valuable knowledge that enables to effectively design marketing activities using visual messages (Jerzyk, 2017).

Having looked at the results for queries such as "eye tracking" or "eye tracker" or "eye movement measurements" in the EBSCO database, an increase in the popularity of this method in the research is observed. Figure 1 shows the number of publications that concerned this technique. In recent years (2014-2018) more than twice as many papers related to eye-tracking have been created as in the years 2009-2013. The number of all works on this method created before 2009 (3262) is smaller by approx. 25\% than the number of works from 2009 to 2013 and by almost 65\% than the number of publications from 2014 to 2018. 


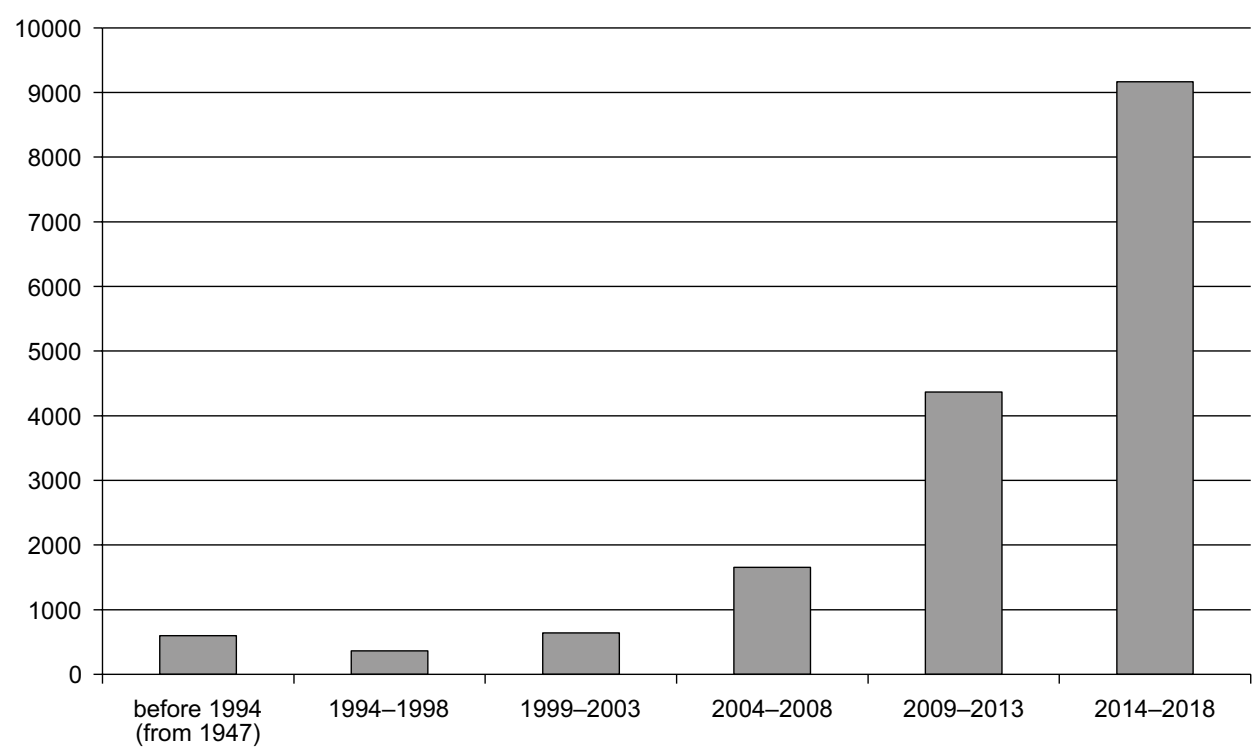

Figure 1. Number of searches for the phrase eye tracking or eye tracker or eye movement measurements in the EBSCO database

To examine the use of eye-tracking in marketing publications, an analysis of the number of searches in the EBSCO database for the phrases "eye tracking" or "eye tracker" or "eye movement measurements" and "marketing" was performed. The number of publications in this area is smaller (687); however, the growth trend is similar. In recent years (2014-2018) more than twice as many publications have been created as in previous years - a rapid increase in their number is observed, especially after 2000.

Experiments depending on recording the eye movements can help comprehend the processing of visual information during the purchasing decision at the point of sale and reveal phases of the decision-making process, which is affected by packaging design (Clement, 2007). The eye movement tracking method was used to test packaging effectiveness - including study by Cholewa-Wojcik and Kawecka (2015), in which the reactions for the package of energy drinks from the viewpoint of purchasing preferences were checked. When it comes to packaging design, aspects that were studied using the eye-tracking technique include shape, size, color of packaging and uses of different font (Clement, Kristensen, Grønhaug, 2013), location and characteristics of nutrition labels (Bialkova, van Trijp, 2011; Graham, Jeffery, 2011) or the presence of potentially misleading elements that may cause clients false expectations (Clement, Smith, Zlatev, Gidlöf, van de Weijer, 2017). In the Disterheft (2017) study, the relationship between the effectiveness and perception of advertising and the attractiveness of the model was analyzed using the analysis of eye movement. The participants were presented with three types of face wash gel ads - with the face of an attractive model, with the face of an average attractive model and without the face of the model. It turned out that the subjects looked at the average attractive model for longer. In the case of advertising with an attractive model, the study participants focused on the advertised product for 
a long time, which, however, did not affect its better remembering (Disterheft, 2017). Other studies using eye-tracking regarding packaging design include, among others, the study of Husic-Mehmedovic, Omeragić, Batagelj and Kolar (2017).

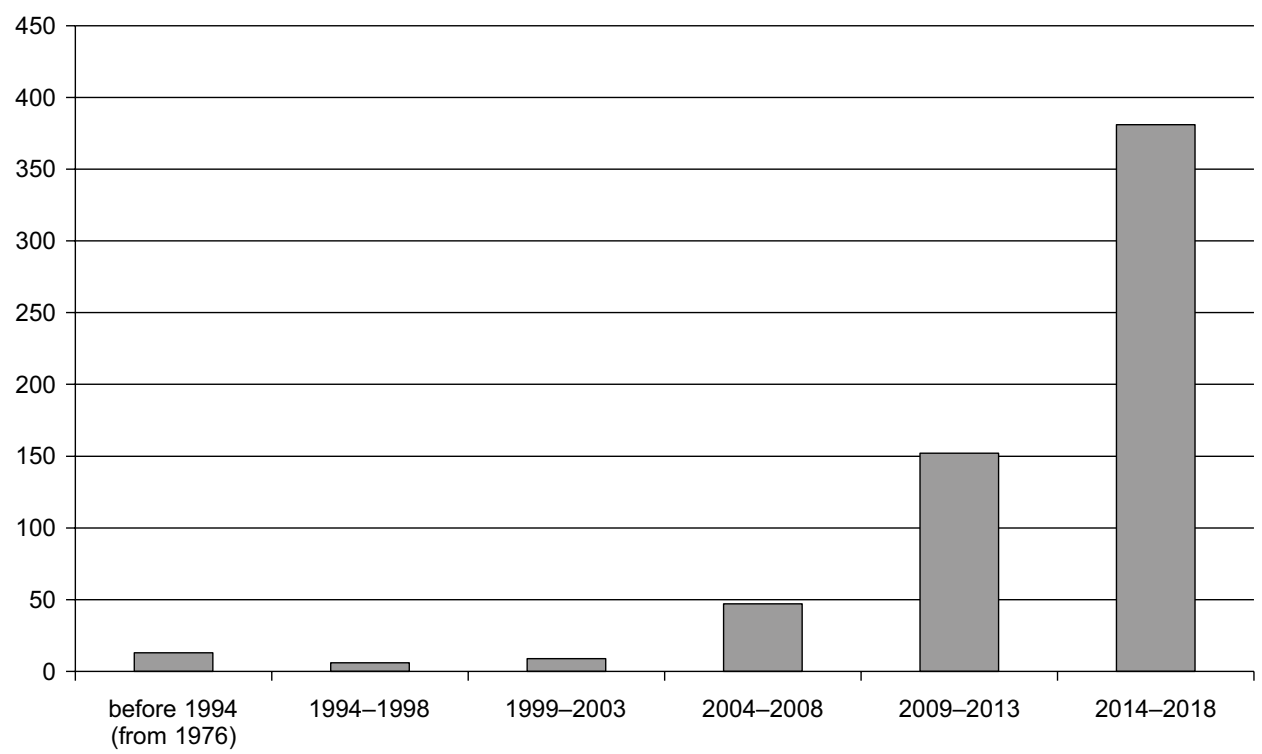

Figure 2. Number of searches for the phrase eye tracking or eye tracker or eye movement measurements and phrase marketing in the EBSCO database

Eye tracking was used in merchandising research as well. In this area, among others, the impact of visual ways of drawing the client's attention to the product, information about it and its price on the purchase intention was examined (Huddleston, Behe, Minahan, Fernandez, 2015). Another study using the technique of tracking the eye movements aimed to verify the impact of the location on the visual search as well as buyers' decision-making processes and their importance for the selection of the products. According to the study, the location-driven patterns of choosing the products by the consumers are crucial for retail shelf management and point-of-purchase decisions (Atalay, Bodur, Rasolofoarison, 2012). In the context of the display of goods on retail store shelves, the method was also used, among others, in the study of Chandon, Hutchinson, Bradlow and Young (2009) or in the study of Wästlund, Shams and Otterbring (2018) regarding peripheral vision.

Given the problems of the relationship between attention and customer preferences to products, purchasing decisions and the real choices, the analysis of eye movement was used in the context of emotion. In the study by Gaczek and Disterheft (2018), the impact of incidental emotions on the application of the satisfaction or maximization rule when selecting food products was examined. Using the eye-tracker, variables related to the decision rule i.e. total fixation time, number of fixations and total scanpath 
length were measured. Eye movements were also recorded when the participants of the study made decisions when choosing jams. The study observed that feeling emotions when making decisions does not affect the application of satisfaction or maximization rule. The analysis showed that the products were slower and more carefully explored by the subjects in a good mood (Disterheft, Gaczek, 2018). When it comes to testing consumer behaviour, the eye-tracker was used as a method to study the impact of shopping goals (and the heuristics used) on visual attention when making purchasing decisions (Wästlund, Otterbring, Gustafsson, Shams, 2015).

The eye-tracking method can also be used to examine the marketing activity of exhibitors concerning trade fair booths. An example of such an application of the technique was presented in the study by Gębarowski (2018), focusing on the overall appearance of the booths and their exhibition part. Eye-tracking can also help determine to what extent the trade fair booth catches the eye of people moving around the market hall and how it stands out from other objects. Besides, it enables to isolate the elements that attract the attention the most and check the response to the presented products (Gębarowski, 2018).

The eye-tracking technique has also been used for television commercials. An example of such an application is the study of Smink, van Reijmersdal and Boerman (2017), which concerned brand placement disclosures. Eye-tracking was used to measure visual activity relative to the brand placement and report on its use. Besides, it was checked whether brand familiarity plays a moderating role in receiving the messages. To this end, areas of interest were analyzed. The study also used self- description methods to measure the recall of the disclosures, brand recall, perceived purchase decision, brand familiarity and brand attitude. Another study using eye-tracking in the context of television advertising was conducted, among others, by Teixeira, Wedel, and Pieters (2010).

Another area of application of eye-tracking is research on printed advertising. The study performed by Puškarević, Nedeljković, Dimovski and Možina (2016) analyzed the impact of the typeface figuration (i.e. regular and irregular forms of styling) on attention and attitude of the audience. The subject of the analysis was also the effect of changing the typeface figuration depending on the type of advertised product (hedonistic or functional). The eye-tracker study has been supplemented with measurement of attitude toward the brand, attitude toward the advertisement and purchase intentions using the Likert scale. An example of the use of eye-tracking in research on print advertising is presented in the study by Hutton and Nolte (2011), in which it was examined how gaze cues provided by models in advertisements affect the focus of attention on a specific area of advertising.

Several studies used eye-tracking for online advertising. For example, Porta, Ravarelli and Spaghi (2013) checked the impact of the congruity between the ad banner subject and webpage content on the perception and remembering of banners in online newspapers. Eye-tracker was also used to measure the number of fixations in the banner area, the total duration of the fixation, the average duration of fixation and the time of the first fixation (Porta, Ravarelli, Spaghi, 2013). In the studies in the area of online advertising, the tracking of eye movements may be helpful to measure the 
phenomenon of banner blindness. The eye-tracker was used, among others, to verify whether Facebook users pay attention to the banners presented in comparison with the recommendations posted by friends (Barreto, 2013). The phenomenon of banner blindness was also investigated using an eye-tracker by Resnick and Albert (2014) who focused on banners that appear when browsing e-commerce websites. The study was completed by measuring the users' familiarity with the page and its visual appeal using the Likert scale. Owens, Chaparro and Palmer (2011), in turn, developed this area of research, exploring the topic of text advertising blindness. To this end, the authors used the eye-tracking method to check the attention of users when it comes to searching for text ads on websites. A similar use of eye-tracking also appeared in the studies of Hervet, Gue and Tremblay (2010) and Lapa (2007). The effectiveness of online advertising banners was the subject of Lee and Ahn study (2012), where it was checked what influence the visual effects of the stimulus (animation) have on attention and whether such cognitive requirements can play a moderating role. Another research has reviewed the relationship between various indicators of attention measured with eye-tracker (i.e. total fixation duration, average fixation duration and fixation frequency) with memory and a change of attitude. Examples of studies using eye-tracking also apply to content on websites and their impact on the observer's attention. In the study of Cao, Qu, Duffy and Ding (2019), the importance of the location of the ad and the colour of the web directories in relation to the users attention was examined.

In conclusion, it should be emphasized that the method of tracking eye movements in market research can be used for various purposes, such as product packaging design tests, website and e-mail communication tests, marketing communication tests (advertising, leaflets, sponsorship and product placement). It is usually combined with quantitative (questionnaires) or qualitative techniques (focus groups, in-depth interviews) (Cosic, 2016). The eye-tracking method is also often combined with other neuromarketing techniques.

\section{Visual activity testing rules}

Eye-tracking is widely used in marketing research since it is a low-invasive testing technique (Cosic, 2016). Before proceeding with the study, participants should be warned that the study will take place using technology that tracks eye movements - but be careful not to reveal too much detail about the procedure, as this may have a negative effect on the results obtained (Kara, Nielsen, 2009).

When carrying out a test using an eye-tracker, it is worth remembering a few fundamental principles that will ensure the reliability of the results obtained. Remember to control the exposure time for each participant - it should be made equal for the subjects. Besides, when the control of exposure time is not possible, the solution may be to express the dwell time in percent instead of absolute values - depending on its duration, other eye movements and other amounts of time spent on watching each element are observed. Time control should only take place when the participant is involved in the study - the time that the respondent spends reporting his experience 
should not be recorded. During the test, eye movements of the subjects should be monitored in real-time, and they should be observed for correct posture. Consider the use of trigger, the point at which the participants focus their attention at the beginning of the experiment. This allows you to control the place from which all subjects begin the experiment (Tullis, Albert, 2008).

It is worth remembering that the results obtained through registering eye movements depend on the environment in which the test is performed. When planning an experiment related to tracking the subject's eyesight, it is worth considering the context in which it is carried out. For example, instead of using an eye-tracker in the store space, for reasons of cost and flexibility, researchers decide to use projectors to create a virtual environment. It should be borne in mind that the most realistic environment is a real physical store - the results of the test may be different depending on whether the eye movement is measured in a natural or artificial environment. The study of Tonkin, Ouzts and Duchowski (2011) proves that visual search is faster in the physical environment compared to the virtual image - although the perceived difference may not be significant. In turn, if the test is carried out in laboratory conditions, it should be remembered that the room in which it takes place has proper lighting. It is not recommended to conduct the test in very bright rooms - too much light may affect the device for recording eye movements (Kara, Nielsen, 2009).

\section{The use of eye-tracking with other neuromarketing methods}

There are examples in the literature of research using eye-tracking with electroencephalography (EEG). Eye-tracking enables to determine where and how long the eyesight is concentrated on some area. However, a longer time of focus on particular place does not necessarily reflect more attention or better remembering of the content (this may also mean that the material presented is too complicated). For this reason, more information can be obtained by supplementing the analysis with measuring the brain's electrical activity, which can be a representation of visual perception, mental activation, concentration, stimulation, memory or tension resulting from previous experiments (Dimpfel, Morys, 2014). The combination of eye movements tracking and EEG can be used in advertising studies as it provides essential information on individual as well as group cognitive and emotional responses leading to the objective assessment of the ads. In relation to TV commercials, both methods were used by Dimpfel (2015). Furthermore, Guixeres et al. (2017) investigated the effectiveness of advertising (recall, liking and viewing rates) available on digital channels (YouTube) using neurophysiological measures such as eye-tracking and brain electrical activity as measured by EEG and heart rate variability. The combination of both methods can be used in consumer decision research as well. Eye-tracking technology can be used to process the EEG recordings in real-time, allowing significant insight into the decision-making process recorded with it (Winslow et al., 2010). The study by Khushaba et al. (2013) aimed to provide information on the design and presentation of products so that they match the preferences of buyers. Authors have investigated the physiological reactions 
of customers when making decisions regarding the products e.g. electrical activity of the brain and eye movements. The eye-tracker system was used to link EEG data with specific product selection options (i.e. to show the transition between selection sets and the actual selection of the object). A combination of methods was used in the Adhami (2013) study on mobile applications - thanks to which it was possible to verify the emotional response of the brain and concentration of attention while browsing, choosing and buying products on a mobile phone.

The challenge in advertising research is to evaluate websites in terms of the content presented on them. In the study of Dimpfel and Morys (2014) eye-tracking was used to indicate in which areas of the website and how long the users' eyesight is focused. In turn, the EEG measurement allowed to conclude about the cognitive reaction, focus of attention, memory processing or tension level. Considering the number of results of a simultaneous search in the EBSCO database, the phrase eye tracking or eye tracker or eye movement measurements and the phrase EEG or electroencephalogram or electroencephalography, 489 publications were published between 2009 and 2018.

As for the other psychophysiological measures, eye-tracking was used also with functional magnetic resonance imaging (fMRI). This combination of methods can help illustrate how brain activity corresponds to eye movement (as well as the gaze direction, pupil dilatation, or blinking frequency). In other words, the combination of these two techniques allows indicating what area of the image presented to the subject (visual stimulus) is observed when a specific part of the brain is activated simultaneously (Begdjani, Steen, 2013). In the study of Garrison, O'Malley, Gueorguieva and Krishnan-Sarin (2018), the brain response (the activity of the nucleus accumbens) was checked for advertisements for various flavours of e-cigarettes and tested whether they interfere with the reception of warning messages contained on labels. The procedure was supplemented with measuring eye concentration to verify how long the attention was focused on advertisements of individual flavours and whether the presented content drew the respondents' eyes from warning labels. Simultaneous searching in the EBSCO database of the phrase eye-tracking or eye tracker or eye movement measurements along with the phrase $\mathrm{fMRI}$ or functional magnetic resonance imaging or brain imaging indicates the existence of 413 publications.

Other methods combined many times with eye-tracking include analysis of electrodermal activity (Guerreiro, Rita, Trigueiros, 2015) and heart rate variability (Christoforou, Christou-Champi, Constantinidou, Theodorou, 2015). Based on the number of searches in the EBSCO database of the phrases electrodermal activity or EDA or GSR or galvanic skin response and heart rate variability or hrv along with the phrase eye tracking or eye tracker or eye movement measurements fewer publications can be observed which may indicate less frequent using both methods simultaneously. Taking into account the mentioned criteria, from 2009 to 2018, 75 papers were published regarding the use of eye-tracking with the measurement of electrodermal activity and 39 - with the measure of heart rate variability.

Combining eye-tracking with other methods - especially with neuroscience techniques - shows the vast possibilities of their use in marketing and consumer research. Tracking eye movement is essentially an indicator of the focus of attention. However, the 
combination of this technique with other methods of measurement enables to obtain more detailed information on the consumer's affective states, beliefs, decision-making processes, preferences or motivations. The use of triangulation of eye-tracking and other neuromarketing methods can also give insight into how the brain works while receiving external stimuli.

\section{Conclusions}

Consumers are regularly exposed to visual stimuli, including watching ads or choosing products arranged on retail store shelves. Thus, tracking eye movements of recipients of such communication seems to be essential for the companies planning their marketing activities. Basically, eye movement is an expression of the consumer's focus on specific content. The popularity of eye-tracking in marketing research is demonstrated by the multitude of areas of application of this technique, ranging from packaging designs, through merchandising, traditional and television advertising, to fair trade stands or websites designs. Tracking eye movements can also be a perfect complement to traditional research methods, such as questionnaires and in-depth interviews. Due to the limited number of studies in this area, the prospects for future research using eye-tracking and other neuromarketing methods are broad.

\section{References}

1. Adhami M. (2013). Using Neuromarketing To Discover How We Really Feel About Apps. International Journal of Mobile Marketing, 8(1), pp. 96-103. Pobrano z http://www.mmaglobal. com/files/vol8no1/IJMM-Summer-2013.pdf\#page $=96$.

2. Atalay S., Bodur H., Rasolofoarison D. (2012). Shining in the Center: Central Gaze Cascade Effect on Product Choice. Journal of Consumer Research. https://doi.org/10.2139/ssrn.2258531.

3. Barreto A.M. (2013). Do users look at banner ads on Facebook? Journal of Research in Interactive Marketing, 7(2), pp. 119-139. https://doi.org/10.1108/jrim-mar-2012-0013.

4. Begdjani T., Steen F. (2014). Design and preliminary testing of an MR-compatible eye tracking system. https://pdfs.semanticscholar.org/54bf/edb8a7c23a48dcacc0874c5a130c151ec9b4. pdf?_ga=2.99265238.978308482.1560780896-18130 06228.1559649133.

5. Bialkova S., van Trijp H.C.M. (2011). An efficient methodology for assessing attention to and effect of nutrition information displayed front-of-pack. Food Quality and Preference, 22(6), pp. 592-601. https://doi.org/10.1016/j.foodqual.2011.03.010.

6. Bojko A. (2013). Eye Tracking the User Experience: A Practical Guide to Research. Rosenfeld Media, New York.

7. Borys M., Plechawska-Wójcik M. (2017). Eye-tracking metrics in perception and visual attention research. European Journal of Medical Technologies, 3(16), 11-23. Pobrano z http://www. medical-technologies.eu/upload/2_eye-tracking_metrics_in_perception_-_borys.pdf

8. Bylinskii Z., Borkin M.A. (2015). Eye Fixation Metrics for Large Scale Analysis of Information Visualizations. [In:] ETVIS Workshop on Eye Tracking and Visualization. Chicago. 
9. Cao Y., Qu Q., Duffy V.G., Ding Y. (2019). Attention for Web Directory Advertisements: A TopDown or Bottom-Up Process? International Journal of Human-Computer Interaction, 35(1), pp. 89-98. https://doi.org/10.1080/10447318.2018.1432162.

10. Chandon P., Hutchinson J.W., Bradlow E.T., Young S.H. (2009). Does In-Store Marketing Work? Journal of Marketing, 73(6). https://omura.wordpress.com/2009/10/31/does-in-store-marketing-work/

11. Cholewa-Wójcik A., Kawecka A. (2015). The Influence of Effectiveness of Packaging Elements on the Consumers' Preferences with the Use of Marketing Eye-Tracking Technique. Modern Management Review, XX, 22(1), pp. 49-61. http://oficyna.prz.edu.pl/download/SnOHgoGC1bQzl3fSU6ZG46AWQiPFhDYGFqeUhtISs9akBvJDcSPw,SpJn01DTQ1HGYZeTIYPzM9cS9-IAdAKisyKRQrYjE9NgBvJWleaCtDJVk/mmr-2015-01-pw-01.pdf

12. Christoforou C., Christou-Champi S., Constantinidou F., Theodorou M. (2015). From the eyes and the heart: A novel eye-gaze metric that predicts video preferences of a large audience. Frontiers in Psychology, 6(579), pp. 1-11. https://doi.org/10.3389/fpsyg.2015.00579

13. Clement J. (2007). Visual influence on in-store buying decisions: an eye-track experiment on the visual influence of packaging design. Journal of Marketing Management, 23(9-10), pp. 917-928. https://doi.org/10.1362/026725707×250395

14. Clement J., Kristensen T., Grønhaug K. (2013). Understanding consumers' in-store visual perception: The influence of package design features on visual attention. Journal of Retailing and Consumer Services, 20(2), pp. 234-239. https://doi.org/10.1016/j.jretconser.2013.01.003

15. Clement J., Smith V., Zlatev J., Gidlöf K., van de Weijer J. (2017). Assessing information on food packages. European Journal of Marketing, 51(1), pp. 219-237. https://doi.org/10.1108/EJM09-2013-0509

16. Cosic D. (2016). Neuromarketing in Market Research. Interdisciplinary Description of Complex Systems, 14(2), pp. 139-147. https://doi.org/10.7906/indecs.14.2.3

17. Dimpfel W. (2015). Neuromarketing: Neurocode-Tracking in Combination with Eye-Tracking for Quantitative Objective Assessment of TV Commercials. Journal of Behavioral and Brain Science, 5, pp. 137-147. https://doi.org/10.4236/jbbs.2015.54014

18. Dimpfel W., Morys A. (2014). Quantitative Objective Assessment of Websites by Neurocode-Tracking in Combination with Eye-Tracking. Journal of Behavioral and Brain Science, 4, pp. 384-395. https://doi.org/10.4236/jbbs.2014.48037

19. Disterheft A. (2017). Atrakcyjność modelki a percepcja i efektywność reklamy na przykładzie produktów do pielęgnacji ciała. Handel Wewnętrzny, 2(367), pp. 45-55. Pobrano z http:// cejsh.icm.edu.pl/cejsh/element/bwmeta1.element.desklight-e6ad3e2b-1fab-4bc2-8764fb5d64721f8a/c/IBRKK-handel_wew_2-2017.45-55.pdf

20. Disterheft A., Gaczek P. (2018). Wpływ emocji incydentalnych na skłonność do posługiwania się regułą satysfakcji lub maksymalizacji w kontekście wyboru produktów spożywczych. Handel Wewnętrzny, 2(373), pp. 127-138. Pobrano z http://cejsh.icm.edu.pl/cejsh/element/bwmeta1.element.desklight-9a5d1f36-3169-4b24-a4c4-8518af3868fa/c/HW_2-2018-127-138.pdf

21. Duchowski A.T. (2007). Eye Tracking Methodology. Springer-Verlag, Londyn. https://doi. org/10.1007/978-3-319-57883-5

22. Garczarek-Bąk U. (2016). Użyteczność badań eye trackignowych w pomiarze utajonych determinant zachowań zakupowych nabywców. Ekonometria, 3(53), pp. 55-71. https://doi. org/10.15611/ekt.2016.3.05

23. Garczarek-Bąk U., Disterheft A. (2018). Analiza obszarów zainteresowania w oparciu o badania eyetrackingowe na przykładzie produktów marek własnych i producenckich. Prace Naukowe 
Uniwersytetu Ekonomicznego we Wrocławiu, (525), pp. 211-226. https://doi.org/10.15611/ pn.2018.525.18

24. Garrison K.A., O'Malley S.S., Gueorguieva R., Krishnan-Sarin S. (2018). A fMRI study on the impact of advertising for flavored e-cigarettes on susceptible young adults. Drug and Alcohol Dependence, 186, pp. 233-241. https://doi.org/10.1016/j.drugalcdep.2018.01.026

25. Gębarowski M. (2018). Koncepcja badania stoisk targowych z wykorzystaniem metody eye tracking. Prace Naukowe Uniwersytetu Ekonomicznego we Wrocławiu, 525, pp. 227-236. https://doi.org/10.15611/pn.2018.525.19

26. Graham D.J., Jeffery R.W. (2011). Location, location, location: Eye-tracking evidence that consumers preferentially view prominently positioned nutrition information. Journal of the American Dietetic Association, 111(11), pp. 1704-1711. https://doi.org/10.1016/j.jada.2011.08.005

27. Guerreiro J., Rita P., Trigueiros D. (2015). Attention, emotions and cause-related marketing effectiveness. European Journal of Marketing, 49(11-12), pp. 1728-1750. https://doi.org/10.1108/ EJM-09-2014-0543

28. Guixeres J., Bigné E., Azofra J.M.A., Raya M.A., Granero A.C., Hurtado F.F., Ornedo V.N. (2017). Consumer neuroscience-based metrics predict recall, liking and viewing rates in online advertising. Frontiers in Psychology, 8, pp. 1-14. https://doi.org/10.3389/fpsyg.2017.01808

29. Hervet G., Gue K., Tremblay S. (2010). Is Banner Blindness Genuine? Eye Tracking Internet Text Advertising. Applied Cognitive Psychology, 716, pp. 708-716. https://doi.org/10.1002/ acp. 1742

30. Hoffman J.E., Subramaniam B. (1995). The role of visual attention in saccadic eye movements. 57(6), pp. 787-795.

31. Huddleston P., Behe B.K., Minahan S., Fernandez R.T. (2015). Seeking attention: An eye tracking study of in-store merchandise displays. International Journal of Retail and Distribution Management, 43(6), pp. 561-574. https://doi.org/10.1108/JJRDM-06-2013-0120

32. Husić-Mehmedović M., Omeragić I., Batagelj Z., Kolar T. (2017). Seeing is not necessarily liking: Advancing research on package design with eye-tracking. Journal of Business Research, $80, \mathrm{pp}$. 145-154. https://doi.org/10.1016/j.jbusres.2017.04.019

33. Hutton S.B., Nolte S. (2011). The effect of gaze cues on attention to print advertisements. Applied Cognitive Psychology, 25(6), pp. 887-892. https://doi.org/10.1002/acp.1763

34. Jerzyk E. (2017). Zastosowanie okulografii w badaniach uwagi wzrokowej konsumentów. Handel Wewnętrzny, 6(371), pp. 122-131. Pobrano z http://cejsh.icm.edu.pl/cejsh/element/bwmeta1.element.desklight-33380366-0eb8-4947-ad31-1c762af232c9/c/HW_6.122-131.pdf

35. Khushaba R.N., Wise C., Kodagoda S., Louviere J., Kahn B.E., Townsend C. (2013). Consumer neuroscience: Assessing the brain response to marketing stimuli using electroencephalogram (EEG) and eye tracking. Expert Systems with Applications, 40(9), pp. 3803-3812. https://doi. org/10.1016/j.eswa.2012.12.095

36. Lapa C. (2007). Using eye tracking to understand banner blindness and improve website design. http://195.130.87.21:8080/dspace/handle/123456789/399

37. Lee J., Ahn J.-H. (2012). Attention to Banner Ads and Their Effectiveness: An Eye-Tracking Approach. International Journal of Electronic Commerce, 17(1), pp. 119-137. https://doi. org/10.2753/jec1086-4415170105

38. Ober J., Dylak J., Gryncewicz W., Przedpelska-Ober E. (2009). Sakkadometria - nowe możliwości oceny stanu czynnościowego ośrodkowego układu nerwowego. Nauka, 4, pp. 109-136. http://www.pan.poznan.pl/nauki/N_409_10_Ober.pdf 
39. Owens J.W., Chaparro B.S., Palmer E.M. (2011). Text Advertising Blindness: The New Banner Blindness? Journal of Usability Study, 6(3), pp. 172-197.

40. Pernice K., Nielsen J. (2009). How to Conduct Eyetracking Studies. https://media.nngroup. com/media/reports/free/How_to_Conduct_Eyetracking_Studies.pdf

41. Porta M., Ravarelli A., Spaghi F. (2013). Online newspapers and ad banners: An eye tracking study on the effects of congruity. Online Information Review, 37(3), pp. 405-423. https://doi. org/10.1108/OIR-01-2012-0001

42. Resnick M., Albert W. (2014). The Impact of Advertising Location and User Task on the Emergence of Banner Ad Blindness: An Eye-Tracking Study. International Journal of Human-Computer Interaction, 30(3), pp. 206-219. https://doi.org/10.1080/10447318.2013.847762

43. Rojna W. (2003). Eye tracking. Metodologia i jej zastosowanie w badaniach percepcji reklamy i zachowań konsumentów. [In:] IV Ogólnopolski Kongres Badaczy Rynku i Opinii.

44. Schall A., Bergstrom J.R. (2014). Eye tracking in user experience design. Waltham: Elsevier Ltd. Oxford. https://doi.org/https://doi.org/10.1016/C2012-0-06867-6

45. Smink A.R., van Reijmersdal E.A., Boerman S.C. (2017). Effects of Brand Placement Disclosures: An Eye Tracking Study Into the Effects Of Disclosures and the Moderating Role of Brand Familiarity. Advances in Advertising Research, 8, pp. 85-96. Springer Nature, Wiesbaden. https://doi. org/10.1007/978-3-658-18731-6_5

46. Teixeira T.S., Wedel M., Pieters R. (2010). Moment-to-Moment Optimal Branding in TV Commercials: Preventing Avoidance by Pulsing. Marketing Science, 29(5), pp. 783-804. https://doi. org/10.1287/mksc.1100.0567

47. Tonkin C., Ouzts A.D., Duchowski A.T. (2011). Eye tracking within the packaging design workflow: Interaction with Physical and Virtual Shelves. [In:] Conference on Novel Gaze-Controlled Applications, pp. 1-8. https://doi.org/10.1145/1983302.1983305

48. Tullis T., Albert B. (2013). Measuring the User Experience Collecting, Analyzing, and Presenting Usability Metrics. Waltham: Elsevier Inc.

49. Wąsikowska B. (2016). Eye tracking in marketing research. Zeszyty Naukowe Uniwersytetu Szczecińskiego. Studia Informatica, 36(863), pp. 177-192. https://doi.org/10.18276/ si.2015.36-13

50. Wästlund E., Otterbring T., Gustafsson A., Shams P. (2015). Heuristics and resource depletion: Eye-tracking customers' in situ gaze behavior in the field. Journal of Business Research, 68(1), pp. 95-101. https://doi.org/10.1016/j.jbusres.2014.05.001

51. Wästlund E., Shams P., Otterbring T. (2018). Unsold is unseen ... or is it? Examining the role of peripheral vision in the consumer choice process using eye-tracking methodology. Appetite, 120, pp. 49-56. https://doi.org/10.1016/j.appet.2017.08.024

52. Wawer R., Pakuła M. (2012). Zastosowanie techniki eyetrackingowej do analizy postrzegania historycznej przestrzeni wystawienniczej przez osoby starsze i młodzież : teoretyczne i metodologiczne podstawy badań. Zeszyty Naukowe Uniwersytetu Szczecińskiego. Ekonomiczne Problemy Usług, 88, pp. 698-707. Pobrano z http://www.wzieu.pl/zn/703/ZN_703.pdf

53. Winslow B., Carpenter A., Flint J., Wang X., Tomasetti D., Johnston M., Hale K. (2010). Combining EEG and Eye Tracking: Using Fixation-Locked Potentials in Visual Search. Journal of Eye Movement Research, 6(4), pp. 1-11. https://doi.org/10.16910/jemr.6.4.5 